University of Louisville

ThinkIR: The University of Louisville's Institutional Repository

Electronic Theses and Dissertations

8-2014

\title{
The walkable dividend : the impacts of walkability on housing and socio-economic composition in Louisville, Ky.
}

Wesley Laurance Meares

University of Louisville

Follow this and additional works at: https://ir.library.louisville.edu/etd

Part of the Public Affairs Commons, and the Urban Studies and Planning Commons

\section{Recommended Citation}

Meares, Wesley Laurance, "The walkable dividend : the impacts of walkability on housing and socioeconomic composition in Louisville, Ky." (2014). Electronic Theses and Dissertations. Paper 957.

https://doi.org/10.18297/etd/957

This Doctoral Dissertation is brought to you for free and open access by ThinkIR: The University of Louisville's Institutional Repository. It has been accepted for inclusion in Electronic Theses and Dissertations by an authorized administrator of ThinkIR: The University of Louisville's Institutional Repository. This title appears here courtesy of the author, who has retained all other copyrights. For more information, please contact thinkir@louisville.edu. 


\title{
THE WALKABLE DIVIDEND: THE IMPACTS OF WALKABILITY ON HOUSING AND SOCIO-ECONOMIC COMPOSITION IN LOUISVILLE, KY
}

Wesley Laurance Meares

B.A., LaGrange College, 2010

M.P.A., Western Kentucky University, 2011

\author{
A Dissertation \\ Submitted to the Faculty of the \\ College of Arts and Sciences of the University of Louisville \\ in Partial Fulfillment of the Requirements \\ for the Degree of \\ Doctor of Philosophy \\ Department of Urban and Public Affairs \\ University of Louisville \\ Louisville Kentucky
}

August, 2014 
Copyright 2014 by Wesley Laurance Meares

All rights reserved 



\title{
THE WALKABLE DIVIDEND: THE IMPACTS OF WALKABILITY ON HOUSING AND SOCIO-ECONOMIC COMPOSITION IN LOUISVILLE, KY
}

\author{
By \\ Wesley Laurance Meares \\ B.A., LaGrange College, 2010 \\ M.P.A., Western Kentucky University, 2011
}

A Dissertation Approved on

June 2, 2014

By the following Dissertation Committee:

Dissertation Director, Dr. John I Gilderbloom

Dr. Steven Koven

Dr. David Simpson

Dr. Gregory Squires 


\section{DEDICATION}

To Sarah, my loving wife and best friend 


\section{ACKNOWLEDGEMENTS}

There are a number of people that I wish to thank in writing this dissertation. First, I would like to thank Dr. John Gilderbloom, my committee chair, whose support, guidance, advice and friendship were invaluable. Dr. Gilderbloom pushed me to focus my arguments and express my ideas with clarity and transparency. I would also like to thank my other committee members, Dr. Gregory Squires, Dr. Steven Koven and Dr. David Simpson for their ideas, guidance, edits and revisions throughout this process. All of their input and contributions were instrumental and I greatly appreciate their wisdom, time and advice.

Dr. Janet Kelly and Dr. David Imbroscio provided support and general council to me throughout my time at the University of Louisville. Also, Dr. Janet Kelly and the Kentucky State Data Center staff, especially Sarah Ehresman, deserve special thanks for their assistance in locating data for this project. Additionally, I want to give a distinct acknowledgement to Tony Lindauer and Jay Mickle of the Jefferson County Property Valuation Administration. They provided data that was crucial to this dissertation, without their contribution this project would have not been possible.

I would also like thank Dr. William T. Bielby for his advice on the methodological section of this paper. Andres Duany and Dr. Emily Talen were sounding boards during a symposium hosted at the University of Chicago and provided encouragement, support and ideas that were extremely helpful. Furthermore, I want to thank Dr. William "Billy" Riggs for his expertise and guidance. Part of this dissertation was inspired and derived from 
research that Dr. Riggs, Dr. Gilderbloom and I have done. Thank you gentlemen for letting me use some of our work in this dissertation.

All of the faculty, students and staff at the Department of Urban and Public Affairs at the University of Louisville have been supportive and encouraging to me throughout my tenure, and for that I thank you. You all have helped to make my experience enriching and rewarding.

I would also like to thank my whole family, especially my parents Ronald and Nancy Meares, who have given me enormous love and support throughout life and always encouraged me to pursue my dreams. Last, I owe the greatest debt of gratitude to my wife and best friend Sarah Meares, whose love, support, encouragement and humor have been priceless to me in completing this goal. 


\title{
ABSTRACT \\ THE WALKABLE DIVIDEND: THE IMPACTS OF WALKABILITY ON HOUSING AND SOCIO-ECONOMIC COMPOSITION IN LOUISVILLE, KY
}

\author{
Wesley Laurance Meares
}

June 2, 2014

Until 2008, there has not been a reliable measure of the social, health, and economic impact of walkable neighborhoods. This changed dramatically when scholars were able to quantify walkability, which measures how accessible daily living activities are by foot. However, most of these studies focus on mega cities, sections of cities or on random parcel data. Absent from the literature is the impacts of walkability on mid-size cities. This dissertation seeks to fill this void by examining the impacts of walkability on neighborhood housing valuation, foreclosures, vacancy rates and socio-economic composition in Louisville, $\mathrm{KY}$.

This dissertation employs ordinary least squares regression, spatial regression and logistic regression in order to better understand the impact of walkability on neighborhoods in Louisville, KY from 2000-2010. The results indicate that walkability is correlated with higher housing values and lower foreclosures. In terms of socio-economic composition walkable neighborhoods tend to have smaller households compared to non-walkable neighborhoods in 2000 and 2010. Additionally, in 2010 walkable neighborhoods were more likely to have higher levels of poverty and a population with a younger median age. The 
results inform two policy areas for cities to pursue: 1) increase the diversity of land uses and 2) affordability options and standards. 


\section{TABLE OF CONTENTS}

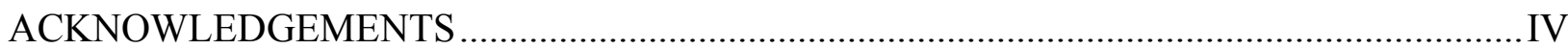

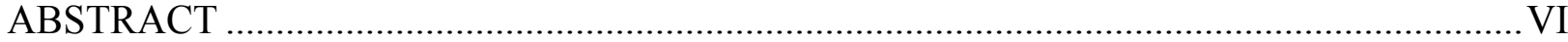

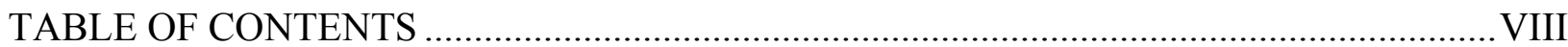

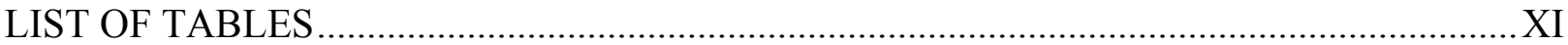

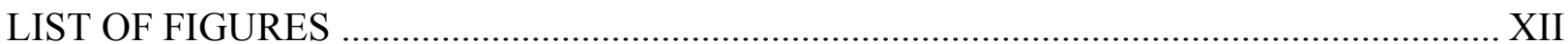

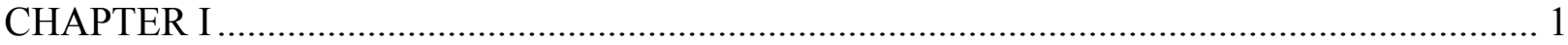

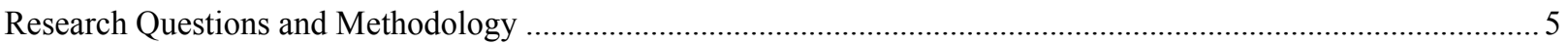

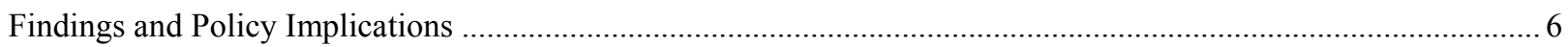

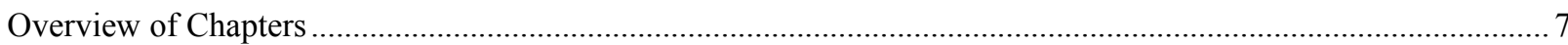

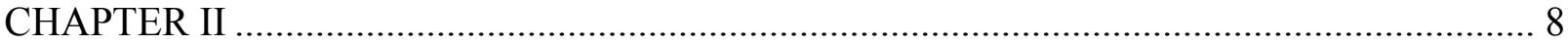

Neighborhood Design: Sprawl via Compact Development .............................................................................. 9

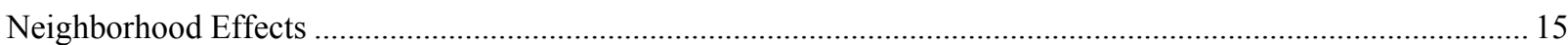

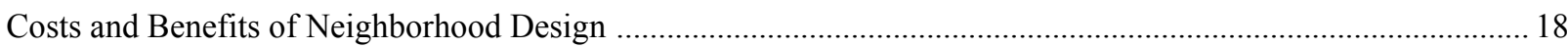

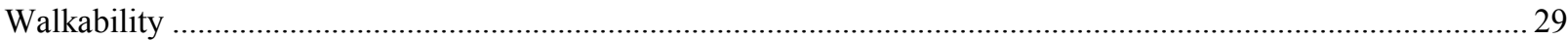

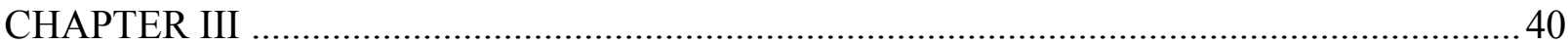

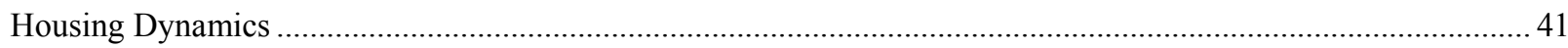

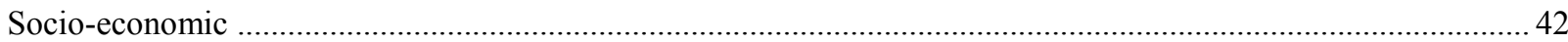




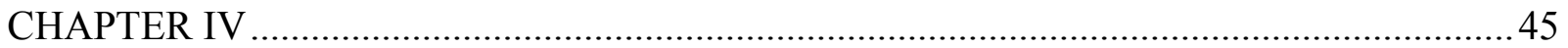

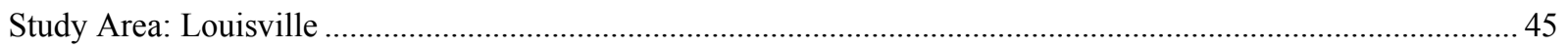

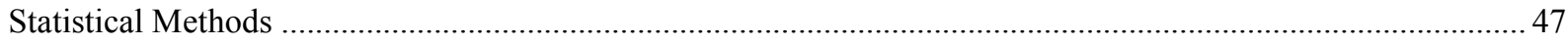

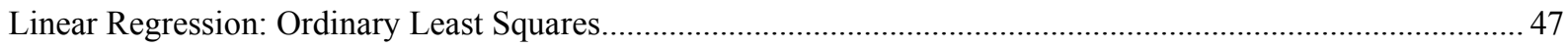

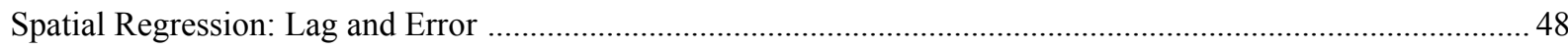

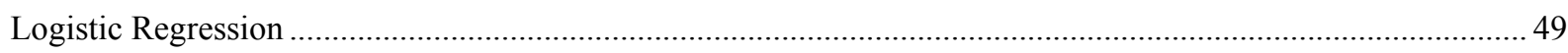

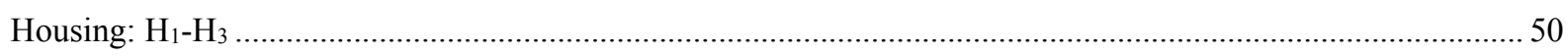

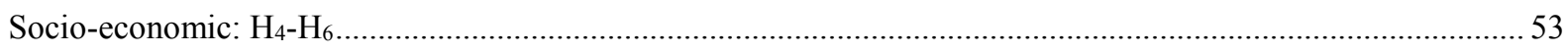

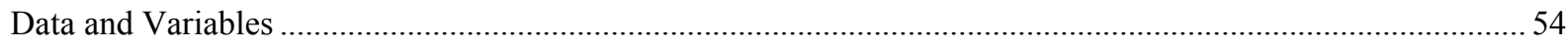

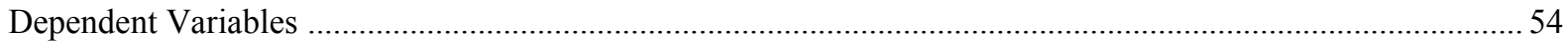

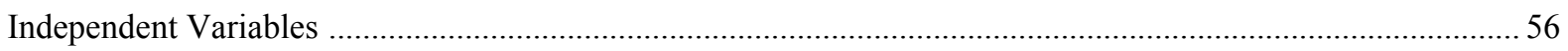

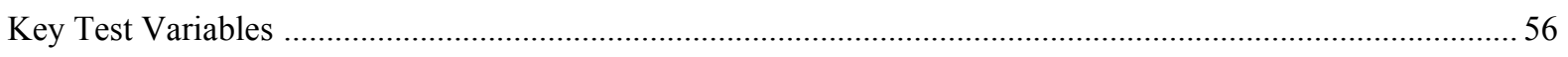

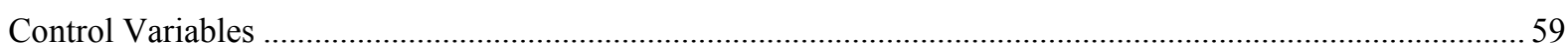

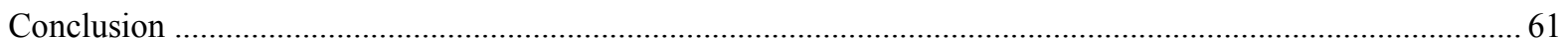

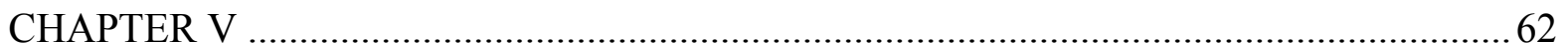

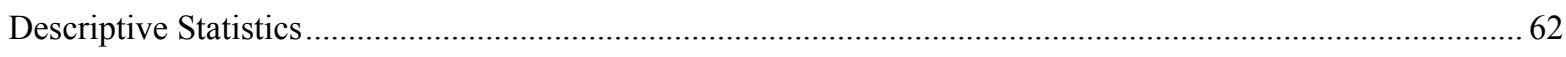

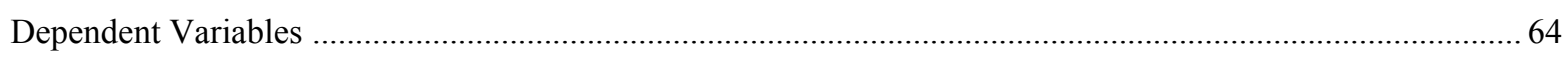

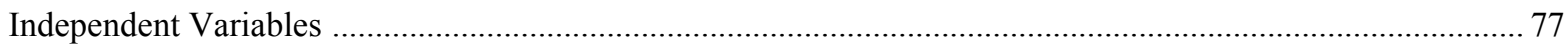

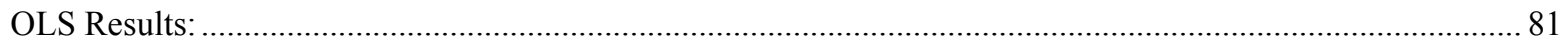

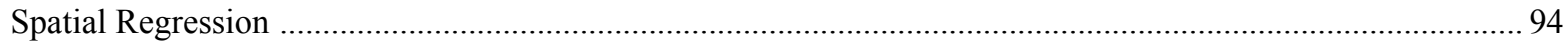

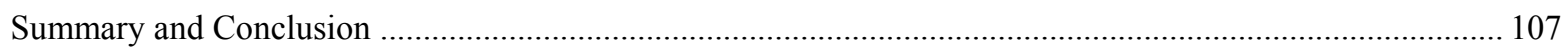

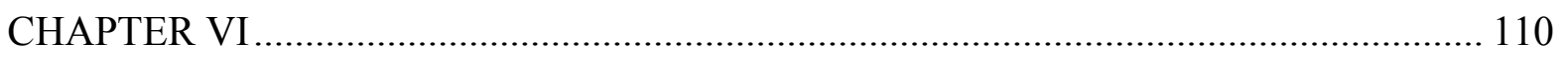

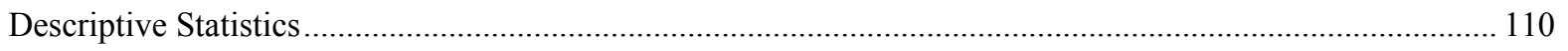




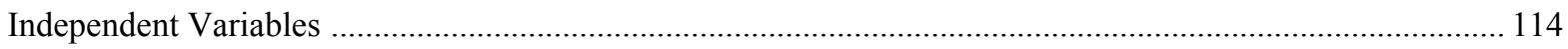

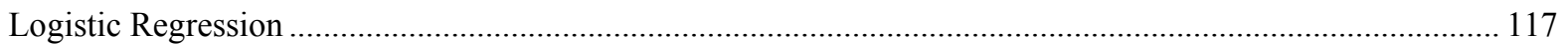

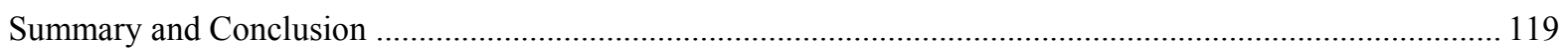

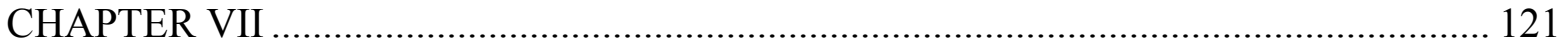

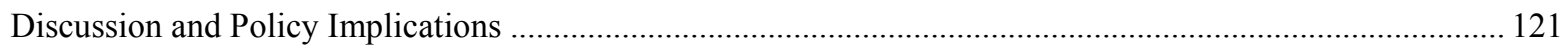

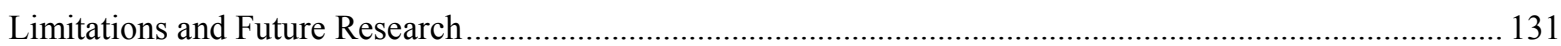

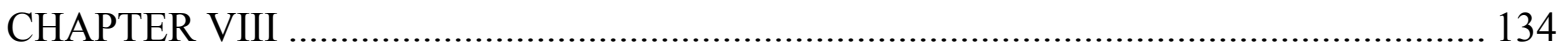

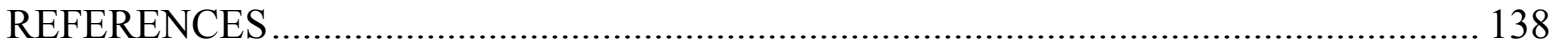

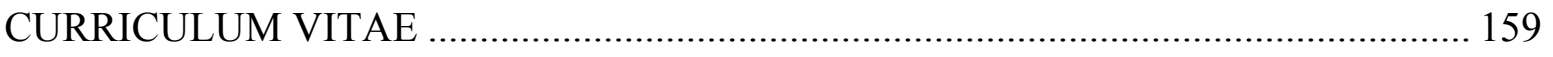


TABLE

\section{LIST OF TABLES}

5.1 Descriptive Statistics for Dependent Variables..............................63

5.2 Descriptive Statistics for Independent Variables.............................80

5.3 Median Assessed Value 2000 OLS Regression............................... 83

5.4 Median Assessed Value 2010 OLS Regression...................................86

5.5 Changes in Median Assessed Value between 2000-2010 OLS Regression............88

5.6 Foreclosures 2004-2008 OLS Regression.....................................90

5.7 Vacancy Rate 2000 OLS Regression....................................92

5.8 Vacancy Rate 2010 OLS Regression.....................................93

5.9 Median Assessed Value per Square Foot 2000 Spatial Regression...................96

5.10 Median Assessed Value per Square Foot 2010 Spatial Regression..................98

5.11 Changes in Median Assessed Value per Square Foot from 2000-2010 Spatial Regression......................................................... 100

5.12 Foreclosures from 2004-2008 Spatial Regression............................... 102

5.13 Vacancy Rate 2000 Spatial Regression.................................... 104

5.14 Vacancy Rate 2010 Spatial Regression..................................106

6.1 Descriptive Statistics for Dependent Variables...............................111

6.2 Descriptive Statistics for Independent Variables............................. 116

6.3 Walkable Neighborhood (1/0) Binomial Regression Results....................118

6.4 Walkable Neighborhood (1/0) Binomial Regression Results.....................119 


\section{LIST OF FIGURES}

FIGURE

PAGE

2.1 Ariel Photo of Suburban Sprawl. Springdale Road in Louisville, KY.................12

2.2 An example of a compact neighborhood. The Highlands Louisville...................13

2.3 A diverse mix of land $u$ ses. The Highlands Louisville............................ 14

2.4 A traditional neighborhood. Ariel Photo of the Highlands Louisville, KY..........15

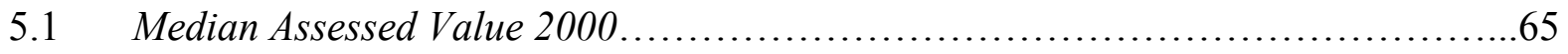

5.2 Median Assessed Value per Square Foot 2000...............................66

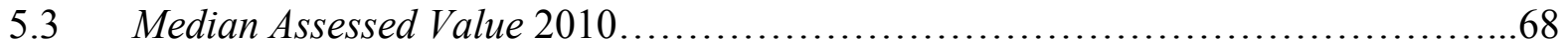

5.4 Median Assessed Value per Square Foot 2010................................69

5.5 Median Assessed Value Change 2000-2010..................................71

5.6 Median Assessed Value Change per Square Foot, 2000-2010....................72

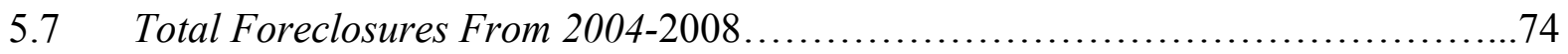

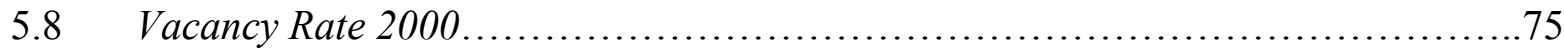

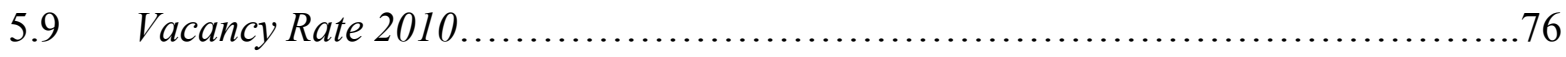

6.1 Louisville's Walkable Neighborhoods, 2008 Walk Score.........................112

6.2 Louisville's Walkable Neighborhoods, 2013 Streetsmart Score.....................113

7.1 Ariel Photo of Norton Commons. Louisville, KY.............................127

7.2 Ariel Photo of Dadeland. Kendall, FL.................................... 128

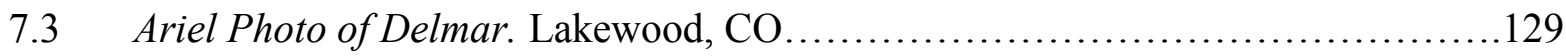




\section{CHAPTER I}

\section{INTRODUCUTION}

The purpose of this dissertation is twofold. First, it explores the impact of walkability as a proxy for accessibility, on neighborhood housing values, foreclosures and vacancy rates in Louisville, KY. Second, it examines the socio-economic composition of neighborhoods in Louisville to determine the differences between residents in walkable communities and nonwalkable communities.

Louisville is a mid-sized Midwestern city, located on the Ohio River, adjacent to the Indiana border. In 2010, the city had a population of 605,105 (U.S. Census Bureau, 2010). Using Louisville as a study area is a more suitable choice than megacities such as New York, Los Angeles and Chicago; its size and Midwestern location makes Louisville more representative of U.S. cities (Barrow, 2004; Savitch \& Vogel, 2004; Ambrosius, 2010; Gilderbloom et al., 2012).

Social scientists have studied how the immediate environment can affect residents, neighborhood attributes and neighborhood opportunity structures (Guerry, 1883; Durkheim 1897; Parks \& Burgess, 1925; Jacobs, 1961; Appelbaum et al., 1976; Wilson, 1978; Logan \& Molotch, 1987; Gilderbloom \& Appelbaum, 1988; Squires, 1992; Dreier et al., 2001; Duany et al., 2001; Ambrosius et al., 2010; Sampson, 2012). The findings have contributed to the theory of neighborhood effects, which are independent causal effects of a neighborhood (i.e. residential community) on any number of social, health or environmental outcomes (Jenks 
and Mayer, 1990; Mayer and Jenks, 1999; Oakes, 2004). Studies of neighborhood effects date back as far as 1883 . However, the prevalence of neighborhood effects in urban literature flourished with the work of the Chicago School theorists (Judd \& Simpson, 2011). When the Chicago School faded, the frequency of neighborhood effect studies plummeted.

Sampson, Morenoff and Gannon-Rawley (2002) reviewed the literature on neighborhood effects over the past half century and found neighborhood effect studies have resurged. Moreover, the frequency of these studies sharply increased after Wilson's (1978) work in Chicago. In which he proposed that individuals are negatively affected by living in neighborhoods of concentrated poverty ${ }^{1}$. Furthermore, Wilson (1978) hypothesized that people living in neighborhoods of concentrated poverty have fewer opportunities and dilapidated housing and environment conditions compared to individuals living in neighborhoods of low poverty ${ }^{2}$.

The hypothesis that neighborhoods affect individuals was tested in the outcomes of the Gautreaux program in Chicago. Researchers found that families moving from neighborhoods of concentrated poverty to neighborhoods of low poverty experienced significant increases in health, education, safety and employment, when compared to families who remained (Galster \& Killen, 1995; Rosenbaum, 1995; Popkin et al., 2000; Dreier et al., 2001; Wilson, 2009; Turner, 2010). These findings, along with others supporting the theory of neighborhood effects, inspired the Moving To Opportunity (MTO) demonstration in the 1990s. In this program, families received vouchers to move into different neighborhoods.

\footnotetext{
${ }^{1}$ Neighborhoods of concentrated poverty are defined as census tracts with a poverty level of $40 \%$ or higher (Wilson, 1996; Gans, 1990).

${ }^{2}$ Wilson (2009) defined neighborhoods of low poverty as census tracts with a poverty level of $10 \%$ or less.
} 
The thesis was that poor families who moved into low poverty high opportunity areas would have significant gains in employment, education, safety and health. Researchers' short term results were not as promising as anticipated. The only significant gains for families who left neighborhoods of concentrated poverty for low poverty high opportunity neighborhoods were increases in perceived safety and mental health (Goetz, 2003; Imbroscio, 2010; Goetz \& Chapple, 2010). These findings have led critics to question the neighborhood effect theory (Duke, 2009; Imbroscio, 2010; Chaskin \& Joseph, 2012). However, a recent study by Turner et al. (2012) found significant gains in health, education, employment and income for families living in low poverty areas, when tenure in low poverty areas is taken into account,

Neighborhood effect proponents have proposed that the Gautreaux program and the MTO demonstration did not truly address the neighborhood level, since both relied mainly on deconcentration efforts (Talen \& Koschinsky, 2010; Sampson, 2012). Furthermore, the comparisons have not included any type of control for neighborhood design and accessibility. Studies have generally relied only on a measure of poverty to compare neighborhoods (Rosenbaum, 1995; Popkin et al., 2000; Gilderbloom, 2008; DeLuca \& Rosenbaum, 2009; DeLuca et al., 2010). This dissertation seeks to address this gap in the research.

Accessibility, as specified in this study, is the level of access that neighborhood residents have to amenities needed to carry out daily life (Frank et al., 2007; Cortright, 2009; Pivo \& Fisher, 2010). The shorter the distances are to these amenities, the greater the accessibility of a neighborhood, which can positively affect residents, especially the impoverished (Gilderbloom, 2008; Talen, 2010). Accessibility relies on neighborhood density, design and diversity. Denser traditional neighborhoods will generally be more accessible than sprawl neighborhoods (Duany et al., 2001; Speck, 2012). Additionally, the 
traditional or compact developments have greater levels of connectivity than sprawling neighborhoods. The literature on neighborhood design has correlated the difference in design with a number of attributes including equity, development costs and environmental impacts (Appelbaum \& Gilderbloom, 1988; Williamson et al., 2002; Leinberger \& Alfonso, 2012). Though both density and design play important parts in accessibility, diversity of land use and desirable neighborhood attributes are equally important. Sprawl is notorious for its separation of uses, while compact development is more compatible with diverse mix land uses (Duany et al., 2001; Litman, 2006; Williamson, 2010). Although the literature has reviewed neighborhood design and density, the topic of accessibility has been relatively absent.

One possibility for excluding accessibility is the lack of a readily available quantifiable measure, until 2008 when Front Seat Inc. released a measure of walkability. Walkability, as employed by Front Seat Inc., is a proxy of accessibility, since it measures the distance to a number of amenities needed to carry out daily life (Cortright, 2009; Pivo \& Fisher, 2010; Duncan et al., 2011; Riggs, 2011; Leinberger \&Alfonso, 2012). Since the creation of the index, the impacts of walkability on housing valuation, foreclosures and economic development have been explored. However, many of these studies focus on mega cities, sections of cities or on random parcel data sales data (Cortright, 2009; Pivo \& Fisher, 2010; Riggs, 2011; Speck, 2012; Ehrenhalt, 2012; Leinberger \& Alfonso, 2012).

Absent from the literature is the residential composition of walkable versus nonwalkable neighborhoods in the same city. This dissertation aims to correct the dearth of literature by exploring the effects of walkability on housing dynamics, while addressing the void of walkable neighborhood composition. 


\section{Research Questions and Methodology}

There are a number of research questions utilized in this examination of the relationships between neighborhood type, housing dynamics and neighborhood composition:

How does walkability affect neighborhood housing dynamics? Does this differ from non-walkable neighborhoods?

What is the socio-economic composition of walkable neighborhoods? How does that compare to the rest of the city?

This exploratory examination will further the understanding of the impacts of walkability on neighborhood housing, thus shedding more light on the subject of walkability. Additionally, understanding the socio-economic composition of walkable neighborhoods residents and the differences between the residents and residents of non-walkable neighborhoods are crucial to policies that promote walkability.

This study relies on a number of statistical methods to test the value of walkability. They include univariate descriptive statistics, ordinary least squares (OLS) regression, logistic regression and spatial regression. A number of commonly used control variables identified by the literature are included in the examination, along with a measure of walkability provided by Front Seat Inc. Front Seat Inc. operationalizes walkability as a measure of distance to land uses within a one-mile radius. The distances are converted and normalized into a progressive scale of $0-100$. 


\section{Findings and Policy Implications}

This study identified three key findings surrounding walkability's impact on Louisville's neighborhood housing: 1) greater levels of walkability tended to have higher valuation in 2010 and greater increases in valuation between 2000 and 2010; 2) Louisville neighborhoods with greater levels of walkability were associated with a lower number of foreclosures from 2004-2008; and 3) vacancy rates were not significantly correlated with walkability.

There were also three significant findings surrounding the socio-economic composition of neighborhoods in Louisville: 1) smaller average household sizes were significant in calculating the probability of a neighborhood being walkable in 2000 and 2010; 2) race and median household income were not significant factors in estimating the probability of walkability in Louisville neighborhoods; and 3) in 2010 greater levels of poverty and neighborhoods with younger average age were significant in determining the probability of a neighborhood being walkable.

These findings inform two policy areas: 1) increase the diversity of land uses and 2) affordability options and standards. Policies were recommended to relax zoning, expand VAPSTAT (Vacant and Abandoned Property Statistics), identifying vacant and underutilized properties to be repurposed with a mix of uses, below market rate obligation on developers and encourage the development of housing at various price points to encourage the mixing of socio-economic classes.

There are limitations in the research, which provide opportunities for future research. There are three key areas that would have provided greater validity to the results of this 
study: 1) a longitudinal study of multiple cities; 2) an attentive examination of metrics and benchmarking techniques; 3 ) and, inclusion of street quality variables.

\section{Overview of Chapters}

Chapter II examines the literature and identifies the gaps in the literature which this dissertation will address. This includes an examination of difference in neighborhood design along with the implications for these differences, and the definition, findings and specification of walkability in the literature. Chapter III and Chapter IV introduces the research questions, hypotheses, data and the methodology. The findings are contained in the next two chapters, Chapter V contains the results for the hypotheses pertaining to housing and Chapter VI reports the findings for hypotheses related to socio-economic composition. Chapter VII discusses implications for research and the limitations of the analyses. Finally, Chapter VIII provides an overview and conclusion. 


\section{CHAPTER II}

\section{REVIEW OF THE LITERATURE}

The impact of walkability, as a measure of access, has had limited exposure in the literature. This is due to the absence of ways to quantify walkability (Leinberger, 2008; Riggs, 2011). Therefore, even when past authors thought walkability was important (Jacobs, 1961; Newman, 1973; Holin et al., 2003), they were unable to measure its impact. In 2008, a measure of walkability was released by Front Seat Inc. (Leinberger, 2009). Since then, a number of studies have shown walkability's positive impacts on neighborhoods and residents (Cortright, 2009; Ambrosius et al., 2010; Pivo \&Fisher, 2010; Talen, 2003, 2010; Speck, 2012).

Most studies focus on real estate sales, or particular neighborhoods within cities, instead of all the neighborhoods within the city. This study differs from previous examinations by testing the idea of walkability and the impact it has on all neighborhood housing markets within a mid-size American city. It compares neighborhoods' walkability in an attempt to understand if a significant difference exists between neighborhood housing markets. Additionally, this dissertation examines the relative socio-economic compositions of walkable and non-walkable neighborhoods.

This chapter surveys the literature on walkability and its effects on housing dynamics and the socio-economic composition of a neighborhood First, the categorical differences in the types of neighborhood design are examined. Next, the effects of sprawl on neighborhoods 
and residents are explored. This section analyzes the literature according to various categories: equity, preferences, environmental impacts, development costs, social capital, and economic segregation. This review concludes by examining findings of previous research on walkability and its impact on residents and neighborhood housing dynamics.

\section{Neighborhood Design: Sprawl via Compact Development}

In $\underline{\text { Suburban Nation, }}$ Duany et al. (2001) argued that there are two types of neighborhood design: sprawl and traditional/compact. Currently, sprawl has been the dominant form of development in the United States since the post WWII era (Duany et al., 2001; Dreier et al., 2001; Williamson et al., 2002; Williamson, 2010).

Sprawl has been defined in a number of ways throughout the literature. There are technical definitions, such as the one offered by Galster et al. (2001), which conceived sprawl as a multi-dimensional problem requiring a multi-dimensional technical definition. They defined sprawl not as a process but as a condition of land use measured in eight aspects:

- Density: average number of residential units per square mile.

- Continuity: degree land has been developed at urban densities in an unbroken fashion.

- Concentration: degree which development is located in a few square miles of the Urban Area.

○ Compactness: degree which development is clustered to minimize the amount of land in each square mile of developable land. 
- Centrality: closeness of development to the central business district of an urban area.

- Nuclearity: extent to which an urban area is characterized as a mononuclear development pattern (as compared to polynuclear).

- Diversity: degree to which different land uses exist within the same micro-area and how typical the pattern is within the urban area.

○ Proximity: degree to which different land uses are close to each other.

For the purposes of this dissertation, a precise quantitative method like Galster et al. (2001) will not be used to identify sprawl.

Other definitions of sprawl are based upon characteristics. Duany et al. (2001) defined sprawl categorically as areas of single use zoning that are separate from other land uses. Sprawling developments are constructed around the use of the automobile; thus, they contain little street grid connectivity, making it difficult to use non-automotive forms of transit to reach destinations. The practice of isolating single uses creates bubble development, a collection of a single land use accruing in an area removed from areas with other uses. Bubble development, along with the lack of connectivity between uses, causes greater distances between living, shopping, work and play. Sprawl can be in the form of low density developments, scattered developments, strip developments, or leapfrog developments. Sprawl does have benefits. It provides individuals with privacy and mobility, by allowing citizens to access the American dream of owning a home in a safe and pleasant neighborhood (Williamson, 2010). 
Scholars have argued the cost of sprawl outweighs the benefits of homeownership and privacy (Wilson, 1978; Downs, 1994; Duany et al., 2001). The notorious view of sprawl is currently the mainstream opinion in the academic literature. Still, there are some scholars who claim that sprawl is more beneficial than harmful for urban areas (Gordon \& Richardson, 1998; Brooks, 2004; Brugmann, 2005; Bogart, 2006). For nearly twenty years, opponents of sprawl have been advocating an array of policies to limit sprawl, including such tactics as urban growth boundaries, developer impact fees, and congestion taxes (Williamson, 2010). Despite these efforts, sprawl prevails as the most common form of development. However, diverse policy solutions to sprawl have led to greater understanding of the effectiveness of various policies in curbing it.

Critics of sprawl developments promote the other category of neighborhood design, known as traditional or compact (Downs, 1994; Duany et al., 2001; Leinberger, 2009; Owen, 2009). Compact developments are naturally the opposite of sprawl. They are dense, mix use developments that tend to promote walking and non-auto transportation (Duany et al., 2001; Leinberger, 2009; Owen, 2009; Talen, 2013). These developments were the dominant form of urban neighborhood design prior to World War II. Though compact developments are currently not the prominent type of urban development, they are a part of America's urban growth especially in movements such as smart growth, complete streets, and new urbanism. Current models of compact development promote livable streets, minimum densities for new developments, greater intensity of land use, and the integration of living, working, shopping and playing in close proximity (Riggs, 2011). 


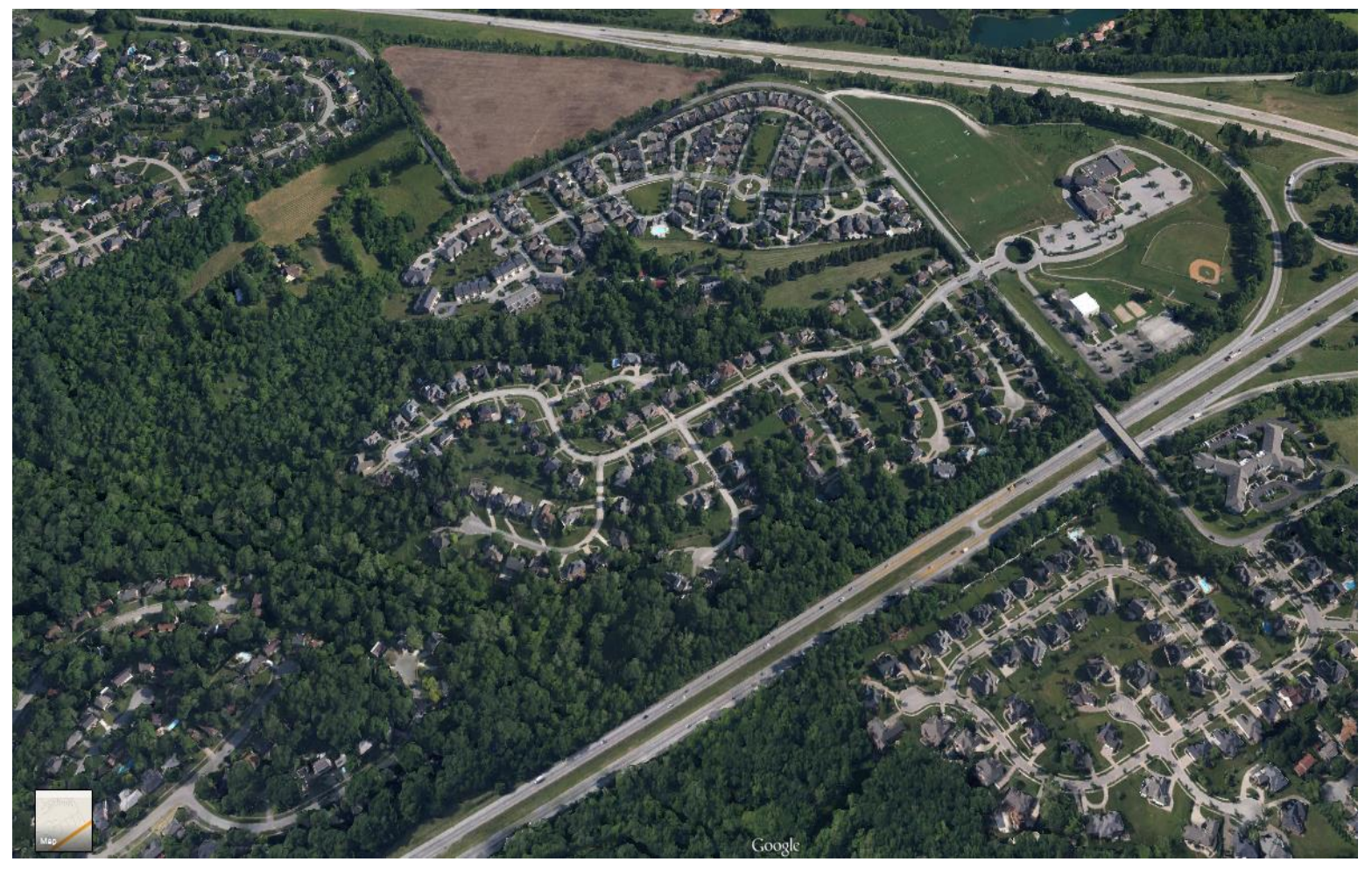

Figure 2.1 [An Example of Sprawl]. @ Google Maps. (2014). Ariel Photo of Suburban Sprawl on Springdale Road in Louisville, KY. Accessed online at:

https://www.google.com/maps/@,38.2939386,$\underline{85.6099032,2300 \mathrm{a}, 35 \mathrm{y}, 38.94 \mathrm{t} / \mathrm{data}=! 3 \mathrm{~m} 1 ! 1 \mathrm{e} 3 ? \mathrm{hl}=\mathrm{en}-\mathrm{US}}$ 


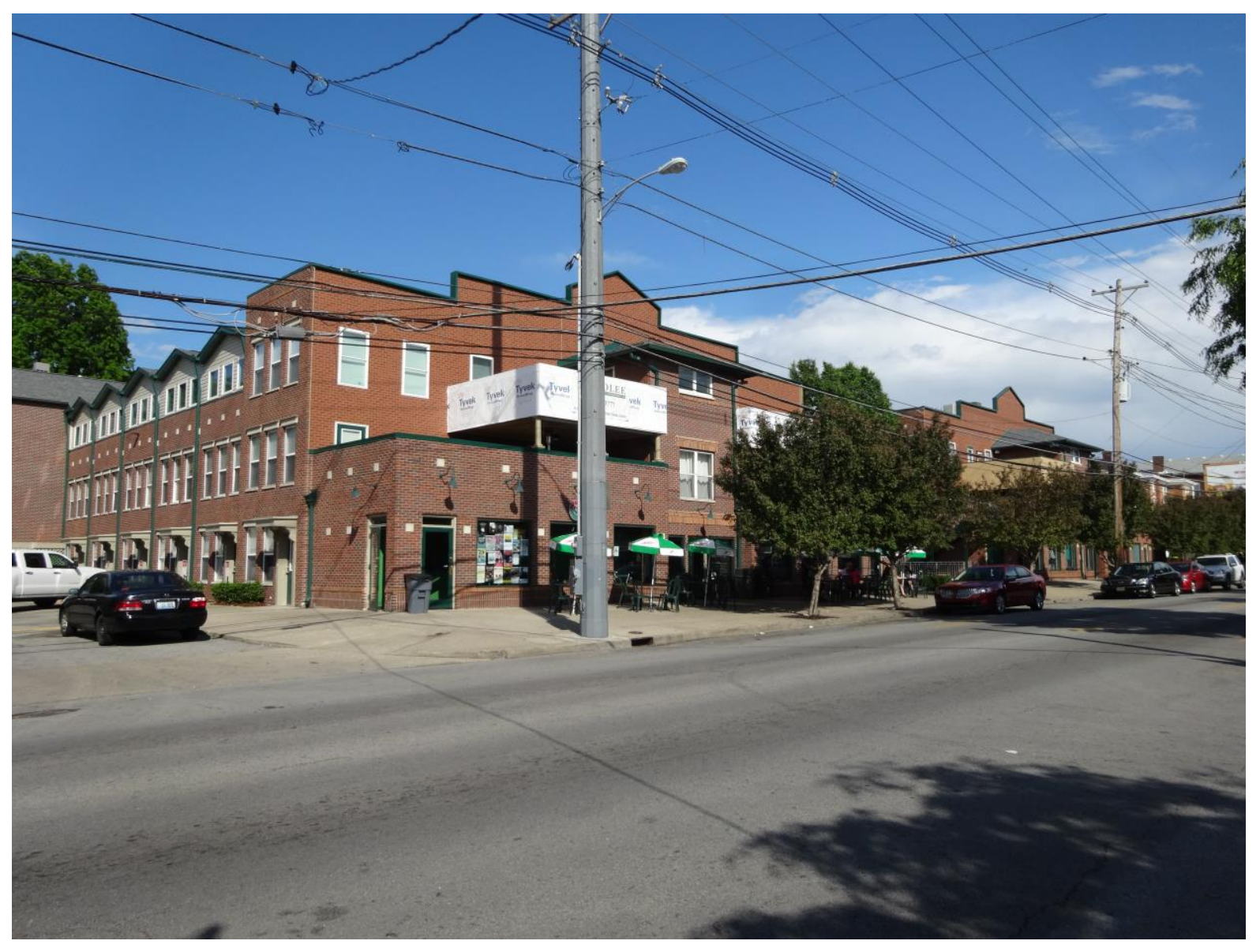

Figure 2.2 [An example of a compact neighborhood]. The Highlands Louisville. 


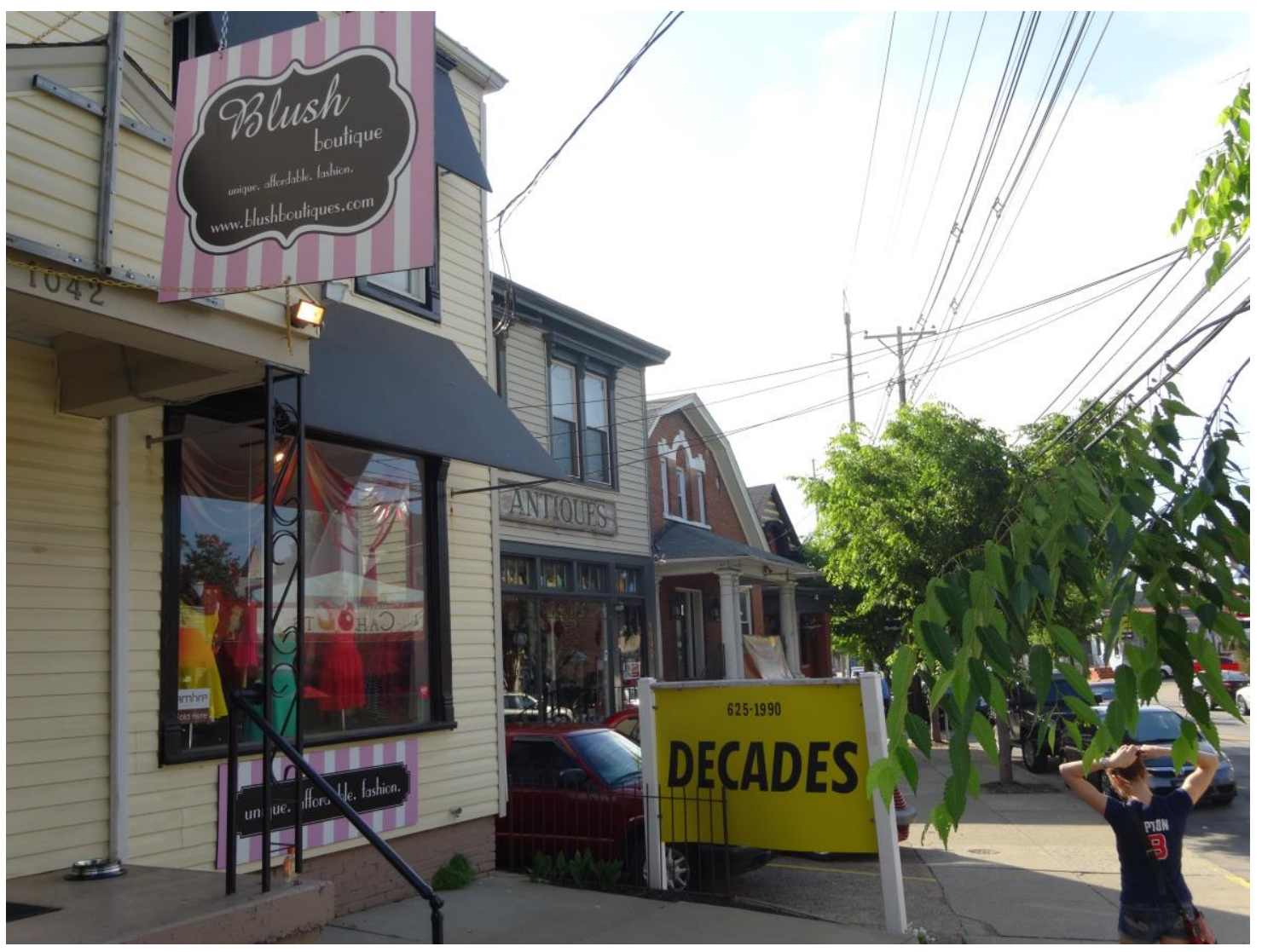

Figure 2.3 [A diverse mix of land uses]. The Highlands Louisville 


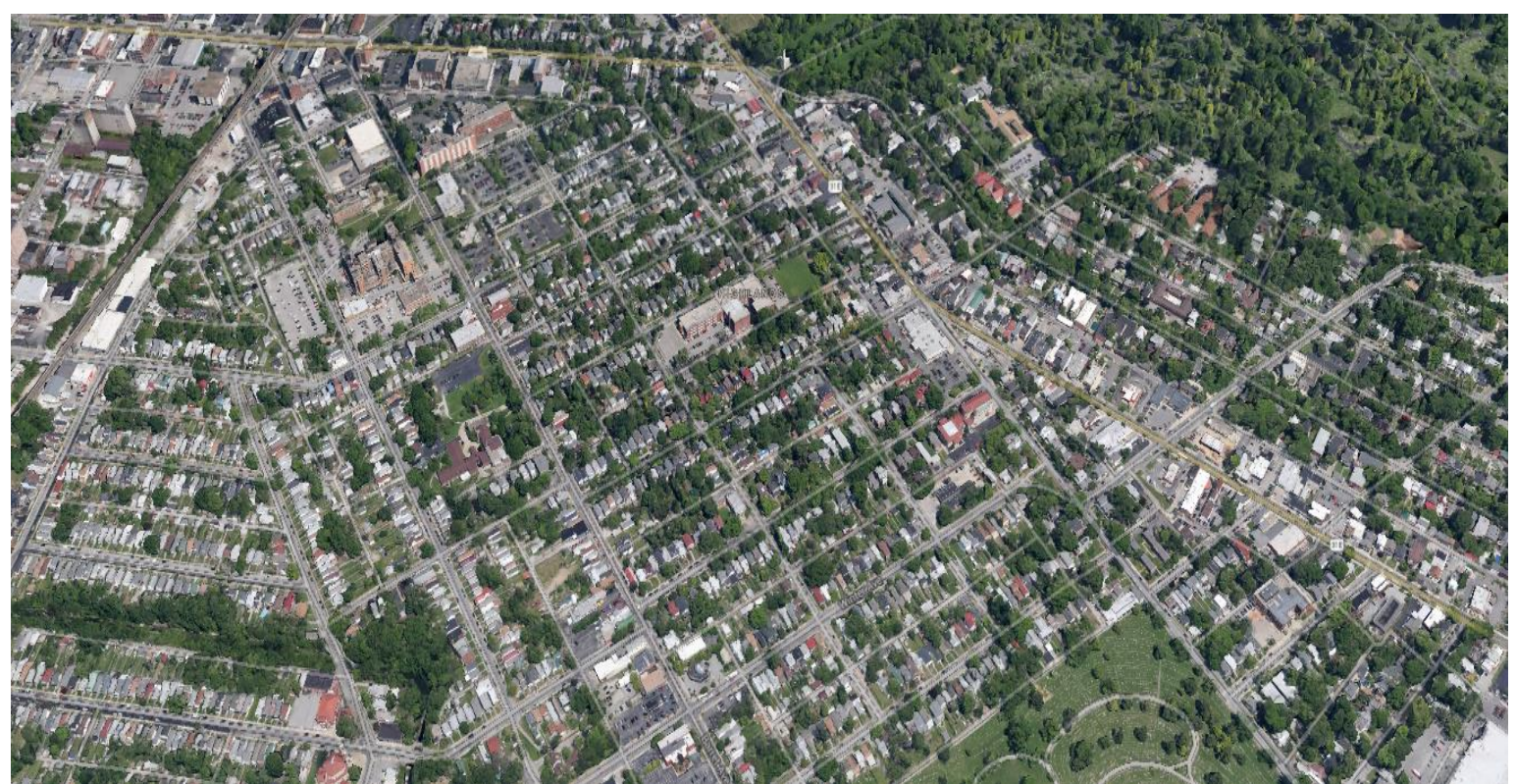

Figure 2.4 [A traditional neighborhood]. (c) Google Maps.

(2014). Ariel Photo of the Highlands Louisville, KY. Accessed online at: https://www.google.com/maps/@,38.2939386,$85.6099032,2300 \mathrm{a}, 35 \mathrm{y}, 38.94 \mathrm{t} / \mathrm{data}=! 3 \mathrm{~m} 1 ! 1 \mathrm{e} 3 ? \mathrm{hl}=\mathrm{en}-\mathrm{US}$

Now that the two categorical types of development have been disclosed, it is paramount to explore how neighborhood design can impact neighborhoods, individuals and their life opportunities.

\section{Neighborhood Effects}

Neighborhood design can have a powerful impact on residents, the opportunities they can access and their quality of life. Despite the ever growing importance and reach of globalization, the local space that an individual occupies still significantly matters (Jacobs, 1961; Castells, 1977; Wilson, 1978; Dreier et al., 2001; Glaeser, 2011; Florida, 2012; Ludwig et al., 2012; Sampson, 2012). Therefore, where people live is not simply a place where they carry out their lives. It is a structure of opportunity and mobility.

Neighborhood effects are defined by Sampson (2012) as follows: 
...a durable spatial logic organizes or mediates much of social life, with neighborhoods and local communities a key component ... we react to neighborhood difference and these reactions constitute social mechanisms and practices that in turn shape perceptions, relationships and behaviors that reverberate both within and beyond traditional neighborhood borders, and which taken together further define the social structure of the city (p. 21-22).

The idea of neighborhood effects is not new; it dates back to the 1800s. Early theorists, such as Guerry (1883) and Durkheim (1897), demonstrated that one's environment influences behavior and action, outside of psychology and biology. It flourished in the Chicago School where scholars, such as Park and Burgess (1925), used spatial explanations to describe the city processes and citizen interactions. A flaw of the Chicago School was its inability to recognize the influence of capitalism and political forces beyond the boundaries of the neighborhood; however, political economy theorists were able to integrate these ideas and furthered the theory of neighborhood effects. They demonstrated that neighborhood inequalities are shaped directly and indirectly by capital accumulation, institutional racism and the growth machine (Logan \& Molotch, 1987; Massey, 1993; Sampson, 2012). While studies in the earlier portion of the $20^{\text {th }}$ century focused on neighborhood norms, later studies began to focus on individual outcomes and behaviors (Wilson, 1978; Dreier et al., 2001). The Gautreaux program in Chicago exhibited how low income individuals who escaped concentrated poverty, and the uneven geography of opportunity, through integration into middle and upper class areas experienced improvements in employment, education and social 
integration, compared to those who did not move into areas of high opportunity (Rosenbaum, 1995; Galster \& Killen, 1995; Wilson, 2009).

The findings on how neighborhoods can influence individual outcomes inspired the "Moving to Opportunity" (MTO) program in the 1990s. MTO was a quasi-experimental program that sought to measure how different neighborhoods affected the life opportunities of low income individuals. The program's short term results showed that impoverished residents moving to neighborhoods of opportunity had higher levels of perceived safety and mental health, when compared to those impoverished individuals in low opportunity areas. Critics were quick to point out that no other significant improvements were found (Goetz, 2003; Briggs, 2005; Imbroscio, 2010; DeLuca \& Rosenbaum, 2010). However, a recent study discovered families that had a longer tenure in high opportunity low poverty areas had significant gains in terms of health, employment, education and income (Turner et al., 2012). Despite these recent findings, the results still raise a number of questions concerning the viability of neighborhood effects and neighborhood level interventions. Scholars criticized MTO, claiming that the design of the program did not address the neighborhood level or neighborhood effects (Sampson, 2012; Talen \& Koschinsky, 2010). Sampson (2008) explains:

By design, MTO was an individual-level intervention that offered housing vouchers to extremely poor, largely minority families. Therefore, nothing can be inferred from MTO about the success or failure of neighborhood-level interventions, and any generalizations 
about voucher effects are restricted to an important but small segment of the population (p. 229).

These studies have provided some understanding of neighborhood effects, though neighborhood design was not considered. Consequently, there is a lack of information about the relative outcomes of residents' with or without access to amenities. An examination of design could enlighten policy makers on the impacts of neighborhood access on a population.

\section{Costs and Benefits of Neighborhood Design}

This section will consider the costs and benefits of neighborhood design and its impact on community. The literature is broken down into the following categories: equity, preferences, environmental impacts, development costs, social capital and economic segregation.

\section{Equity}

Sprawl has provided upper and middle class neighborhoods the opportunity to engage in exclusionary tactics to keep individuals they deem undesirable out of their communities. Duany et al. (2001), Dreier et al. (2001), and Wilson (2011) have proposed that exclusionary practices, brought on by sprawl, deepen racial, cultural and ethnic cleavages between neighborhoods. Sprawl also creates inequalities in quality of life, incomes, opportunity structures and public services between communities (Dreier et al., 2001). Additionally, the pursuit of sprawl promotes the societal values of privatism ${ }^{3}$ and consumerism while degrading other values, such as social justice and the idea of equal opportunity.

\footnotetext{
${ }^{3}$ Privatism is the pursuit of personal interests, welfare, or ideals to the exclusion of public costs or broader social issues, or as Squires (2012: 120) stated, "[privatism] refers to a broader ideological view of the world generally and relationships between the public and private sectors in particular."
} 
Compact developments are a potential alternative to sprawl, which cause or exacerbate social problems (Duany et al., 2001). By eliminating space and reducing fragmentation, inequalities will become more diluted (Rusk, 1999). While the possibility of homogenous enclaves is still present in compact developments, the compactness of the urban area will ultimately increase interaction with other groups (Duany et al., 2001; Putnam, 2001; DeLuca \& Rosenbaum, 2010). However, Duke (2009), Imbroscio $(2008,2012)$ and Goetz (2003) argued that different social or economic classes existing in close proximity to one another does not guarantee integration; it is possible for different classes or groups to live with each other and not interact or accept each other, thereby reinvigorating social segregation. Other scholars disagree with this claim, arguing that different classes living in close proximity is an important first step to creating a common identity that will eventually lead to quality interaction and acceptance (Bothwell et al., 1998; Leyden, 2003; Gilderbloom, 2008; DeLuca \& Rosenbaum, 2010).

Health equity is another issue affected by the two types of design. Frumkin et al. (2004) and Frank et al. (2003) explained that sprawling developments, especially those located in suburbia, have had a negative effect on the health of the nation, particularly obesity and obesity related diseases. Recent literature has linked sprawling neighborhoods with disproportionate amounts of instability and negative health impacts (Frumkin et al., 2004; Williamson, 2010). These types of communities do not encourage walking, biking and other passive physical activities. On the other hand, people who live in compact areas have more opportunities to exercise through daily routines, such as walking or biking to destinations, and the design of the community is not hostile to active means of transportation 
(Jacobs, 1961; Frank et al., 2003). Compact development does not ensure that people will participate in moderate physical activity, such as walking, but environments more suitable for walking have been correlated with more incidences of walking and a reduction in obesity related diseases (Riggs, 2011).

From the viewpoint of equity, the evidence suggests that sprawl exacerbates and creates burdensome problems for metropolitan areas. While compact developments do not necessarily resolve issues of equity, they have not been shown to exacerbate the burdensome problems usually associated with sprawl (Downs, 1994; Duany et al., 2001; Gilderbloom, 2009).

\section{Preferences}

Public choice proponents explain the free market and individual mobility allow people to locate where their preferences are met (Tiebout, 1956; Ostrom \&Ostrom, 1971; HowellMoroney, 2009). Allowing this to occur freely in the market will lead to the most efficient use of urban land (Wirth, 1939; Tiebout, 1956). This premise suggests that people will vote with their feet by moving to a neighborhood that meets individual preferences. This free market view of mobility suggests that America has a preference for sprawling developments.

However, a number of scholars would take issue with this perspective (Squires, 1992: Massey, 1993; Downs, 1994, Dreier et al., 2001; Duany et al., 2001; Squires, 2002). They argue that the market is not free; rather, all levels of government have intervened with the private market, which has resulted in the creation and perpetuation of sprawl's dominance in U.S. urban land development. The federal government has steered American development towards sprawl in a number of ways: first, through the use of redlining practices of mortgage 
insurance ${ }^{4}$; second, through the subsidization of the highway system; and third, through the tax incentives that pull residents toward suburban developments and homeownership (Jackson, 1985; Dreier et al., 2001; Williamson, 2010). The state government has steered towards a model of sprawl through its regulation of transportation, public good provision and assignments of municipal powers. Localities create a desire for sprawling developments through their zoning powers, the projects which they approve, and their planning functions (Williamson et al., 2002). The interjection of government demonstrates the market is not free, but is tainted with government intervention. This decision to favor sprawl, through policies or incentives, has pushed wealth into sprawling suburbs.

This is not to say that individual preferences do not matter in the choice of a house or community design. A number of studies have examined the preference of individuals in choosing neighborhoods (Tiebout, 1956; Charles, 2005; Gilderbloom, 2008; Handy et al., 2008). Tiebout (1956) expounded that individuals have a list of preferences for their ideal house and neighborhood. They will move into the area that most closely matches their preferences. However, this does not make them immobile. If another area becomes a better match for their preferences, they will most likely move into that area. Americans value the dream of homeownership in a spacious community that is pleasant and safe (Brooks, 2004; Brugmann, 2005; Bogart, 2006; Williamson, 2010). Sprawl has allowed individuals to access these preferences.

\footnotetext{
${ }^{4}$ According to Dreier et al. (2001) redlining was a common practice of private mortgage lenders and property insurance companies. The federal government did not create the practice but it did embrace it.
} 
Charles (2005) explained a major preference for housing tenure choice is the desire to live in a homogenous neighborhood. In fact, when the racial preference for any given group is not met in their neighborhood, then residents will most likely "vote with their feet" and move to a neighborhood that meets their inclinations, i.e. too many minority neighbors create a tipping point, which results in the departure of non-minority residents (Charles, 2005; Goering, 2013). The preference for homogenous communities and the availability of land has helped fuel sprawl (Duany et al., 2001).

Some scholars claim that there is a new generation of Americans desiring the compact dense lifestyle found in cities (Florida, 2012; Ehrenhalt, 2012; Speck, 2012). However, many of these studies focus on mega-cities such as New York, Houston, Atlanta, Chicago and Los Angles. These cities are not representative of the average American city, and little work has been done to understand the dynamics occurring in more typical midsized American cities.

\section{Environmental Impacts}

One area of concern receiving a plethora of attention in the literature is the impact of development type on the environment. Sprawling developments have a larger negative environmental footprint compared to compact developments (Downs, 1994; Leinberger, 2009; Owen, 2009). Sprawl consumes land at three times the rate of population growth.

Individuals who live in sprawl areas consume larger housing (Duany et al., 2001). Naturally, larger housing devours more energy and uses more finite resources than smaller housing units (McKibben, 2008; Glaeser, 2011). Compact developments are able to preserve greater amounts of green space and put less stress on finite environmental resources. 
Sprawl creates an auto-dependent culture. Through the separation of single-use zoning, sprawl generates more miles traveled by individuals (Downs, 1994; Duany et al., 2001). The increase in travel causes traffic congestion (Dreier et al., 2001; Duany et al., 2001). The excess congestion and travel increases the amount of environmental pollution (Downs, 1994). In fact, two-thirds of all carbon monoxide emissions in the United States is produced by automobiles (Williamson et al., 2002).

On the other hand, compact neighborhoods, with mix-uses within the same area, decrease the number of miles that needs to be travelled. The shorter distance between places encourages the use of alternative transportation, such as biking and walking (Leinberger, 2009; Owen, 2009).

Proponents of sprawl have attempted to discredit the claims of accelerated environmental degradation created by sprawl, claiming exaggerations. (Gordon \& Richardson, 1997, 1998). Such claims have been discredited by other academic work, in which the general consensus is that sprawl has a large negative net impact on the environment. In contrast, compact development is more compatible with environmental sustainability (McKibben, 2008).

\section{Development Costs}

There are many financial costs generated by sprawl. A number of these costs are subsidized by urban area residents, while residents living in new developments escape paying for the true total costs of their housing tenure choice. Logan and Molotch (1987) explained how developers leverage local governments in order to develop land cheaply; thus, the new community escapes paying for the true infrastructure costs it generates (Brueckner, 2000). 
Furthermore, the costs of local government services increase for everyone, as low density growth continues. These costs often pass to non-mobile populations who are not benefiting from the extension of services (Schragger, 2009). Another problem is that individuals from outside the city use goods and services, such as roads but do not have to pay for them. This creates a free rider problem (Brueckner, 2000).

Dreier et al. (2001) claimed that sprawl creates a financial burden for urban areas and undermines their economic competitiveness. Kenworthy and Laube (1999), and Hartgen and Fields (2009), reported that cities most dependent on automobiles are less wealthy and economically competitive than cities oriented to a greater diversity of transportation modes. Moreover, a study of 46 international cities reported that large urban areas characterized by compact layouts and efficient transportation infrastructure are typically associated with higher levels of productivity than other forms of urban settlements (Local Government Commission's Center for Livable Communities, 2000). Additionally, Schrank, Lomax and Eisele (2011) calculated a \$101 billion urban road congestion cost to Americans in 2010. This figure included the opportunity costs to motorists, reduced productivity and increased operating costs for trucking and shipping companies.

Compact areas are considered to be more competitive and productive than their low density counterparts (Kenworthy \&Laube, 1999; Hartgen \&Fields, 2009; Brueckner, 2011; Glaeser, 2011). Being more compact allows cities to benefit from agglomeration effects and lower the costs of production. Furthermore, compact areas are centers for interaction, innovation, creativity and the exchange of ideas (Glaeser, 2011; Florida, 2012; Speck, 2012; 
Katz \&Bradley, 2013). These factors ultimately lead to a competitive advantage for compact areas.

\section{Social Capital}

The flight of the middle and upper class into low density areas has eroded social capital (Bothwell et al., 1998; Putnam, 2001; Warren et al., 2001). Social capital is a resource exemplified in the social ties among people, networks, norms and trust (Sampson, 2012). The degradation of social capital is detrimental to community by damaging civic engagement and social capital. The deprivation in civic engagement and democratic participation contribute to higher levels of distrust in the government (Putnam, 2001). As sprawl decays social capital, highly valuable social networks are lost (Putnam, 2001). Furthermore, as sprawl continues to promote privatism, the idea of the common good is lost.

Proponents of sprawl argue that living in compact developments have negative societal bearings, such as riots, high levels of crime and social unrest. They claim that low density sprawling developments ease the tension found in the densely compact areas (Gordon \& Richardson, 1998; Bogart, 2006).

Critics claim the sprawl model neither solves nor alleviates problems, but exacerbates them (Jacobs, 1961: Dreier et al., 2001). Dense developments tend to increase the likelihood of interaction, which translates to greater social capital (Bothwell et al., 1998; Putnam, 2001; Leyden, 2003; DeLuca \& Rosenbaum, 2010). One prevalent fear that drives people to sprawling areas is the disproportionately high murder rate in the city compared to the suburbs. However, if one were to calculate the murder rate versus the rate of automobile 
related deaths, the dense city might be safer than the suburbs (Leinberger, 2009; Speck, 2012).

Sprawl's association with privatism, and the erosion of social capital, has contributed to many poor neighborhoods being left behind. Furthermore, it has degraded opportunity structures and meaningful democratic participation throughout the city.

\section{Economic Segregation}

A significant negative externality that is a byproduct of pursuing sprawl is the economic segregation of neighborhoods. Sprawl has contributed to white and middle class flight from the city. However, economic segregation is more than the separation of inner city neighborhoods and the suburbs. It concerns the difference between neighborhoods of low opportunity and high opportunity, which both can be found inside and outside most American city's limits. Some inner city enclaves are resource and opportunity rich, such as Manhattan in New York City or the Highlands in Louisville, KY.

Dreier et al. (2001) and Wilson $(1978,2009,2011)$ have shown that economic segregation is a significant contributing factor to urban poverty across the United States. Economic segregation has been found to accelerate inequalities, especially income inequalities between neighborhoods of low opportunity and neighborhoods of high opportunity. Economic segregation damages democratic processes and hinders the quality of life for poorer residents (Wilson, 1978; Williamson, 2010).

Economic segregation intensified with the flight of affluent blacks. In 1968, the federal government took action against racial segregation in the housing market and passed 
the Fair Housing Act. This enabled middle-class minorities with the economic means to move to the suburbs (Dreier et al., 2001; Schwartz, 2006). The exodus of the black middle class from the inner city caused lower class residents, many of whom were black, to concentrate in inner-city ghetto neighborhoods. This caused pronounced inequality, since income mixing had been more prevalent in ghetto neighborhoods. Simultaneously, the economy was restructured. Manufacturing jobs held by lower class inner city workers left the inner city for the periphery, or another country, leaving many of black inner city residents unemployed (Wilson, 1978; Dreier et al., 2001; Squires, 2002). Sustained joblessness creates self-destructive behaviors, obstructs the ability to socialize, and destroys social capital. In addition, the search for structure has the potential to lead to gang membership among youth (Anderson, 1990). The poor were concentrated in certain neighborhoods, mostly inner city and first generation suburbs, thus creating concentrated poverty.

Neighborhoods of concentrated poverty contain limited opportunities. Therefore, residents do not get to access to the same opportunities as those who live in high opportunity neighborhoods (Rosenbaum, 1995; Dreier et al., 2001; Sampson et al., 2003; Sampson, 2012). In contrast, high opportunity areas have more resources, and are leveraged to provide a higher quality of services. Opportunity rich neighborhoods are able to exercise exclusionary practices, such as lot size requirements and density restrictions, which hinders the mobility of poor residents and denies them the option to locate in opportunity rich areas (Burns, 1994; Dreier et al., 2001; Duke, 2009; Briggs, 2010).

Wilson (1978), building off the work of Kain (1968), explained that economic segregation produces two critical mismatches. The first is a job spatial mismatch, where the 
poor are limited in their ability to access areas that host a large number of entry level and low skilled jobs. The urban poor are confined to areas with few low skill and entry level jobs. The second example of spatial mismatch is in education, when the poor cannot access available jobs because they lack the qualifications to hold those jobs. Many jobs in the city require a higher level of education than most poor inner-city residents have attained. Access to jobs is limited. The concentration of the poor, the inequalities they suffer, and the lack of opportunity and class mobility create negative neighborhood effects (Kain, 1968, 1992; Dreier et al., 2001; Briggs, 2005; Wilson, 1978). These negative effects include high crime rates, deteriorating neighborhood conditions, joblessness, neighborhood disinvestment, loss of social capital, shortage of neighborhood resources, deficiency in educational opportunities, and an increase in health hazards (Bullard, 2000; Briggs, 2005; Wilson, 2009; DeLuca et al., 2010; Acevedo-Garcia et al., 2010; Wilson, 1978).

One solution to the mismatches and economic segregation is to disperse concentrations of impoverished individuals and provide them economic opportunities in more opportunity rich neighborhoods. Another solution is to infuse neighborhoods with resources and invest into the "brick and mortar," bringing the opportunity to the neighborhood without moving residents. Both solutions draw attention to residents' level of access to amenities needed for daily life; however, the proponents of these policies have not conducted sufficient quantitative or qualitative formal testing of how their approaches would facilitate such access. This is a major oversight, which this dissertation seeks to remedy.

While the distinction of neighborhood design has allowed researchers' insight into the neighborhood, little research has been conducted to understand the impact that walkability, as 
a measure of access, can have on neighborhoods and residents. Urbanists have long considered walkability important (Jacobs, 1961; Newman, 1973), but they have been unable to access a readily available quantifiable measurement of walkability. This was unavailable until Front Seat Inc. launched their metric in 2008. Since then, researchers have studied the impacts of walkability. The next section of this literature review will focus on the research surrounding walkability while also providing a definition of walkability.

\section{Walkability}

Jane Jacobs (1961) described walkability as the core of urban vitality and vibrancy. The mixture of short blocks, density, land use mix and building types create a "sidewalk ballet" in which the residents and visitors of the neighborhood exist (Jacobs, 1961, p. 50). Frequency of walking in a neighborhood signals an area is safe and interesting.

Walkability can be defined differently (e.g. proximity, accessibility, suitability). Thus, it is important to establish an operational definition for the purpose of this dissertation. Many associate walkability with suitability factors such as street width, number of lanes, safe speeds, crossing improvements, presence of trees and other pedestrian level-of-service and suitability factors (Dowling et al., 2008). Others cite perception of safety, such as fear of crime or heavy traffic (Southworth, 2005). All these factors are important.

For the purpose of this study, a definition of walkability was developed that focuses on accessibility based on the importance of destination, land use and population characteristics (Ewing and Cervero, 2010). This definition does not dismiss the value of suitability factors that improve the quality of the environment; nor does it deny Southworth's (2005) emphasis on safety, quality of path and path context, despite their exclusion. This 
study focuses on measurable factors, including various destinations and street connectivity. Thus, Pivo and Fisher's (2010) definition best fits this study, “...as the degree to which an area within walking distance of a property encourages walking trips from the property to other destinations" (p.2).

\section{Walkability and Neighborhood Quality of Life}

A large body of research has correlated neighborhood walkability with higher density, street intersections, higher land use mix, and closer access to resources (Frank et al., 2003; Frank et al., 2005; Moudon et al., 2006). Walkable neighborhoods tend to be denser, better serviced by transit, more centrally located and have a greater land use mix. Studies have found that neighborhoods classified as walkable have higher levels of incidental walking and a lower incidence of obesity (Frank et al., 2007).

The American Obesity Association (2007) reported that 65\% of American adults are overweight and $30.5 \%$ obese. Wang et al. (2008) expect the rate of obesity to double within the next ten years. Being overweight or obese increases the risks of high blood pressure, high cholesterol, heart disease, stroke, cancer, gall bladder and respiratory disease, joint and bone disease and diabetes (Pi-Sunyer, 1993).

Studies suggest that obesity is mitigated by increased activity associated with a walkable environment. Studies have shown that light-to-moderate activity levels correlate with substantially reduced risk of developing disease (Thompson et al., 1999; Hu et al., 2003). Many urban planning scholars agree that the built environment influences physical activity levels (Ewing, 2005; Handy et al., 2005; Handy et al., 2006). Furthermore, environments that are walkable have been correlated with higher levels of walking (Saelens 
et al., 2003; Doyle et al., 2006) and decreased risk of obesity and related illnesses (Frank et al., 2005).

\section{Walkability, Economic Value and Demand}

In addition to health benefits, a growing body of work shows walkable neighborhoods encourage economic transactions and social exchanges (Litman, 2003, 2011), while bolstering real estate property values (Cortright, 2009; Diao \& Ferreira, 2010). Research by Matthews and Turnbull (2007) showed that a grid-like street pattern increases property values in more pedestrian-oriented neighborhoods and decreases property values in autooriented neighborhoods. Other work found that each incremental increase in walkability is associated with an increase in property value of up to 9\% (Pivo \& Fisher, 2010).

Improved walkability entices consumers to purchase more local goods and promotes greater economic resilience (Litman, 2006). The attributes associated with walkability may also have the capacity to improve safety and decrease crime (Leslie et al., 2005; Foster and Giles-Corti, 2008; Troy \& Grove, 2008), which have an indirect effect on real estate values. There is also literature that suggests walkability bolsters real estate values. A recent study showed that increased consumer demand for walkable attributes spans socio-economic statuses (Handy et al., 2008). This finding contradicts previous studies suggesting that many individuals, especially Caucasians, prefer large single-family homes (Bajari and Kahn, 2005) and racial homogeneity (Farley, et al., 1978; Farley et al., 1997; Krysan \& Farley, 2001; Meen \& Meen, 2003).

There is limited evidence showing the extent to which walkability factors enter into housing purchases; however, a broad spectrum survey of real estate professionals showed 
that walkability is considered a major amenity (Riggs, 2011). Consequently, there is a large unmet demand for walkable neighborhoods, which drives price increases in central cities (Frank et al., 2007; Leinberger, 2009).

\section{Walkability and Foreclosures}

Considering the economic and social-equity stabilization effects provided by walkable neighborhoods, it is not surprising that recent studies have shown the resilience of these areas in the face of economic crises. Studies have shown high patterns of foreclosures inside the urban core and on the suburban fringe (Leinberger, 2009; Gilderbloom et al., 2009); some studies have shown that suburban areas are suffering from higher rates of foreclosure than the inner city (Immergluck 2009; NRDC, 2010). Other studies have correlated foreclosures with higher transportation costs and longer trips to work (NRDC, 2010) and have shown a disproportionate impact on central city neighborhoods (Immergluck, 2009), which are presumably more walkable, but have a high minority population.

Recent studies associated reduced foreclosure probability with higher walkability. One such study concluded that the probability of foreclosure varied according to income (Rauterkus et al., 2010). In high-income areas, with higher walkability, the probability of foreclosure was lower, while foreclosure increased in low-income areas with higher walkability (Rauterkus et al., 2010). This could be due to the preponderance of minorities who have historically lived in the low-income dense areas of inner cities, something apparent in preliminary work in Louisville, Kentucky (Gilderbloom et al., 2012).

\section{Walkability and Equity}


It is important to emphasize the limitations associated with self-selection and the disproportionate resource choices available for the poor and minorities. Research indicates self-selection of housing is often related to income (Nakosteen and Zimmer, 1980), and neighborhood self-selection shapes behaviors (Handy et al., 2006; Ioannides and Zabel, 2008).

Many minorities remain unable to find adequate housing in cities, and cannot afford to purchase nicer housing in the suburbs for a variety of reasons, including predatory lending and insurance practices (Cutler, Glaeser \& Vigdor, 1999). Past studies suggest a housing markup of approximately 7\% for blacks, compared to whites (Kain and Quigley, 1972). Recent work confirms continued mortgage discrimination, resulting in lower ownership and higher segregation (Ellen, 2008). Kain and Quigley (1977) pointed out that there can be a price discount to blacks if the housing supply is large relative to the demand. Racial price markups only exist where the minority population is constrained to a restricted supply. In many of today's majority-minority aging industrial cities, a surplus supply of housing resulting from white flight resulted in low values and a racial price discount. This is important because many health problems that might be mitigated by walkability, are focused in areas with a higher proportion of minorities, compared to the general population (Galea, Freudenberg \& Vlahov, 2005; Geronimus \& Thompson, 2004; Williams \& Jackson, 2005). Studies have suggested that certain populations, such as blacks, are less likely to engage in walking behavior (Brownson et al. 2000). However, research has not often examined the quantifiable aspects of the built environment and individuals relating to housing in walkable neighborhoods. 
Talen and Koschinsky (2010) explained the importance of walkability to neighborhood quality:

The effects of neighborhood form may be especially pronounced for low-income residents who rely disproportionately more than high-income residents on neighborhood and community-based resources. Research over the past decades has confirmed that neighborhood form has a significant effect on physical health, accessibility, crime, safety, and social interaction, all of which are important aspects of neighborhood quality of life (p. 2).

Talen and Koschinsky (2011) demonstrated how walkability is disproportionately distributed; nearly three quarters of the U.S. public housing is located in neighborhoods with poor access to social services and facilities; thus, revealing the poor access and the lack of opportunities that these neighborhoods possess, especially for low income families who tend to be most affected by their physical environment.

\section{Walkability and Neighborhood Access}

Accessibility to goods and services is used to define spatial equality and is a central theme in understanding cities (Pahl, 1979). Accessibility is seen as a way to expand opportunities for all populations but has a profound impact on the impoverished (Jacobs, 1961; Wilson, 1978; Dreier et al., 2001; Gilderbloom, 2008; Talen \& Koschinsky, 2011). Neighborhood accessibility is transparent in measures of walkability, especially the measures which calculate the proximity of amenities required for daily routines, “ ... [local accessibility is] primarily determined by nearby activity, most of which is oriented to 
convenience goods, such as supermarkets and drug stores, and located in small centers" (Handy, 1993: p. 63). Density has been shown to correlate positively with neighborhood access. Land use diversity is also associated with access; having a mix of desirable uses is essential to create a sustainable mixed income neighborhood (Duany et al., 2001; Holin et al., 2003). Land use diversity not only creates diverse neighborhoods, but makes them economically resilient, which increases the level of accessibility in the area (Duany et al., 2001).

Proximity to resources impacts the social mobility and opportunities of neighborhood residents, especially for low income people who are vulnerable to the effects that limited access has on time and money (Wilson, 1978). Though proximity does not always mean access and improved outcomes, lower income residents, who rely on alternative or public transportation, have a greater need for services and goods to be located in proximity (Steinberg, 2010; Riggs, 2011).

Using walkability as a proxy for neighborhood access to measure opportunity has an advantage. Information about accessibility provides scholars with a deeper understanding of neighborhood design and features. Desirable neighborhoods can be more than just lowpoverty areas; the suburbs are areas of low poverty and still can be undesirable because they contain few nearby amenities and are poorly serviced. By using neighborhood access in conjunction with poverty measures, one can contrast the design, attributes and amenities of various neighborhoods while continuing to account for neighborhood poverty.

\section{Measures of Walkability}


In order to further the understanding of walkability as a concept, it is pertinent to trace how it has been specified in previous research. This includes an understanding of how built environment variables have been used to classify walkability, and how its specification has evolved. As described in previous sections, a number of variables have been used to quantify walkability; yet, only few variables have been consistently used throughout the literature. A recent meta-analysis by Ewing and Cervero (2010) found street-grid connectivity to be the strongest determinant of walkability. Other studies have identified the significance of residential density, land use, individual characteristics (i.e. perceived safety and physical health) and desirable destinations. This literature raises the question of how to best quantify walkability.

Riggs (2011) identified three common indices of walkability. These indices are based upon quantitative built environment variables measuring the environmental features, population characteristics and proximity, they are as follows: (1) SMARTRAQ developed by Frank, Andresen and Schmid (2004); (2) a GIS method that was developed by Leslie et al (2005); and (3) the Walk Score tool that uses methods similar to SMARTRAQ.

\section{SMARTRAQ}

Frank, Andresen and Schmid (2004) developed SMARTRAQ from the Seattle SMARTRAQ study. Using urban form variables, they created an index of walkability. The variables used included: (1) net residential density (number of residential units per residential acre); (2) street connectivity (number of intersections/square kilometer); and (3) land use mix. These measures are normalized, weighted and combined using Z-scores. In later 
publications, Frank concluded that a higher weight for land use is a better measure of walkability (Riggs, 2011).

\section{GIS}

Based upon Frank, Andresen and Schmid (2004), Leslie et al. (2007) developed a method that uses a GIS buffer approach alongside urban form variables. Their walkability index uses variables for dwelling density, intersection density, land use and net retail area. Scores are normalized and summed, and each location is given a score on of 4 to 40 . This tool has a number of limitations with the exclusion of certain variables, which have been pointed out in the literature. These variables include the presence of parks, walking path conditions, accessibility to alternative transportation, topography, physical barriers and individuals' preferences.

\section{Walk Score}

Walk Score uses the Google database to measure the walkability of a location. The methodology is similar to SMARTRAQ, combining land use mix, density and grid density. Traditional Walk Score uses Google databases to calculate the distances of 13 amenity categories $^{5}$ that serve as a proxy for land use mix. Density is drawn from the current U.S. Census data, and intersections are counted using an algorithm. Traditional Walk Score does not reward more points to neighborhoods with multiple amenities in the same category, but bases the neighborhood's score on the closest amenity in each category. Each category has the same weight in traditional Walk Score. The weighted z-scores for each category are normalized and added together, with a range of scores between $0-100$. The algorithm

\footnotetext{
${ }^{5}$ The categories are: grocery store, coffee shop, movie theater, park, bookstore, drug store, clothing/music store, restaurant, bank, school, library, fitness and hardware store.
} 
includes a decaying factor to control for the distance to amenities, which translates into lower scores for amenities that are further away and a score of 0 for amenities outside of a one-mile radius. Highest priority is placed on land use mix as the leading predictor of walking behavior (Riggs, 2011). Walkability in this specification is a direct function of how many destination categories are located within a short distance. Distances are not calculated based on walking paths but as a straight line or "as the crow flies".

The inability of traditional Walk Score methods to consider street quality, measuring actual walking distance and the evenly distributed weight among categories, led the creators to add a second measure for walkability. Streetsmart Score addresses the shortcomings of the traditional score, although the traditional method is still available and widely used. The Streetsmart Score accounts for street quality by measuring the number of intersections and the average length of blocks in the neighborhood. However, many factors are still excluded from this measure, such as quality of sidewalk and crime, but this is still an important progression of the metric. Streetsmart Score uses actual walking distance, which allows for a more accurate depiction of the neighborhood's accessibility. Lastly, the Streetsmart Score accounts for amenities that generate the most walkability. This is reflected in the new weights Streetsmart metric gives to categories.

All the measures discussed here attempt to move the specification of walkability beyond the idea of suitability. These measures are designed to implement walkability as a proxy for accessibility and livability. This study focuses on walkability in terms of accessibility, particularly the aspects of walkability that determine access to goods, services 
and various types of land use, while also including measurable factors that influence walking, such as destination and connectivity.

\section{Conclusion}

This literature review demonstrates there is a gap in the scholarship concerning walkability, principally because of a lack of research in mid-sized American cities. This study seeks to fill this gap. Furthermore, this study will fill another gap in the literature by examining how the socio-economic composition of walkable neighborhoods differs from non-walkable neighborhoods. The next chapter will introduce the research questions and the hypotheses used in this dissertation. 


\section{CHAPTER III}

\section{RESEARCH QUESTIONS AND HYPOTHESES}

This dissertation seeks to explore the relationship between walkability, as a proxy for accessibility, and neighborhood housing markets and residential composition. A number of questions that have emerged from the literature review will guide this dissertation:

How does walkability affect neighborhood housing dynamics in a mid-size city? Does this differ from non-walkable neighborhoods?

What is the socio-economic composition of walkable neighborhoods? How does that compare to the rest of the city?

This exploration seeks to better understand the impacts of accessibility on neighborhood housing markets. Additionally, exploring the composition of walkable neighborhoods, and the type of residents found there, will help to understand walkability as well as the effects of policies that promote walkability.

The questions presented here have been developed into several hypotheses, which have been categorized into two groups: 1) housing dynamics-examines the impact of walkability on measures for neighborhood housing; 2) socio-economic composition surveys the impact of walkability on common measures used to identify the socio-economic composition of a neighborhood. Below, each hypothesis is stated and explored by category. 


\section{Housing Dynamics}

$\mathbf{H}_{1}$ : Housing valuation is more likely to be higher in neighborhoods with greater levels of walkability.

Studies have explored the impact of walkability, as a proxy of access, on property valuation (Cortright, 2009; Pivo \& Fisher, 2010). However, these studies are limited in the number of control variables used and their reliance on housing sales data. This study differs from previous ones by using census tract aggregated data to understand the effect of walkability on neighborhood housing valuation, and allowing for the use of more control variables, such as the percentage of minorities in the neighborhood. Understanding the effect of accessibility on housing valuation can enhance insight into programs and policies that advocate for greater accessibility.

$\mathbf{H}_{2}$ : Neighborhoods with greater levels of walkability are more likely to have a lower rate of foreclosure.

A significant advantage in using 2000-2010 as the years for study is the ability to examine the resiliency of neighborhoods after the housing market crash of 2007 . The differences in resiliency between neighborhoods with high versus low levels of walkability has been a topic not well explored in the literature. However, some studies have discovered that neighborhoods with higher levels of walkability tend to have fewer foreclosures (Rauterkus et al., 2010; Gilderbloom et al., 2012). The model for exploration in this dissertation is built upon the findings of Gilderbloom et al. (2012). This study examines the 
impact of walkability on the level of neighborhood foreclosures, while adding additional control variables excluded from the Gilderbloom et al. (2012) model.

H3: Neighborhoods with greater levels of walkability are more likely to experience lower vacancy rates.

Studies of walkability have shown that walkable neighborhoods are in high demand. In fact, people will pay a premium to live in a walkable neighborhood (Leinberger, 2009; Speck, 2012). Other studies show walkability is a prominent preference in that individuals are willing to sacrifice preferences that have been previously dominant in housing tenure decisions, such as the desire to live in a neighborhood with racial homogeneity (Riggs, 2011). Leinberger (2009) discussed the unmet demand of walkable neighborhoods, claiming that the market is saturated by consumers who can't secure the housing product they desire. Thus, one can hypothesize that greater walkability creates more demand while decreasing the number of vacancies in a neighborhood.

\section{Socio-economic}

H4: Walkable neighborhoods are more likely to have lower levels of poverty.

Higher levels of walkability can increase the attractiveness of the neighborhood; especially, if Leinberger's (2009) notion of an underserved demand for walkability holds true. This suggests that, within city core or suburban rings, increasing walkability may help to alleviate Wilson's (2012) job spatial mismatch by bringing the inner city poor unemployed into close proximity to jobs through the reintroduction of wealth, investment and business into inner city neighborhoods. Conversely, walkability could further isolate the poor if a 
situation is created where the demand prices the poor out of homes and causes them to leave the neighborhood; thus, driving down the poverty of the neighborhood. The absence of understanding which is occurring has caused a problem that has plagued poverty deconcentration policy prescriptions. The intention of this research is to see if poverty reduction is occurring in walkable neighborhoods and if the walkable neighborhoods are significantly different from those that are not walkable.

H5: Walkable neighborhoods are more likely to have higher levels of racial integration.

Handy et al. (2008) suggested that the preference for walkable neighborhoods could span socio-economic preferences traditionally associated with housing tenure choice, such as racial homogeneity. If this is so, one would expect the city's walkable neighborhoods to have higher levels of racial integration compared to other non-walkable neighborhoods in the same city. This incidence is particularly important to understand, especially since policies aimed at urban renewal are often criticized for being unable to create a greater racial mix in the neighborhood (Brazley and Gilderbloom, 2007).

H6: Walkable neighborhoods are more likely to have lower unemployment levels.

Walkable neighborhoods locate shopping and entertainment near residents. Bringing amenities closer to individuals increases access and creates employment opportunities. Thus, walkable neighborhoods located in the inner city can help overcome the job spatial mismatch identified by Wilson (2012).

Greater employment in these areas contributes to two possible outcomes (or a combination of them): 1) greater increases in employment for the population in the 
neighborhood; 2) greater numbers of employed middle income individuals move into these neighborhoods, which can raise prices that push low income persons out of neighborhoods. Whatever the explanation, it is important as a preliminary step to determine if a difference in unemployment figures exists between neighborhoods with high walkability versus low walkability.

\section{Conclusion}

The hypotheses explored in this dissertation will contribute insights into the housing and socio-economic characteristics of walkable neighborhoods. Results will illuminate the impact of walkability, as a measure of access, and contribute to current policy discourse. Prior to exploring these hypotheses, the methodology and data used in this dissertation will be reviewed. 


\section{CHAPTER IV}

\section{METHODOLOGY}

In this dissertation, quantitative methods are implemented to explore the impact of walkability on neighborhoods. This dissertation relies on cross-sectional data points to assess the housing and socio-economic aspects of neighborhoods. A quasi-experimental design is used to analyze the proposed hypotheses. The quasi-experimental design provides more validity than a non-experimental design; however, it lacks the levels of internal validity and control that is present with a true experimental design. This design allows the researcher to reveal the effects of a given attribute, i.e. the impact of walkability, on a given dependent variable(s). Prior to discussing the statistical methods to be used in this analysis, a review of the specific study area will be discussed.

\section{Study Area: Louisville}

Louisville, Kentucky, a medium-sized U.S. city, one of 150 cities in the United States, with a population greater than 50,000 that is not located within 40 miles of another neighboring city of more than 50,000 (Appelbaum et. al, 1976; Gilderbloom \&Appelbaum 1988; Ambrosius et al., 2010; Gilderbloom et al., 2012). Louisville provides an excellent case study, since it is more representative of typical U.S. cities than that of a mega city. Louisville's urban landscape possesses characteristics representative of other U.S. cities such as Indianapolis, IN, Lexington, KY, Nashville, TN and Fresno, CA (Appelbaum et al., 1976; 
Ambrosius et. al, 2010). Scholars consider the Midwest region to be the most representative demographically of all the regions in the U.S. (Ambrosius, 2010). These representative demographic characteristics include a minority population of approximately one-third in the inner city core and one-fifth across the metropolitan area. Popularly held to be the "gateway from the North to the South", Louisville's location on the border of the South and Midwest sections of the U.S., and its proximity to the Ohio River, similarly result in cultural characteristics comparable to other large Northern and Midwestern populations. River cities such as St. Louis, Memphis, New Orleans and Cincinnati have similar characteristics (McMeekin, 1946; Ambrosius et al., 2010).

Prior to 2003, the city of Louisville was a separate entity from Jefferson County (Savitch and Vogel, 2004; Ambrosius et al., 2010). Subsequent to their merging in 2003, the consolidated "Louisville Metro" ranked $18^{\text {th }}$ in population nationally and $48^{\text {th }}$ as a Metropolitan Statistical Area (U.S. Census Bureau, 2007).

Louisville may be further reduced into sub-regions, which include the following: 1) the poorer African American region in western Louisville; 2) the wealthier white neighborhoods in eastern Louisville; 3 ) and the working class mixed-race neighborhoods in the southern region. Louisville Metro government has attempted to redefine the city's perception of its housing markets subsequent to the merger, with the reclassification of three new regions: 1) the inner beltway (inner ring); 2) the area between the beltways (middle ring); 3) and, outside the outer beltway (outer ring) (Louisville-Jefferson County Metro, 2006). Despite these efforts, eastern Louisville has retained its reputation as a superior 
housing submarket, and western Louisville is still largely perceived to house undesirable land and an impoverished populace.

Louisville's mid-size and relative isolation make it a more manageable study area than mega cities or other mid-sized areas in proximity to megalopolis regions (Ambrosius, 2010). While research findings on Louisville are not representative of the nation as a whole, or even all other cities, a Louisville case study provides results that are more generalizable for the typical American community.

\section{Statistical Methods}

This dissertation uses both descriptive and analytical statistics to address the hypotheses above. The changes between groups are examined using univariate descriptive statistics. Ultimately, this examination will progress to multivariate modeling techniques including linear regression, also known as ordinary least squares (OLS), spatial lag (SLM), spatial error regression (SEM) and logistic regression (Agresti and Finlay, 2009; Talen, 2010; Schutt, 2011; Talen and Koschinsky, 2011). These methods have been employed in past research and still are used in current studies (Holin et al., 2001; Popkin et al., 2004; Talen \& Koschinsky, 2011).

\section{Linear Regression: Ordinary Least Squares}

A linear regression equation attempts to calculate a linear relationship between the dependent variable and a single or a set of independent variables. The multiple linear regression (MLR) equation, in simple form, is represented below: 


$$
y=x \beta+e
$$

$Y$ is the dependent variable; $x \beta$ is a trajectory of independent variables; and e is an error term.

There has been a multitude of procedures developed for parameter estimation and interpretation for linear regression. The most common is ordinary least squares (OLS), which estimates $\beta$ by minimizing the sum of squared prediction errors. Although it is rather unsophisticated, compared to more modern techniques, many scholars still rely on this method solely for their analysis or as an initial point of analysis (Krueger and Lewis-Beck, 2008). There are a number of assumptions that OLS regression is based upon and can be referenced in any statistical text (see Agresti and Finlay (2009) or Stevens (2009) for a full discussion).

\section{Spatial Regression: Lag and Error}

With OLS regression, one cannot depict the neighborhood characteristics that are often influenced by adjacent neighborhoods or a clustering of amenities, thus creating a spatial dependence. The inability of OLS regression to compensate for spatial dependence may violate the assumptions concerning the independence of errors and can create biased or inefficient estimates. In order to overcome these complications scholars have developed two techniques: spatial lag models (SLM), which addresses spatial correlation in the dependent variables, and spatial error models (SEM), which accounts for spatial correlation in error terms. Unlike OLS, both techniques rely on maximum likelihood when making estimates. 
The SLM model contains an autocorrelation parameter, which is the average value of the dependent variable for the neighboring jurisdictions. Thus, the standard MLR formula is transformed:

$$
\mathrm{Y}=\mathrm{pWy}+\mathrm{x} \beta+\mathrm{e}
$$

$Y$ is the dependent variable; $x \beta$ is a trajectory of independent variable(s); $p$ is the spatial autocorrelation parameter; $W$ is the spatial weight matrix; and e is an error term.

The way SEM model alters the standard MLR formula is:

$$
\mathrm{Y}=\lambda \mathrm{Wy}+\mathrm{x} \beta+\mathrm{e}
$$

$Y$ is the dependent variable; $x \beta$ is a trajectory of independent variable(s); $\lambda$ is the spatial error parameter; $W$ is the spatial weight matrix; and e is an error term.

Since both errors and lag have the possibility to occur in the examination, both tests are performed to compare the conclusions to the results of the OLS. This illuminates how the results can possible change when controlling for spatial dependence that can be present in the OLS model.

\section{Logistic Regression}

The last statistical method applied to this dissertation is a Logistic Regression. When attempting a regression on a nominal variable one cannot rely on OLS regression for a number of reasons (Agresti and Finlay, 2009). The first assumption of OLS regression is that the variance of the dependent variable is constant across values of the predictor(s). Second, if linear regression is implemented, the predicted values will become greater than one and less 
than zero along the $\mathrm{X}$-axis. These values are theoretically inadmissible. Third, since there are only two categories for the dependent variable, the test's regression weights for OLS are unreliable. Therefore, in testing the socio-economic composition of neighborhoods logistic regression will be relied on since the dependent variable is a binary coding of whether a neighborhood is walkable or non-walkable, and the independent variables are a mix of continuous and categorical variables. A full model in simple form is represented below:

$$
\operatorname{Logit}[P(y=1)]=\alpha+x \beta
$$

Where $[P(y=1)]$ is the probability of an event to occur; $\alpha$ is the constant; and $x \beta$ is a trajectory of independent variables.

In this model, the dependent variable is the natural $\log$ of the binary variable.

Therefore, it describes a population's proportion to the independent variables. Furthermore, this method relies on maximum likelihood to fit the model, which is more appropriate for binary data than least squares (Agresti, 2009; Babbie, 2012).

\section{Housing: $\mathrm{H}_{1}-\mathrm{H}_{3}$}

Using OLS, this dissertation engages neighborhood median assessed value as the dependent variable for neighborhood housing valuation. Median assessed housing value is represented in three measures (2000, 2010 and the percent change in value between 2000 and 2010). Median assessed value is used rather than sales prices for several reasons. First, local assessment data was collected by the Jefferson County Property Valuation Administration and is readily available for analysis. Second, assessments closely approximate actual market values, despite their reputation as undervaluing properties (Ambrosius et al., 2009;

Gilderbloom et al., 2009). Proponents of using assessed values in analysis argue that gross 
assessment error is corrected by the appeals process and audits by state governments and that assessed value "'acts as a proxy for the true market value”, (Clapp and Giaccotto 1992: 301). Kentucky Revised Statute 134.385 requires that local property assessments be at least $80 \%$ of the fair market value. Therefore, it is assumed that assessed value is a proxy for true market value. As defined by Lacour-Little and Green (1998), the rationale for this portion of the dissertation is explained by the following equations:

$$
\begin{gathered}
P=V+e_{1} ; \\
A=V+e_{2} ; \\
E\left[e_{1}\right]=E\left[e_{2}\right]=0 ; \\
E[A-P]=0 ;
\end{gathered}
$$

$P$ is selling price; $A$ is assessed value; $V$ is market value; and $e_{1}$ and $e_{2}$ are error terms.

Housing scholars view OLS hedonic modeling as an appropriate way of measuring the effects of neighborhood amenities on housing values (Gilderbloom and Appelbaum, 1988; Cortright, 2009; Ambrosius et al., 2010; Pivo and Fisher, 2010; Gilderbloom et al., 2011). In this model it is assumed that a house $[\mathrm{H}]$ is a package of characteristics described by its structure [S], neighborhood [N] and local public services [L], represented below:

$$
[H]=f([S][N][L])
$$

The OLS model for this hypothesis uses important control variables identified in the literature focusing on the impacts of amenities on housing valuation, while testing the importance of walkability. A full model is represented below: 
$Y=\alpha+\beta_{1} *$ Walk Score/Streetsmart $+\beta_{2} *$ distance to the central business district $+\beta_{3} *$ percent of nonwhite residents $+\beta_{4} *$ median housing age $+\beta_{5} *$ number of housing units $+\beta_{6} *$ number of bus stops $+\beta_{7}$ *high interest loans $+\beta_{8} *$ percent of vacant units $+\beta_{9} *$ median household income $+\beta_{10}$ total crime 2007 per 1,000 residents $+\beta_{11} *$ total jobs located in tract $+e$ (10)

Where $Y$ is mean housing valuation; $\alpha$ is the constant; and e is an error term.

The second dependent variable in the housing dynamics section that is tested is foreclosures. Using data provided by the Jefferson County Property Valuation Administration, a raw count of foreclosures is calculated in each tract from 2004-2008. Furthermore, building off the work of Gilderbloom et al. (2012), this examination seeks to improve their foreclosure model by adding additional control variables to their significant findings. A full model the second hypothesis is represented below:

$$
\begin{aligned}
& Y=\alpha+\beta_{1} * \text { Walk Score }+\beta_{2} * \text { distance to the central business district }+\beta_{3} * \\
& \text { percent of nonwhite residents }+\beta_{4} * \text { median housing age }+\beta_{5} * \text { number of } \\
& \text { housing units }+\beta_{6} * \text { total crime } 2007 \text { per } 1,000 \text { residents }+\beta_{7} * \text { high interest } \\
& \text { loans } \wedge+\beta_{8} \text { number of bus stops } \wedge+\beta_{9} * \text { total jobs located in tract } \wedge+\beta_{10} * \\
& \text { median household income }+e
\end{aligned}
$$

Where $Y$ is the number of foreclosures; $\alpha$ is constant; $e$ is an error term; and ${ }^{\wedge}$ notes new control variables different from Gilderbloom et al. (2012).

The final dependent variable for the housing dynamics is the vacancy rate for the census tract. Using data from the 2000 and 2010 U.S. Census Bureau, the vacancy rate for each census tract was gathered. If walkability does create greater demand, then it can be assumed that the vacancy rate will be lower. A full model for the third hypotheses is represented below: 
$Y=\beta_{1} *$ Walk Score/Streetsmart $+\beta_{2} *$ distance to the central business

district $+\beta_{3} *$ percent of nonwhite residents $+\beta_{4} *$ median housing age $+\beta_{5} *$ number of housing units $+\beta_{6} *$ number of bus stops $+\beta_{7} *$ median household income $+\beta_{8}$ total crime 2007 per 1,000 residents $+\beta_{9} *$ total jobs located in tract $+e$

Where $Y$ is vacancy rate; $\alpha$ is constant; and e is an error term.

A spatial regression is also implemented for each of these hypotheses to control for autocorrelation. These assessments allow for greater control and understanding of the impacts of walkability on neighborhood housing dynamics (Appelbaum et al., 1976; Galster et al., 1999; Gilderbloom et al., 2011; Gilderbloom et al., 2012), particularly if there are benefits for living in areas with higher walkability.

\section{Socio-economic: $\mathrm{H}_{4}-\mathrm{H}_{6}$}

Logistic regression is used to understand the socio-economic characteristics of walkable neighborhoods. Understanding the socio-economic attributes of a walkable neighborhood and if they differ from non-walkable neighborhoods is relatively absent from the literature. For this section, the walkability index will be used in order to develop a nominal walkable neighborhood. This nominal variable will serve as the dependent variable and the variables present below will be key independent variables in the model. This examination will allow further insight into the typical resident who lives in these neighborhoods.

The first variable examined is poverty. Understanding the poverty level allows insight into the ability of impoverished individuals to reside in these neighborhoods. The second variable is racial integration, which is represented by the number of nonwhite residents in the 
neighborhood. The third is the median age of residents within each census tract, which is the average of age of all residents within the neighborhood. The fourth variable, the average size of households, is the mean size of households in each census tract. The last variable is the unemployment level of the census tract. This will help identify if employment is higher in neighborhoods that are walkable. A full model that will be tested in this section is represented below:

$$
\begin{gathered}
Y=\alpha+\beta_{1} * \text { median age of resident }+\beta_{2} * \text { percent of unemployed people }+\beta_{3} \\
* \text { percent of nonwhite residents }+\beta_{4} * \text { percent of families in poverty }+\beta_{5} * \\
\text { average size of household }+e \\
\text { Where y is the probability of the neighborhood being walkable } \\
(1=\text { walkable } / 0=\text { non-walkable }) ; \alpha \text { is the constant; and e is an error term }
\end{gathered}
$$

\section{Data and Variables}

This dissertation relies on quantitative data. Data was procured from the following sources: 1) the U.S. Census 2000 and 2010 Decennial Census; 2) the 2011 American Community Survey; 3) the Jefferson County Property Valuation Administration (JCPVA); 4) the Louisville Metro Police Department (LMPD); 5) the Walk Score database; and 6) the Louisville/Jefferson County Information Consortium (LOJIC) system.

\section{Dependent Variables}

The following section discusses the various dependent variables employed in this dissertation and how each is specified. This dissertation uses dependent variables that measure the socio-economic and housing conditions of neighborhoods in mid-sized 
American cities. Some of these variables are also used as control variables in other statistical models within this dissertation.

Median Assessed Value. For this study, data from 2000 and 2010 Jefferson County Property Valuation Administration is utilized to calculate the median value of residential property in each census tract for each period of time. This dissertation examined the property value for neighborhoods in 2000 and 2010. Also examined is the raw dollar change in property value from 2000-2010. The groups (walkable and non-walkable) are compared to identify if walkable neighborhoods have significantly higher changes in property values.

Foreclosures. Data from the JCPVA is used to measure foreclosures from 2004 to 2008 per census tract. With this data, the foreclosure rates among neighborhoods is compared. From this, the analysis will be able to identify if walkable neighborhoods are more likely to be stable, especially during the time of an economic recession.

Vacancy Rate. When a neighborhood becomes desirable, then it can be posited the vacancy rate in the neighborhood will be lower. Walkable neighborhoods have amenities that have been found to be highly desired (Cortright, 2009). The greater demand, if present in this sample, should be reflected in lower vacancy rates of the neighborhood. Using information from the U.S. Decennial Census, the vacancy rates in the neighborhoods from 2000 and 2010 will be calculated. From this data, the neighborhoods are compared to explore the possibility of a relationship existing between walkability and vacancy rates.

Walkable Neighborhoods. In order to understand the composition of a walkable neighborhood, a binomial variable identifying whether or not a neighborhood is walkable 
was generated. Using the traditional Walk Score index and the Streetsmart Score index, two separate variables were created. Neighborhoods with a Walk Score of (50-100) are considered walkable and coded with a 1 while neighborhoods with a score of (0-49) were considered non-walkable and coded with a 0 . This variable specification will allow for an exploration of the composition of walkable neighborhoods to understand if it differs from neighborhoods lacking walkability.

\section{Independent Variables}

This section discusses independent variables, both control and test variables. It is important to note that some of the dependent variables discussed above will also serve as control variables in other models.

\section{Key Test Variables}

Traditional Walk Score and Streetsmart Score. While there have been many methods established that objectively measure the walkable environment, this study takes advantage of the tool established by Walk Score, as the key test variable of this analysis. Developed by Front Seat Inc., in partnership with academics, Streetsmart Score uses a method similar to Frank's SMARTRAQ model, which combines land use mix, density, and street grid density based on geo-location. Google is used to index adjacent amenities as a proxy for land use mix, density comes from U.S. Census figures and intersections are counted using an algorithm on a street network. The weighted scores are summed and normalized to 100, yielding a score from $0-100$, from least to most walkable. These methods place the highest priority on land use mix as the leading predictor of walking behavior. 
Using the Walk Score tool has clear advantages. While many tools employ surveys, self-reporting, audits and observational data measures, the Walk Score tool provides a direct and replicable manner of assessing geospatial, population and land use characteristics to benchmark walkability (Brownson et al., 2009; Heath et al., 2006). Studies have concluded that the Walk Score suffices as a reliable tool for measuring the walkability of an area, and may be more accurate than other tools, as Google tends to be reviewed and updated on a more frequent basis than other static databases (Carr et al., 2010, 2011; Duncan et al., 2011). Although, the traditional Walk Score has been validated in the literature, it is still scrutinized for the calculation of distances by the straight line measure and for giving equal weight to all amenity categories.

For the purposes of this study, the Streetsmart Score of the census tract will also be used. New developments by WalkScore.com allow researchers to procure aggregate levels of the Streetsmart Score data. Streetsmart Score has other advantages as well: 1) since it uses actual walking distances, it is a more accurate representation of accessibility; 2) the creators take into account that certain amenities are more important to access than others, this is now reflected in their new scores where categories that Frank et al. (2004) and others have shown to be more important have a heavier weight; and 3) the metric has taken into account the number of intersections within a mile and the average length of a block within a mile, these measures reflect the importance of street quality.

While this method provides a research solution to determine a location's walkability it also has limitations. First, the tool is limited based on its reliance on Google Maps as an underlying database, with potential flaws in the exact geo-location and classification of use 
categories (which are often user contributed). Second, the tool does not account for all variables for street quality (such as the presence of trees, sidewalk width, etc.) and safety (from traffic or crime). Third, a Walk Score is a measure of opportunity for residents of a neighborhood. It does not translate to greater walking activity; rather it indicates that amenities are more easily accessible. Lastly, similar to other metrics, the tool may suffer from aggregation errors based on the unit of spatial analysis.

Poverty Levels. Data employed from the 2000 and 2010 U.S. Decennial Census is used to measure the poverty levels for the neighborhoods. Understanding if walkability is correlated with a lower neighborhood poverty level will go far to inform planners and neighborhood redevelopment policies.

Racial Integration. Understanding if a difference exists in racial composition of walkable neighborhoods is an important aspect of walkability that needs further explanation. Using U.S. Decennial Census data from 2000 and 2010, the percent of non-white residents is calculated by removing anyone who is identified as white from the total population of the neighborhood and dividing the remainder by the total number of residents in the census tract. From this measure, the analysis is able to determine if walkable neighborhoods are correlated with greater racial diversity compared to non-walkable neighborhoods.

Unemployment. Walkable neighborhoods, which are associated with mix use communities, are believed to bring businesses and investments to the neighborhood (Leinberger and Alfonso, 2012; Swanson, 2012). This in turn, will create jobs and help overcome the job spatial mismatch, especially if they are located near the inner city. In order to measure unemployment rates, data from the 2000 and 2010 U.S. Census Data is used to 
create two measures, one for each point in time. From this data, the analysis will detect if there is a difference for the unemployment rates of walkable neighborhoods compared to non-walkable neighborhoods.

Age of Resident. An important demographic of walkable neighborhoods to investigate is the age range of the residents. Riggs (2011) analysis suggests that there is a curvilinear relationship between neighborhood accessibility and age. To put it in other words, he found that younger and older populations tend to live in walkable neighborhoods while middle aged individuals tend to live in non-walkable areas. In order to test this notion, data from the 2000 and 2010 U.S. Census will be used to calculate the mean age of residents each census tract. Integrating this into the logistic regression will allow an understanding into who resides in accessible neighborhoods.

Average Household Size. The average size of a household is another important aspect to consider in understanding the composition of walkable neighborhoods. Riggs (2011) and Speck (2012) presented evidence suggesting younger households without children and empty nesters are more likely to live in walkable areas, usually because they do not need large housing and enjoy the closeness of amenities. Utilizing data from the 2000 and 2010 Census, the average household size of each tract was calculated.

\section{Control Variables}

OLS Neighborhood Characteristic Variables. A number of neighborhood characteristic variables are used within this study that have been deemed important within the literature and may correlate with housing market dynamics, socio-economic composition or walkability. 
The first variable controlled for is distance to the central business district (CBD) in miles. This is calculated using Census data to identify the census tract centroids of the neighborhoods and the centroids of the city's CBD. Second, the percent of nonwhite residents in the neighborhood is included. This is calculated by subtracting the number of residents identified as Caucasian non-Hispanic from the total number of residents and dividing this number by the total number of residents. This measure of race has been used in various neighborhood level examinations (Ambrosius et al., 2010; Gilderbloom et al., 2012). Third, median housing age for the tract is taken from the Census. Fourth, the number of housing units per census tract is taken from the Census. Fifth, the number of bus stops located in each tract is included. This is an interesting control variable serving as a proxy for access to public transportation. Sixth, the high interest loans from 2007-2008 is used to serve as a proxy of the number of high-priced loans in the area. The information for this variable is provided by the JCPVA. Seventh, the percent of vacant units in the neighborhood is derived from Census data. Eighth, neighborhood wealth is controlled for by using the median household income provided by the Census. Ninth, the crime rate in 2007 per 100,000 residents is relied upon as a measure of crime. While it would more preferable to have a measure that includes more years, the author found it difficult to obtain information at this level, and as Savitch (2012) has indicated there is sometimes great difficulty in obtaining data from certain city departments. The final control used in this analysis is the total number of jobs located in each tract, which is derived from the Census. 


\section{Conclusion}

Having defined the research questions, hypotheses, methodology and the specification of the variables, the next chapter will test the hypotheses used to explore the impact of walkability on neighborhood composition and housing markets. The results will be presented in two chapters: the first focusing on hypotheses related to housing and the second presenting findings related to the socio-economic composition of neighborhoods. 


\section{CHAPTER V}

\section{HOUSING CHARACTERISTICS}

This chapter examines the results of the hypotheses related to neighborhood housing dynamics, as outlined above. This chapter relies on ordinary least squares (OLS) regression and spatial regression in order to determine if walkability is associated with neighborhoods housing valuation, foreclosures and vacancies. All models in this section were checked for multicollinearity, the tolerance score for all variables exceeded the threshold of .2 and the variance inflation factors were under 10 . Therefore, no problems related to multicollinearity were detected. Prior to introducing the models, the descriptive statistics of the variables used in this chapter will be explored.

\section{Descriptive Statistics}

The descriptive statistics for the variables used in the analyses for this chapter are located in Table 5.1 and Table 5.2. The variables are presented in three variations: 1) the statistics for all neighborhoods in Louisville; 2) statistics for walkable neighborhoods (Walk Score 50-100); and 3) statistics for all non-walkable neighborhoods (Walk Score 0-49). 


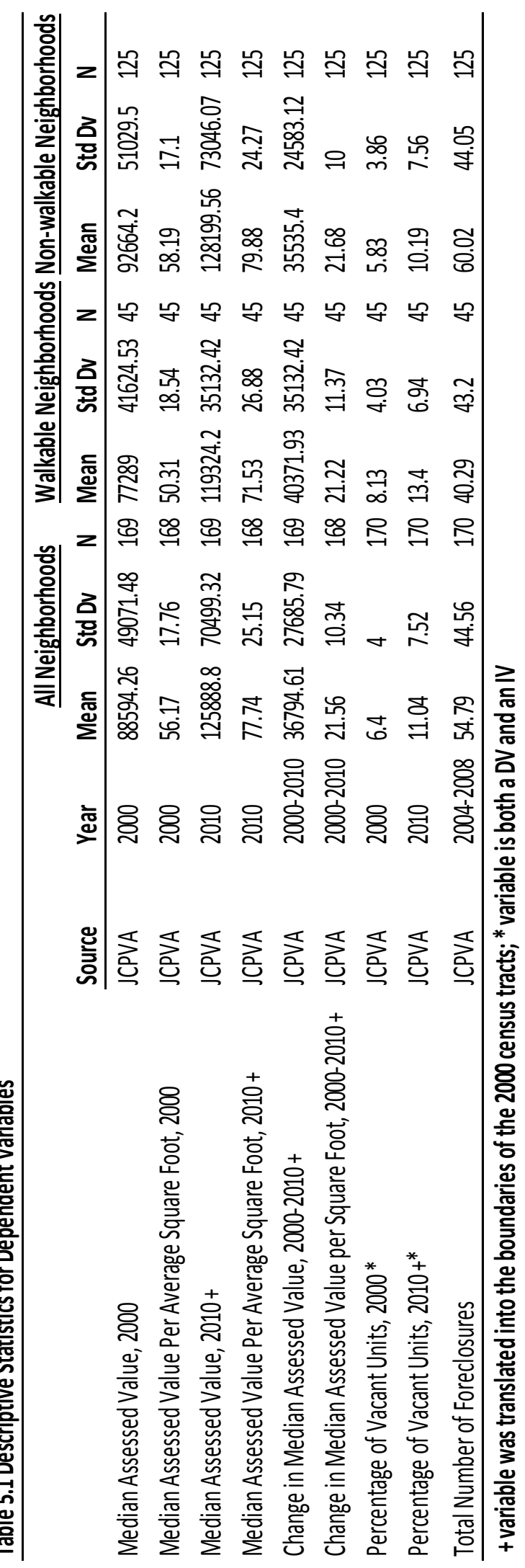




\section{Dependent Variables}

Table 5.1 lists the basic descriptive statistics for the dependent variables in this section. The mean for median assessed housing value for Louisville's neighborhoods in 2000 was $\$ 88,504.26$, walkable neighborhoods mean for assessed housing value is roughly $\$ 15,000$ less than non-walkable neighborhoods. This period of time is the beginning of the housing bubble where housing values throughout the city were at relatively high due to the high demand and ease to buy (Gilderbloom, 2007; Ambrosius et al., 2010). Figure 5.1 shows that the median assessed value for Louisville neighborhoods in 2000 are higher in the outer rings, which reflect historic trends (Ambrosius et al., 2010).

A portion of this difference may be explained in the variation of housing size. Since housing in sprawling areas is generally larger, and nearly all of those census tracts in Louisville are considered not walkable, these homes will have higher values (Pivo and Fisher, 2010). In order to control for differences in size, this dissertation uses median assessed value per average square foot in housing. When this was done, the difference between the means of walkable and non-walkable neighborhoods in 2000 was not as blatant (less than $\$ 8$ a square foot). Figure 5.2 displays the higher values of median assessed value per square foot in 2000 have greater distribution throughout the city compared to the median assessed value specification. However, the outer rings do tend to have higher values. 


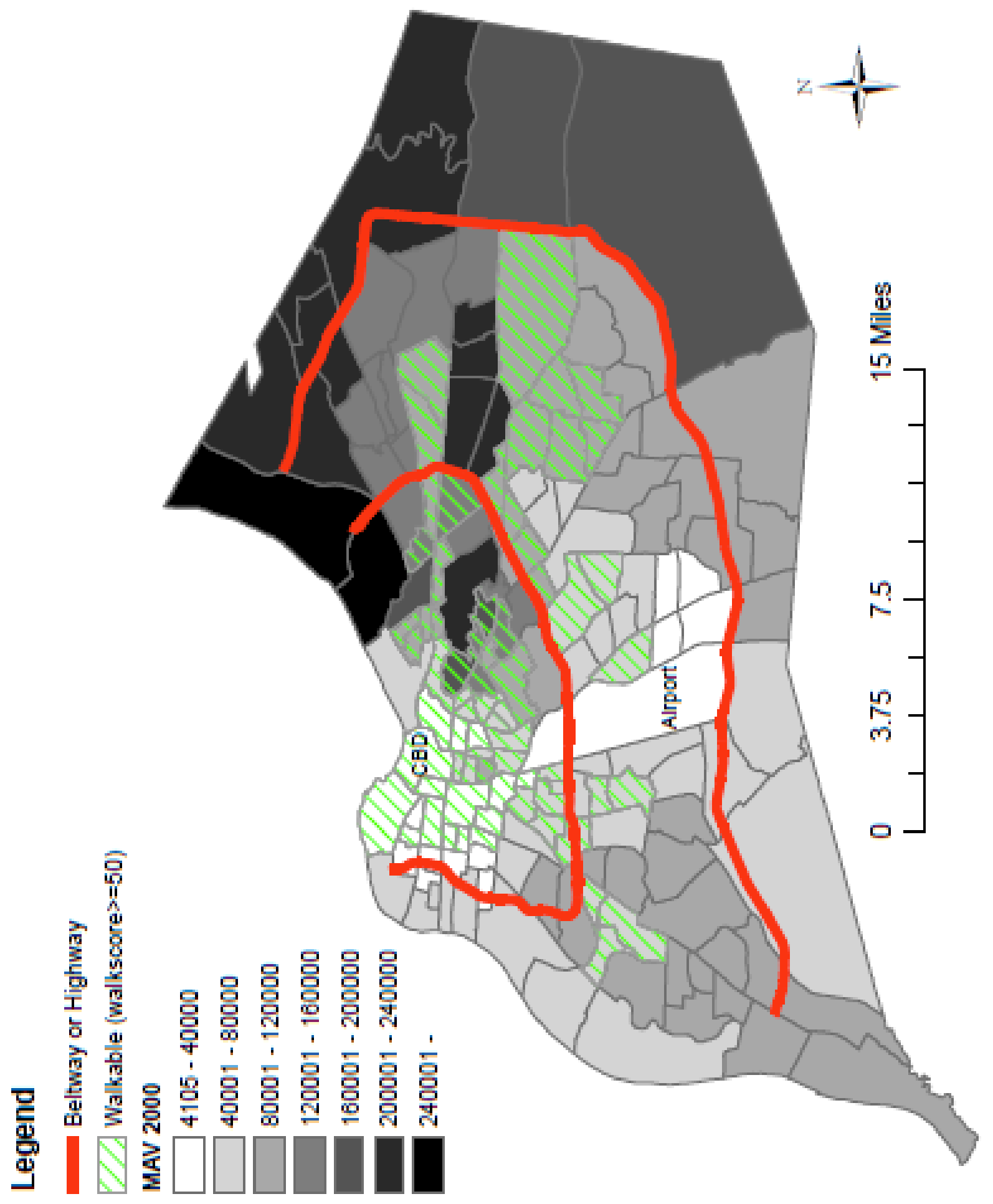

Figure 5.1 Median Assessed Value 2000 


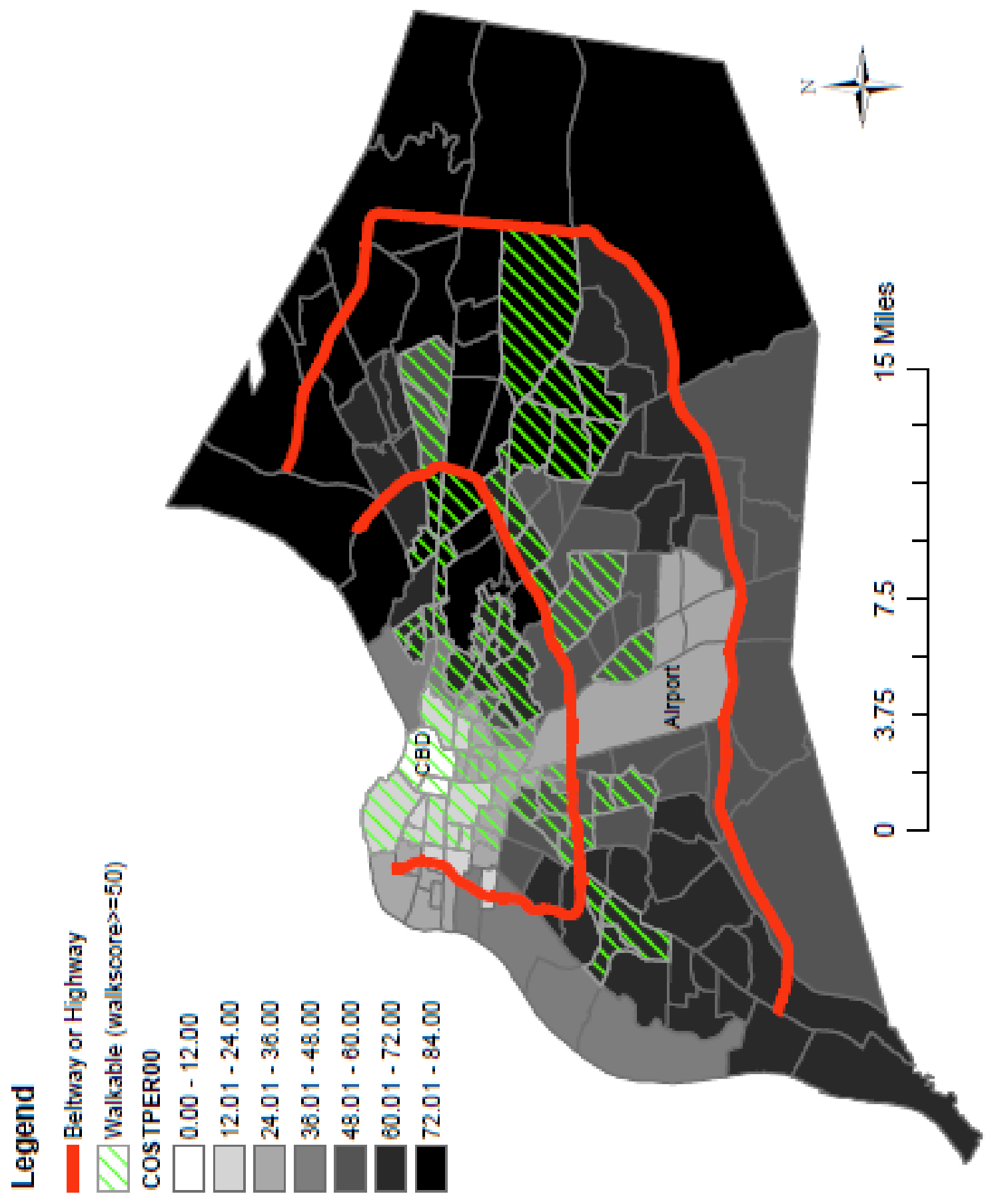

Figure 5.2 Median Assessed Value per Square Foot 2000 
In 2010 , there was a significant change in housing valuation, especially in the differences between the two types of neighborhoods. The mean assessed valuation for the city was $\$ 125,888.80$, for walkable neighborhoods it was $\$ 119,324.20$ and for non-walkable neighborhoods it was $\$ 128,199.56$. Figure 5.3 shows that neighborhood median assessed values have increased in the inner and middle ring, especially in the eastern portion of each ring. The trend of higher valuation in the outer ring neighborhoods continues.

When examining the median assessed value per square foot in 2010 the mean for the city was $\$ 77.74$. Non-walkable neighborhoods (\$79.88) had a slightly higher mean than walkable neighborhoods (\$71.53). Figure 5.4 shows neighborhood median assessed value per square foot in 2010 is higher in the outer rings. Although, the difference between neighborhoods is not as stark compared to a measure of solely median assessed value in 2010. Furthermore, the eastern portion of the city still tends to have higher levels of valuation. 


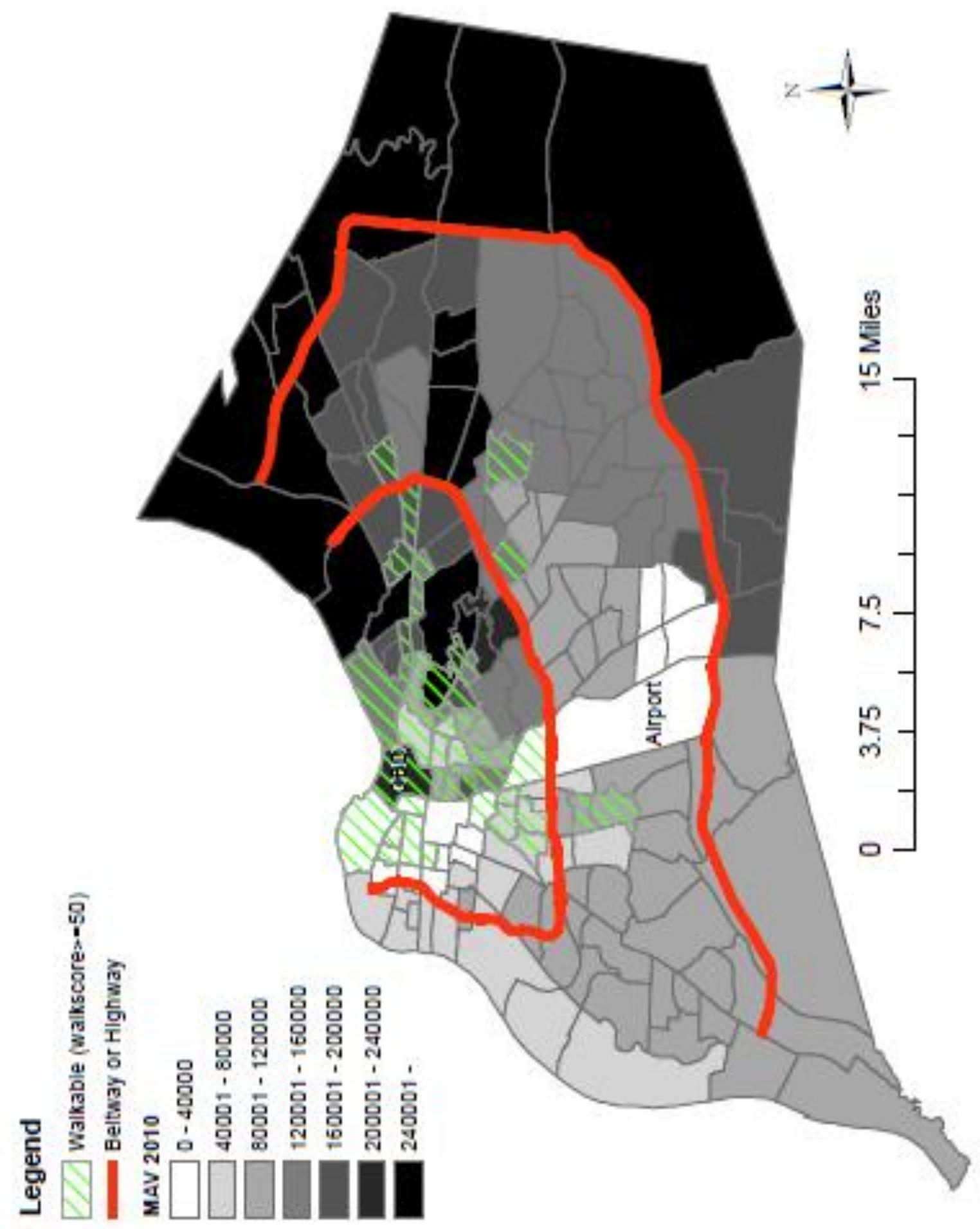

Figure 5.3 Median Assessed Value 2010 


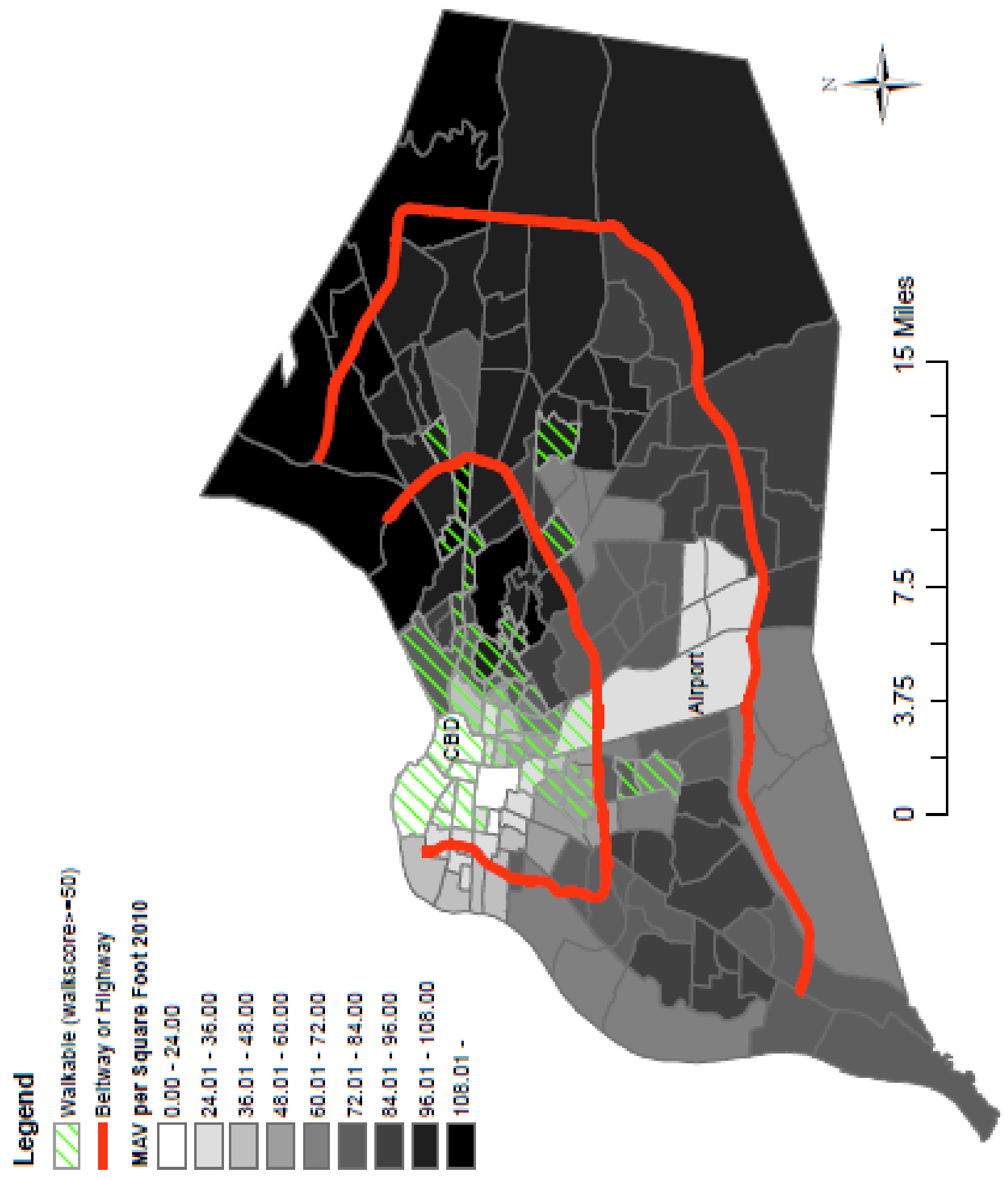

Figure 5.4 Median Assessed Value per Square Foot 2010 
The mean for median assessed housing value change between 2000-2010 shows that housing values did increase, but the increase was greater in walkable neighborhoods. Figure 5.5 shows the change in median assessed value from 2000-2010, which tends to follow the trend of outer ring neighborhoods having higher valuation. Figure 5.6 median assessed value per square foot from 2000-2010, show this measure follows the tends to trend of median assessed value in which the outer rings tend to have higher valuation per square foot especially the Eastern sections. 


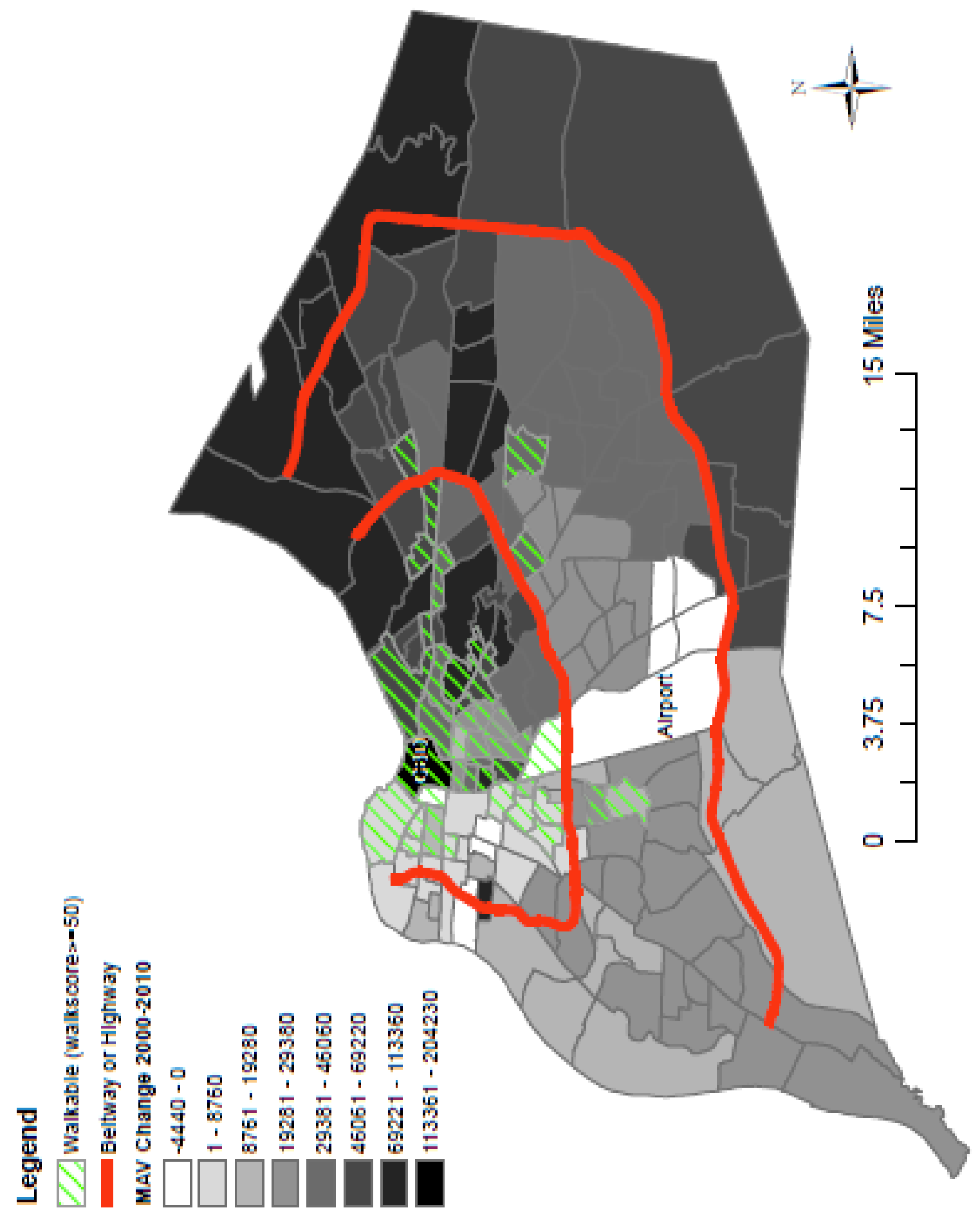

Figure 5.5 Median Assessed Value Change 2000-2010 


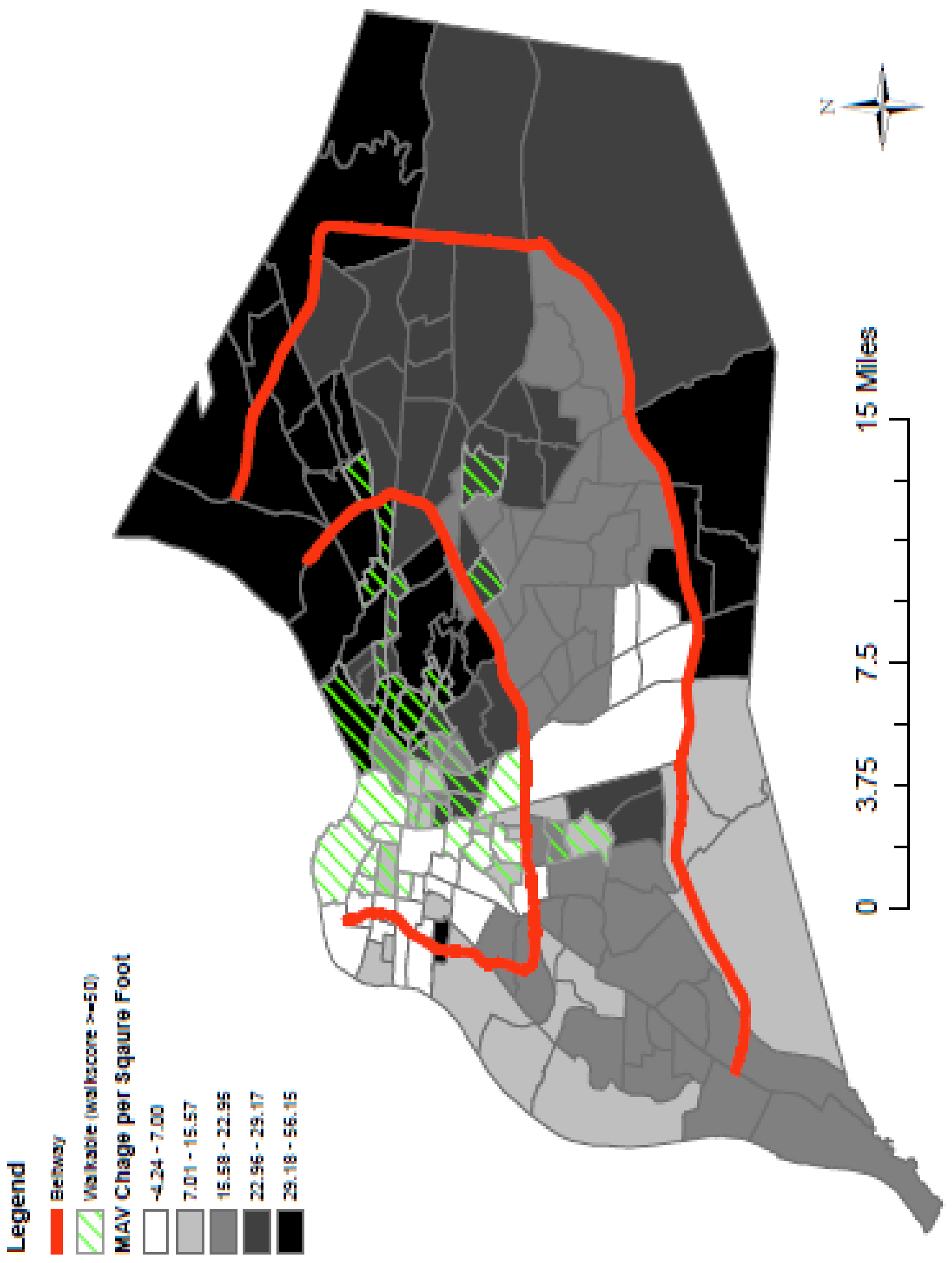

Figure 5.6 Median Assessed Value Change per Square Foot, 2000-2010 
The total number of foreclosures from 2004-2008 reveal there is a difference between the mean of foreclosures for walkable and non-walkable neighborhoods. The mean for the city was 54.79 , walkable neighborhoods had a mean of 40.29 and non-walkable neighborhoods had a mean of 60.02 . Figure 5.7 shows the number of foreclosures from 20042008 is higher in the western section of the Louisville. Additionally, the number of foreclosures seems to increase in the outer rings. The higher rates of foreclosures in the suburban areas are consistent with national trends (Immergluck, 2009).

The mean for vacancy rate in 2000 and 2010 shows there is a minor difference between vacancy rates for two types of neighborhoods. The mean for the all the neighborhoods in the city for 2000 was $6.4 \%$ and increased by $5 \%$ in 2010 . Walkable communities mean for vacancy tends to be higher than non-walkable communities, roughly a $3 \%$ difference in both 2000 and 2010. Figure 5.8 shows vacancy rates for 2000 , which reveals that vacancy tends to be higher in the inner most ring, especially in the North West portion. Figure 5.9 reveals the 2010 vacancy rates for neighborhoods is similar to 2000 , in which the inner ring, especially the western portion of the rings, tend to have higher vacancy rates. 


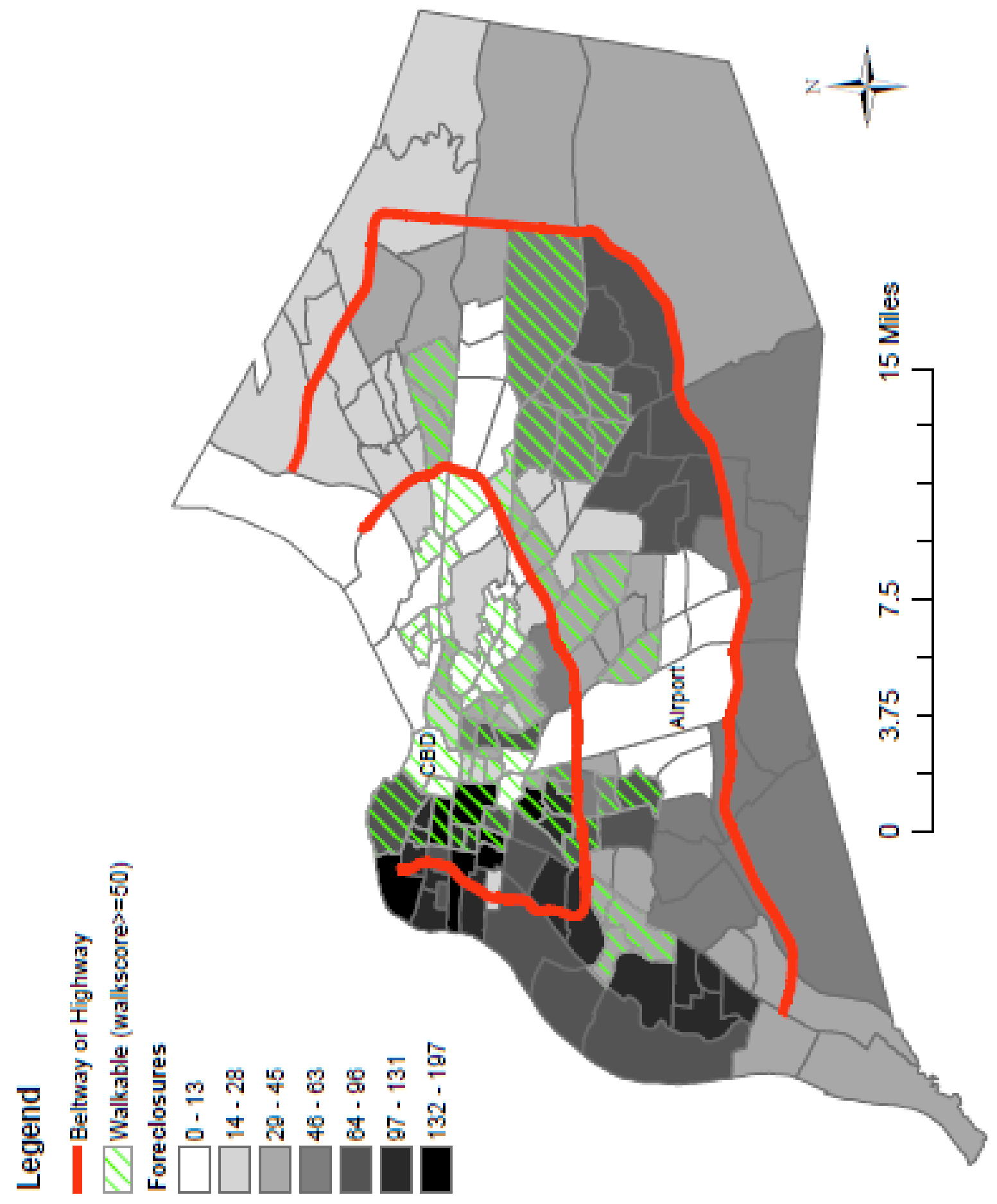

Figure 5.7 Total Foreclosures From 2004-2008 


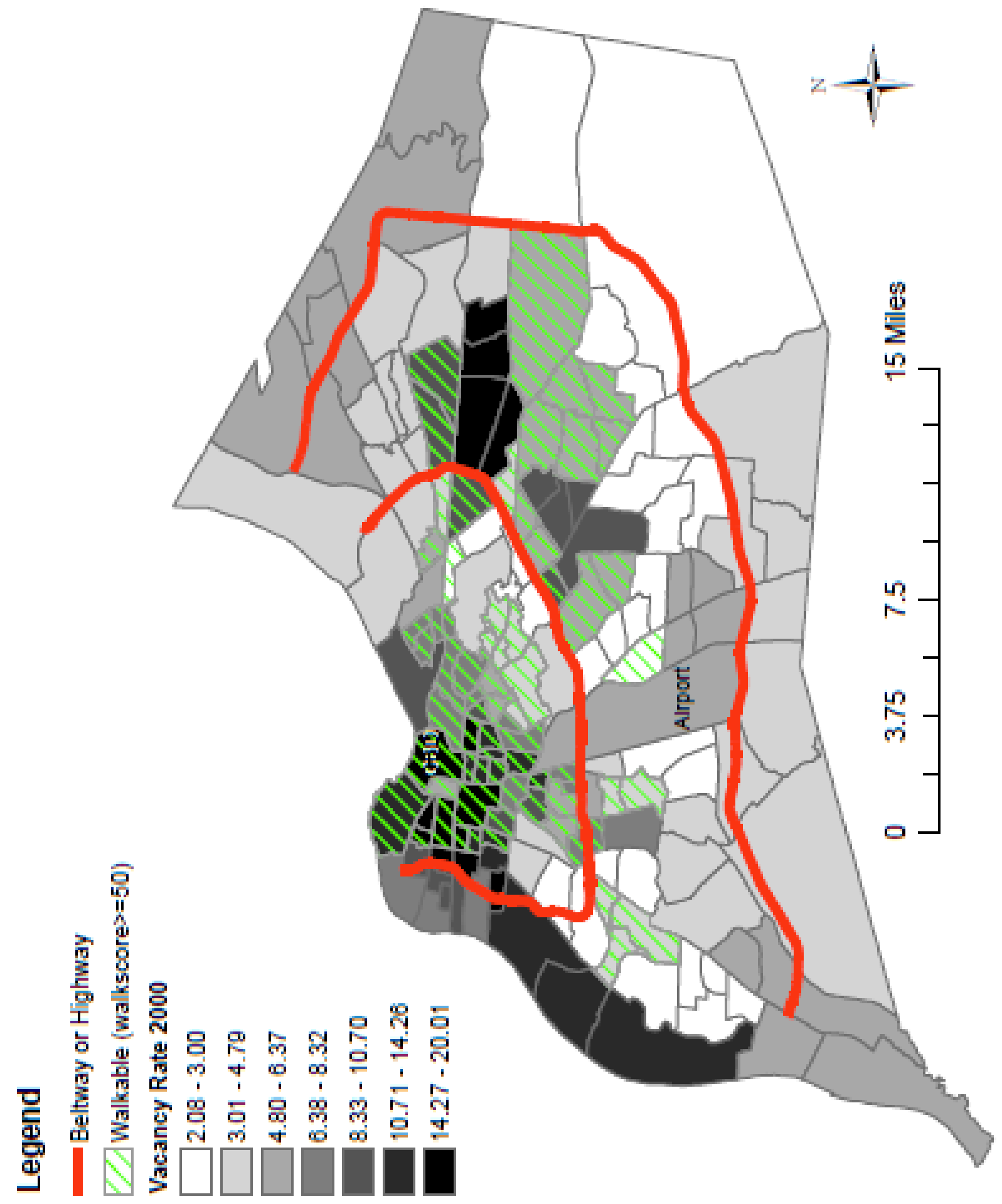

Figure 5.8 Vacancy Rate 2000 


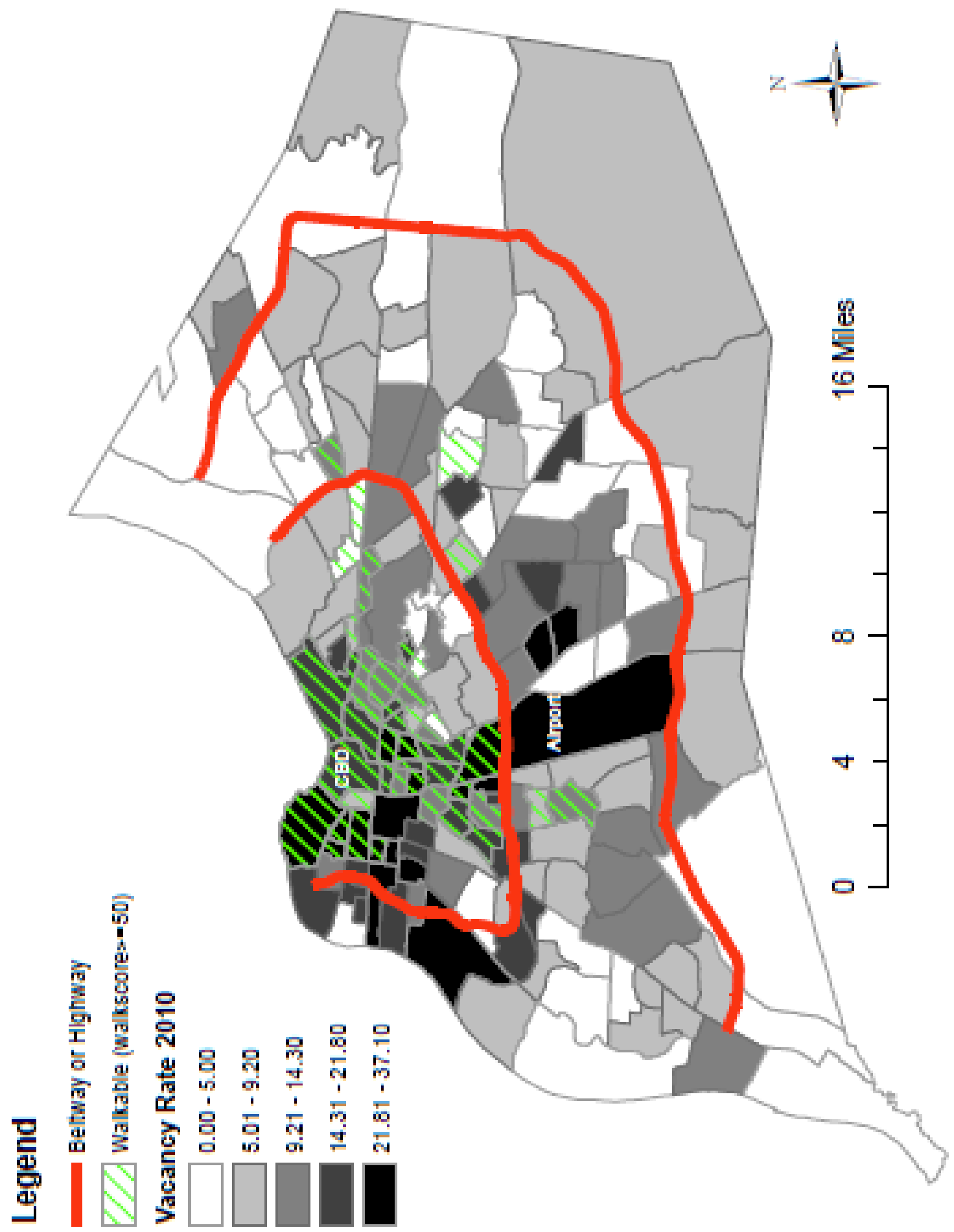

Figure 5.9 Vacancy Rate 2010 
As reviewed, there are differences between the means of walkable neighborhoods visa-vis non-walkable neighborhoods. The question is whether differences between neighborhoods are statistically significant.

\section{Independent Variables}

Table 5.2 lists the descriptive statistics for the independent variables used in the models in this section. The number of bus stops within each census tract is a measure which indicates the level of access each census tract has to public transportation. The variable revealed the mean number of bus stops per census tract in Louisville for 2000 was 24, walkable neighborhoods on average tend to have more bus stops than non-walkable neighborhoods. On average this measure decreased in 2010 for the city as a whole and for non-walkable neighborhoods, but it remained relatively the same for walkable neighborhoods.

The average percentage of nonwhite residents per census tract for Louisville was $25 \%$ in 2000 . This number slightly increased to $31 \%$ in 2010 . For walkable neighborhoods, the average percent of nonwhite residents was $29 \%$ for 2000 and it increased to $34 \%$ in 2010 while, in neighborhoods considered non-walkable, the average percent of nonwhite individuals was roughly $24 \%$ in 2000 but it increased nearly $7 \%$ in 2010 . Suggesting that the rate of minorities moving into neighborhoods considered non-walkable accelerated faster than in walkable neighborhoods.

The median housing age in Louisville was roughly 39 years, but this number was greater for walkable neighborhoods. This is expected since walkable neighborhoods tend to 
be located in older portions of the city (Leinberger, 2009). This also applies to the distance to the central business district variable as well, the average for all Louisville census tracts was 7 miles; however, the distance is greatly reduced for walkable neighborhoods since most of these neighborhoods are the oldest and tend to be closest to the city core compared to nonwalkable neighborhoods. The average number of housing units per census tract for the city of Louisville was 1,296 in 2000. This number increased by nearly 500 in 2010. Walkable neighborhoods tend to have fewer housing units per census tract than non-walkable neighborhoods. However, both had large average growth rates from 2000-2010 but walkable neighborhoods show a larger increase in growth between the two groups.

The mean for median income for households in Louisville was $\$ 40,524$ in 2000. This increased by approximately $\$ 7,000$ in 2010 . Walkable neighborhoods had a mean of $\$ 30,826$ in 2000 and only increased by $\$ 2,000$, but non-walkable neighborhoods had an average of $\$ 44,015$ in 2000 and increased by over $\$ 7,000$ in 2010 . The total number of jobs within the census tract reveals that walkable census tracts, on average, hold more jobs within their borders than non-walkable neighborhoods. However, all three specifications suffered a loss of jobs in 2010.

There was an average of 6.5 occurrences of crime per 100,000 residents in 2007 in all of Louisville's neighborhoods. When examined solely in walkable neighborhoods the mean for crime per 100,000 residents in 2007 was slightly higher (8.76) than non-walkable neighborhoods (5.69). The average number of high interest loans for all Louisville neighborhoods from 2007-2008 was 9.92. The mean for walkable neighborhoods was 6.58 which was less than the number of non-walkable neighborhoods (11.12). The Traditional 
Walk Score index reveals that Louisville is a car dependent city, with a mean of 43 . There is a blatant difference between the mean of scores for walkable neighborhoods (72) and nonwalkable neighborhoods (32). The last variable Streetsmart Score index, which is a more stringent control for neighborhood design compared to Traditional Walk Score, also depicts Louisville as a car dependent city with a mean score of 29 . The differences between the means of walkable (68) and non-walkable neighborhoods (19) are greater than the Traditional Walk Score index. 


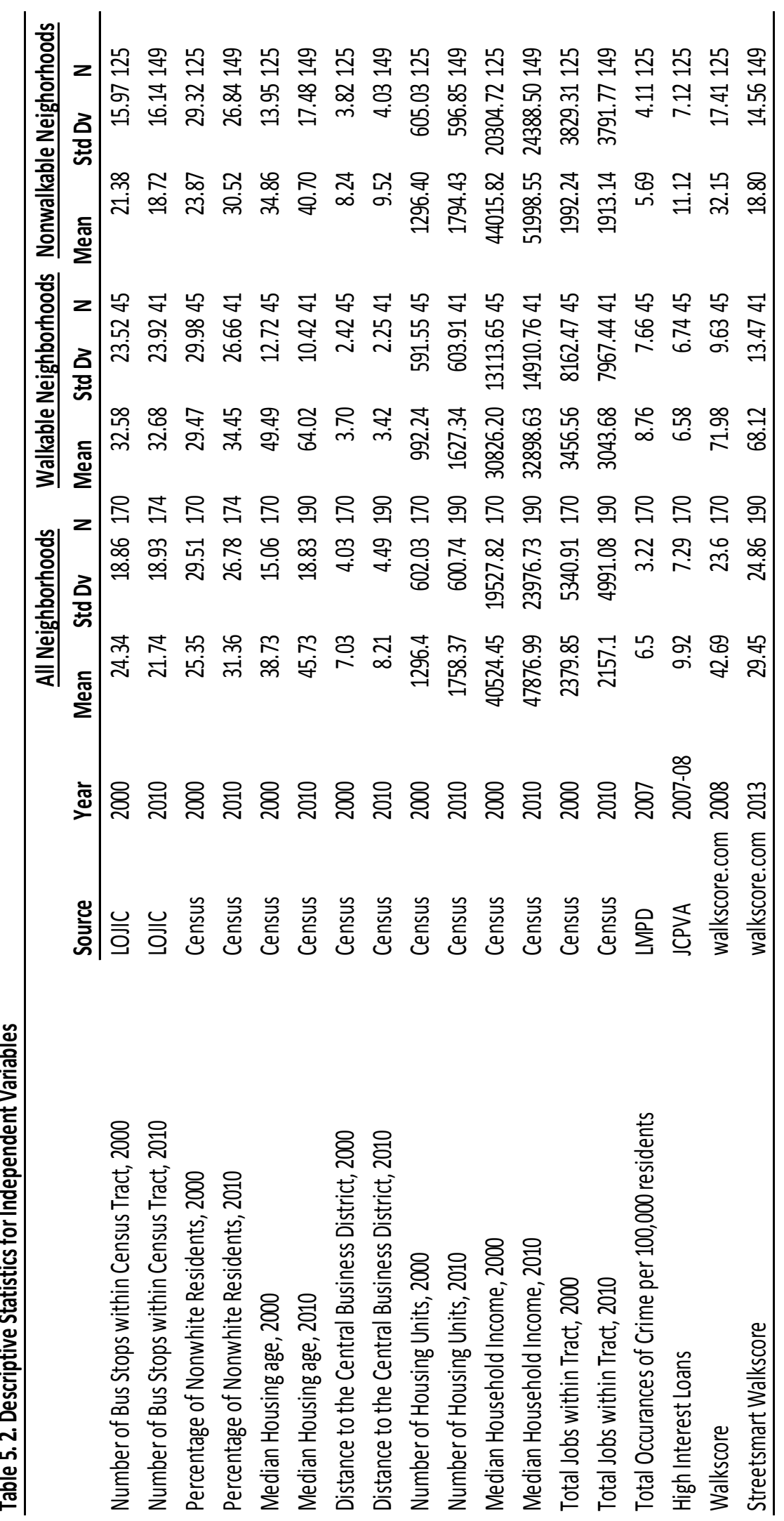




\section{OLS Results:}

\section{Median Assessed Valuation}

The first models discussed are those for the median assessed value in 2000 and median assessed value per square foot in 2000, see Table 5.3. Both model's adjusted Rsquared values (.77 and .86 respectively) were in a range of most hedonic models for neighborhood level valuation (Gilderbloom and Appelbaum, 1988; Ambrosius et al., 2010; Gilderbloom et al., 2009). The 2008 measure of neighborhood walkability was used in order to detect the influence of walkability on the 2000 measures of value. While this measure was not taken in 2000, it is the closest available measure and can still serve as a proxy measure (Gilderbloom et al., 2012).

When examining the impact of Walk Score in 2000 for the measure of median assessed value, there was no significant impact. Furthermore, the distance to the central business district, median housing age and percent of vacant housing units were also nonsignificant. This can be understood as 2000 was within the time frame of the housing bubble where the price of real estate was rapidly increasing in all areas of the city (Ambrosius, 2010; Gilderbloom et al., 2009). Furthermore, since housing is generally larger in non-walkable areas, it would naturally cost more. Therefore, median assessed value per average square foot would a more appropriate specification to understanding the difference in value. All other variables in this model were significant, and their relationships to median assessed value were consistent with the findings in the literature (Gilderbloom and Appelbaum, 1988; Cortright, 2009; Ambrosius, 2010; Gilderbloom et al. 2010). In this model, median household income, the number of housing units, and the number of bus stops within the 
census had the largest impacts on determining median assessed value, as measured by standardized beta.

Table 5.3 also contains the model with median assessed value per average square foot in 2000. In this model, walkability is significant and is positive correlated with median assessed value per average square foot. This provides support for the hypothesis that walkability does have a positive influence on housing values. The percent of vacant units and median housing age also showed to be statistically significant under this specification, and the negative relationship that each displayed is consistent with the literature. Two variables, the total number of jobs per tract and number of housing units per census tract, lost significance in this model when compared to the first. Although, the total number of jobs per census tract is approaching significance. The standardized beta indicates that the percent of nonwhite residents, median housing age and Walk Score are the three variables with the most impact on median assessed value per average square foot in 2000. The next model will examine if walkability had a statistically significant impact on housing valuation in 2010 . 
Table 5.3 Median Assessed Value 2000 OLS Regression

\begin{tabular}{|c|c|c|c|c|}
\hline & \multicolumn{2}{|c|}{$\begin{array}{l}\text { Model 1: } \\
\text { 2000 MAV }\end{array}$} & \multicolumn{2}{|c|}{$\begin{array}{c}\text { Model 2: } \\
\text { 2000 MAV per Sq Ft } \\
\end{array}$} \\
\hline & Unst & Beta & $\underline{\text { Unst }}$ & Beta \\
\hline Constant & 18906.58 & - & $55.85 * * *$ & - \\
\hline Standard Error & 14760.37 & - & $7.02 * * *$ & - \\
\hline Walk Score, 2008 & 126.08 & 0.061 & $.104 *$ & $.135^{*}$ \\
\hline Distance to the CBD, 2000 & -1109.52 & -0.091 & -.34 & -.076 \\
\hline Percent of Nonwhite Residents, 2000 & $-275.56 * * *$ & $\overline{0.17 * * *}$ & $-.16^{* * *}$ & $-.266 * * *$ \\
\hline Median housing Age, 2000 & -175.93 & $\begin{array}{l}-.054 \\
-\end{array}$ & $-.197 *$ & $-.168 *$ \\
\hline Number of Housing Units, 2000 & $-15.98 * * *$ & $.197 * * *$ & -.002 & -.054 \\
\hline Number of Bus Stops in Tract, 2000 & $300.18 * * *$ & $.115 * * *$ & $.128 *$ & $.021 *$ \\
\hline Percent of Vacant Units, 2000 & -24.84 & -.002 & $-1.65 * * *$ & $-.36 * * *$ \\
\hline Median Household Income, 2000 & $2.49 * * *$ & $.990 * * *$ & $.00001 * * *$ & $.000 * * *$ \\
\hline Total Jobs located in Tract & $7.08 *$ & $.077^{*}$ & $.000+$ & $.000+$ \\
\hline Adj. $R^{2}$ & \multicolumn{2}{|c|}{.86} & \multicolumn{2}{|c|}{.77} \\
\hline $\mathbf{F}$ & \multicolumn{2}{|c|}{118.50} & \multicolumn{2}{|c|}{62.83} \\
\hline $\mathbf{N}$ & \multicolumn{2}{|c|}{169} & \multicolumn{2}{|c|}{167} \\
\hline
\end{tabular}

Notes: Unst.= unstandardized beta; Beta $=$ standardized beta. Level of aggregation is census tract. $\quad+\mathbf{p} \leq .1 ; * \mathrm{p} \leq .05 ; * * \mathrm{p} \leq .01 ; * * * \mathrm{p} \leq .001$ 
The next models, three and four, examine the impact of walkability on neighborhood median assessed value in 2010 and neighborhood median assessed value per square foot in 2010, see Table 5.4. The adjusted R-squared for model 3 and 4 show the explained variation of the data to be over $80 \%(.845$ and .813$)$. It is important to note that these models contain more variables than in the previous model; this is due to the lack of data and the inability of gathering a measure within a time frame that would stand as a proxy for conditions that would affect housing prices in 2000. Also, it uses a more stringent measure of Walk Score known as Streetsmart Score ${ }^{6}$. Taking this into account, model 3, which looks at the median assessed value for each census tract in 2010, shows a significant positive correlation with walkability. The significant finding in 2010 despite its insignificance in 2000 is not a discrepancy, but it is expected. The directionality of the relationships between median assessed value and the independent variables were as expected in the literature. There are four variables that were not significant in this model: distance to the central business district, high interest loans, the amount of crime in 2007 per 100,000 residents and the total number of jobs within each tract. However, the high interest loans variable is approaching significance. As discussed above, there is generally a difference in the size of housing so a more appropriate measure of a neighborhood's median assessed value would control for the difference in housing size.

Model 4, which examines median assessed value per square foot in 2010, reveals walkability is still statistically significant. This finding corresponds with the model for 2000,

\footnotetext{
${ }^{6}$ Although, the model was tested with the same measure of Walk Score as used for median assessed valuation in 2000. The results for both measures were similar, but this measure gives better depiction of a neighborhood's accessibility. These tables are available upon request.
} 
thus providing additional evidence to support the hypothesis of walkability having a positive correlation with a neighborhood's median assessed valuation for housing. In this specification the amount of crime in 2007 per 100,000 residents, the total number of jobs within each tract and high interest loans becomes significant. However, the number of housing units does lose significance in this specification, which is congruent with this specification for 2000. Lastly, distance to the central business district remains consistent, in that it is not significant in this model either.

These two cross-section points of time demonstrate that walkability is positively correlated with median assessed value, even with the absence of significance in the first model for median assessed value in 2000. Now, the changes in median assessed value will be tested to understand if walkability still has a significant correlation. 
Table 5.4 Median Assessed Value 2010 OLS Regression

Model 3:

2010 MAV
Model 4:

2010 MAV per Sq Ft

Unst

28324.81

21275.16

$467.66^{* *}$

$-1419.01$

$-357.75^{* *}$

$-567.2 *$

$-17.29 * *$

$453.74 * *$

$-843.08+$

$-237.67$

$3.46^{* * *}$

$-.112$

.353

Std

Unst

Std

$97.62 * * *$

$8.455 * * *$

$165 * * .162 * *$

$.158^{* *}$

$-.081$

$-.109$

$-.017$

$-.148 * * \quad-.28 * * *$

$-.32 * * *$

$.122 *$

$-.47 * * *$

$-.283 * * *$

$-.147 * *$

0

$-.008$

$.122 * *$

$.193 * *$

$.13 * *$

$-.087+$

$-.454 * *$

$-.131 * *$

$-.014$

$-1.56 * * *$

$-.243 * * *$

$.952 * * *$

$.000 * * *$

$.000 * * *$

Adj. $\mathbf{R}^{2}$

.845

Constant

2007 Total Crime per 100,000 Residents

Total Jobs located in Tract

F

84.35

168

Number of Housing Units, 2010

Number of Bus Stops in Tract, 2010

High Interest Loans

Percent of Vacant Units, 2010

Median Household Income, 2010

$\mathbf{N}$

Notes: Unst. $=$ unstandardized beta; Beta $=$ standardized beta. Level of aggregation is census tract. $+\mathbf{p} \leq .1 ;{ }^{*} \mathbf{p} \leq .05 ; * * \mathbf{p} \leq .01 ; * * * \mathbf{p} \leq .001$.

The change in median assessed value between 2000 and 2010 is specified in two ways: 1) raw change of median assessed value and 2) raw change of median assessed value 
per average square foot, see Table 5.5. Since Streetsmart Score is a more stringent measure of walkability, it will be used instead of the 2008 Walk Score. Both models present adjusted $\mathrm{R}$-squared values that account for over half of the variation in each specification.

The first model in Table 5.5, examined the raw change in median assessed value, reports a significant positive relationship between walkability and the change in median assessed value. Thus, demonstrating that walkability is correlated with greater increases in neighborhood median assessed value. Distance to the central business district, number of housing units, number of bus stops in the tract, high interest loans and the percent of vacant units showed no significance in the model. As discussed previously, it is more appropriate to control for the difference in housing sizes.

The second model in Table 5.5 does control for housing size with a dependent variable of median assessed value change 2000-2010 per square foot. This model also shows walkability having a significant and positive relationship to the dependent variable. These findings correspond with the findings of the other models, save the first one. Only one variable changed to significant in this model, high interest loans. The directionality of the variables held across both models. 
Table 5.5 Changes in Median Assessed Value Between 2000-2010 OLS Regression

Model 6:

Model 5:

2000-2010 MAV per Sq Ft

2000-2010 MAV chg

chg

\begin{tabular}{|c|c|c|c|c|}
\hline & Unst & Std & Unst & Std \\
\hline Constant & 1818.97 & - & $32.16^{* * *}$ & - \\
\hline Standard Error & 12827.06 & - & $5.52 * * *$ & - \\
\hline Streetsmart Score & $296.382 * * *$ & $.267 * * *$ & $.14 * * *$ & $.327 * * *$ \\
\hline Distance to the CBD, 2000 & -663.57 & -.096 & -.12 & -.05 \\
\hline Percent of Nonwhite Residents, 2000 & $-142.19 *$ & $-.149 *$ & $-.11 * * *$ & $-.299 * * *$ \\
\hline Median housing Age, 2000 & $-348.32 *$ & $-.19 *$ & $-.291 * * *$ & $-.426 * * *$ \\
\hline Number of Housing Units, 2000 & -5.96 & -.129 & .0 & -.03 \\
\hline Number of Bus Stops in Tract, 2000 & 156.85 & .107 & .05 & .08 \\
\hline High Interest Loans & -302.6 & -.08 & $-.3 * *$ & $-.21 * *$ \\
\hline Percent of Vacant Units, 2000 & -17.46 & -.003 & -.172 & -.07 \\
\hline $\begin{array}{l}\text { Median Household Income, } 2000 \\
2007 \text { Total Crime per } 100,000\end{array}$ & $1133.21 * * *$ & $.794 * * *$ & $.127 * *$ & $.238 * *$ \\
\hline Residents & $-.96 * *$ & $-.189 * *$ & $.000 *$ & $-.151 *$ \\
\hline Total Jobs located in Tract & $.827^{*}$ & $.16^{*}$ & $.0 *$ & $.140^{*}$ \\
\hline $\operatorname{Adj} \mathbf{R}^{2}$ & \multicolumn{2}{|l|}{.64} & \multicolumn{2}{|c|}{.53} \\
\hline $\mathbf{F}$ & \multicolumn{2}{|c|}{27.57} & \multicolumn{2}{|c|}{18.03} \\
\hline $\mathbf{N}$ & \multicolumn{2}{|c|}{168} & \multicolumn{2}{|c|}{167} \\
\hline
\end{tabular}

Notes: Unst. = unstandardized beta; Beta $=$ standardized beta. Level of aggregation is census tract. $+\mathbf{p} \leq .1 ;{ }^{*} \mathbf{p} \leq .05 ; * * \mathbf{p} \leq .01 ; * * * \mathbf{p} \leq .001$ 


\section{Foreclosure}

Table 5.6 contains the single model examining foreclosures occurring between 2004 and 2008. This examination will capture the end of the housing bubble and the eventual crash that occurred in 2007. This work is an extension and an attempt to improve the model presented by Gilderbloom et al. (2012). Although their examination also uses Louisville as a study area, they used data from 2007 and the first six months of 2008 while this study implements a data set that covers a longer period of time. Furthermore, new variables are included that were absent from their analysis, and median sales price is replaced with median household income.

The model has a relatively strong adjusted R-squared value that reveals over fourfifths of the variation in the dependent variable is explained with this model. This is an improvement compared to the adjusted R-squared of .77 in Gilderbloom et al (2012). The measure for Walk Score, Walk Score index of 2008, has a statically significant relationship with the number of foreclosures to occur in each tract from 2004-2008. Moreover, this relationship is negative which indicates the greater the Walk Score for a neighborhood, the fewer number of foreclosure to occur. Furthermore, the total number of jobs and median household income, two of the new variables added, were also significant and had a negative relationship with foreclosures. However, the number of bus stops in a tract was not significant. The variables high interest loans, the percent of nonwhite residents and the number of housing units exerted the strongest effects in the model, as measured by the standardized beta. All variables that were indicated as significant in the Gilderbloom et al. 
(2012) study were significant and share the same directionality as in their model. Therefore, the evidence indicates the inclusion of the new variables into the model was appropriate.

Table 5.6 Foreclosures 2004-2008 OLS Regression

\section{Model 7:}

Foreclosures 2004-2008

\begin{tabular}{llc}
\hline & Unst & Std \\
Constant & $-39.109^{* *}$ & - \\
Standard Error & $15.600^{* *}$ & - \\
Walk Score & $-.315^{* * *}$ & $-.167^{* * *}$ \\
Distance to the CBD, 2000 & $2.371^{* *}$ & $.214^{* *}$ \\
Percent of Nonwhite Residents, 2000 & $.621^{* * *}$ & $.411^{* * *}$ \\
Median housing Age, 2000 & $.772^{* * *}$ & $.261^{* * *}$ \\
Number of Housing Units, 2000 & $.022^{* * *}$ & $.298^{* * *}$ \\
High Interest Loans & $2.751^{* * *}$ & $.450^{* * *}$ \\
Number of Bus Stops in Tract, 2000 & .144 & .061 \\
Median Household Income, 2000 & $.000^{* * *}$ & $-.213^{* * *}$ \\
2007 Total Crime per 100,000 Residents & $.001^{* * *}$ & $.171^{* * *}$ \\
Total Jobs located in Tract & $-.002^{* * *}$ & $-.182^{* * *}$ \\
\hline Adj $\mathbf{R}^{2}$ & \multicolumn{2}{c}{.81} \\
F & \multicolumn{2}{c}{73.99} \\
$\mathbf{N}$ & \multicolumn{2}{c}{169} \\
\hline Notes: Unst:
\end{tabular}

Notes: Unst. $=$ unstandardized beta; Beta $=$ standardized beta. Level of aggregation is census tract. $+p \leq .1 ;{ }^{*} \leq .05 ; * * p \leq .01 ; * * * \leq .001$ 
Vacancy

Table 5.7 contains the model for the vacancy rate for Louisville census tracts for the year 2000. The adjusted R-squared for this test reveals only $45 \%$ of the variation in the dependent variable has been explained by the model. When examining the relationship between walkability and vacancy, there is no significant relationship present in the model. Only distance to the central business district and the percent of nonwhite residents were significantly correlated with the dependent variable. Although, the total number of jobs located in each tract was approaching significance. The percent of nonwhite residents, distance to the central business district, and the total number of jobs located in each tract had the largest impact in on vacancy rate, as determined by the standardized beta. 


\begin{tabular}{|c|c|c|}
\hline & \multicolumn{2}{|c|}{$\begin{array}{c}\text { Model 8: } \\
\text { Vacancy Rate, } 2000\end{array}$} \\
\hline & Unst & Std \\
\hline Constant & $5.98 * *$ & - \\
\hline Standard Error & $2.36^{* *}$ & - \\
\hline Walk Score & -.009 & -.054 \\
\hline Distance to the CBD, 2000 & $-.274 *$ & $-.274^{*}$ \\
\hline Percent of Nonwhite Residents, 2000 & $.064 * * *$ & $.471 * * *$ \\
\hline Median housing Age, 2000 & -.01 & -.038 \\
\hline Number of Bus Stops in Tract, 2000 & .008 & .035 \\
\hline Median Household Income, 2000 & .0 & -.039 \\
\hline Total Jobs located in Tract & $.0+$ & $.139+$ \\
\hline Adj. $\mathbf{R}^{2}$ & \multicolumn{2}{|c|}{.45} \\
\hline $\mathbf{F}$ & \multicolumn{2}{|c|}{20.64} \\
\hline $\mathbf{N}$ & \multicolumn{2}{|c|}{169} \\
\hline
\end{tabular}

When examining the vacancy rate for 2010, the findings were somewhat consistent. The R-squared shows that the model explained $50 \%$ of the variation of the vacancy rate for neighborhoods in 2010. Walkability again does not have a significant relationship to the dependent variable. In this specification only two variables were significant, the percent of nonwhite residents and the median household income. Percent of nonwhite residents has positive relationship with the dependent variable while median household income has a 
negative relationship. These two variables along with total jobs in the tract 2010 had the largest relative magnitude in the model, as measured by the standardized beta. From these two models, 8 and 9, it would seem that in Louisville walkability did not have any significant impact on vacancy rate during these two cross sections in time.

Table 5.8 Vacancy Rate 2010 OLS Regression

\begin{tabular}{|c|c|c|}
\hline & \multicolumn{2}{|c|}{$\begin{array}{c}\text { Model 9: } \\
\text { Vacancy Rate, } 2010 \\
\end{array}$} \\
\hline & Unst & Std \\
\hline Constant & $8.796^{*}$ & - \\
\hline Standard Error & -.006 & - \\
\hline Streetsmart Score & -.006 & -.019 \\
\hline Distance to the CBD, 2010 & -.26 & -.144 \\
\hline Percent of Nonwhite Residents, 2010 & $.088 * * *$ & .346 \\
\hline Median housing Age, 2010 & .061 & .121 \\
\hline Number of Bus Stops in Tract, 2010 & -.035 & -.089 \\
\hline Median Household Income, 2010 & $-4.701 \mathrm{E}-005 * * *$ & -.122 \\
\hline Total Jobs located in Tract, 2010 & .000 & .270 \\
\hline Adj. $\mathbf{R}^{2}$ & .5 & \\
\hline $\mathbf{F}$ & 21.72 & \\
\hline $\mathbf{N}$ & 190 & \\
\hline
\end{tabular}


All of the OLS models presented in this section still have a probability of suffering from some type of spatial autocorrelation. This could create misleading estimates in the model; therefore, it is necessary to examine if spatial autocorrelation is present and if so how the independent variables react when spatial autocorrelation is included in the model.

\section{Spatial Regression}

\section{Median Assessed Value}

The findings from the OLS models for median assessed value suggest that walkability has a significant positive relationship with median assessed value in Louisville neighborhoods for all the specifications, save one median assessed value 2000. For the purpose of this section, only the dependent variables that controlled for the average size of the housing were tested. As discussed earlier, this specification is a better measure for testing neighborhood median assessed value.

Table 5.9, contains the results for model 2 (median assessed value per square foot in 2000) alongside the SLM and SEM. The bottom of the table contains several statistical test to indicate the presence of spatial dependence (Anselin et al., 1996). The OLS model displays a positive spatial autocorrelation in its residuals, as indicated by the significant Moran's I. Furthermore, the Lagrange Multiplier test indicate the presence of spatial lag and error. The additional forms of these tests are robust to the presence of one another. Both robust test still indicated the presence of lag and error within the model. This model indicates that the OLS regression coefficients and significance reports were misleading due to spatial dependence. In particular, the walkability variable loses significance. Also, median housing age and number of bus stops per census tract lose significance. Total jobs per tract increases and 
becomes significant. All of the coefficients diminished in SEM and SLM, but the rate of decline was not consistent across the spatial models. The parameters for each spatial test, rho and lambda respectively, were significant indicating the presence of spatial dependence. However, the log likelihood ratio test for both spatial models was statistically significant at the .001 level, meaning that while both SEM and SLM improved model fit, neither one completely removed the spatial effects. SEM had better model fit, as indicated by greater gains in R-squared and log likelihood. 
Table 5.9 Median Assessed Value per Square Foot 2000 Spatial Regression

\begin{tabular}{|c|c|c|c|}
\hline & $\begin{array}{c}\text { Model 2: } \\
\text { 2000 MAV per } \\
\text { Sq. Ft } \\
\end{array}$ & $\begin{array}{c}\text { Model 11: } \\
\text { SLM 2000 MAV } \\
\text { per Sq. Ft }\end{array}$ & $\begin{array}{c}\text { Model 12: } \\
\text { SEM 2000 } \\
\text { MAV per Sq. Ft }\end{array}$ \\
\hline & Unst & Unst & Unst \\
\hline Constant & $55.85 * * *$ & $10.75 *$ & $38.46 * * *$ \\
\hline Walk Score, 2008 & $.104 *$ & .02 & .014 \\
\hline Distance to the CBD, 2000 & -0.34 & .13 & $.67 *$ \\
\hline $\begin{array}{l}\text { Percent of Nonwhite } \\
\text { Residents, } 2000\end{array}$ & $-.16 * * *$ & $-.07 * *$ & $-.075^{*}$ \\
\hline Median housing Age, 2000 & $-.197 *$ & .001 & .042 \\
\hline $\begin{array}{l}\text { Number of Housing Units, } \\
2000\end{array}$ & -0.002 & .0 & .001 \\
\hline $\begin{array}{l}\text { Number of Bus Stops in } \\
\text { Tract, } 2000\end{array}$ & $.128^{*}$ & .03 & .02 \\
\hline $\begin{array}{l}\text { Percent of Vacant Units, } \\
2000 \\
\text { Median Household }\end{array}$ & $-1.65 * * *$ & $-0.45 * * *$ & $-.38 * *$ \\
\hline Income, 2000 & $.00001 * * *$ & $.0 * * *$ & $.0 * * *$ \\
\hline Total Jobs located in Tract & $.000+$ & $.0 * * *$ & $.0 * * *$ \\
\hline Lag (rho) & - & $.7 * * *$ & - \\
\hline Error (lambda) & - & - & $.91 * * *$ \\
\hline Log Likelihood & -620.85 & -543.1 & -532.26 \\
\hline $\mathbf{R}^{2}$ & .75 & .91 & .93 \\
\hline Moran's I (error) & $.52 * * *$ & - & - \\
\hline Lagrange Multiplier (lag) & $137.23 * * *$ & - & - \\
\hline Robust LM (lag) & $30.58 * * *$ & - & - \\
\hline Lagrange Multiplier (error) & $120.12 * * *$ & - & - \\
\hline Robust LM (error) & $13.46 * * *$ & - & - \\
\hline
\end{tabular}

Notes: Unst. $=$ unstandardized beta; $B$ eta $=$ standardized beta. Level of aggregation is census tract. $+\mathbf{p} \leq .1 ; * \mathbf{p} \leq .05 ; * * \mathbf{p} \leq .01 ; * * * \mathbf{p} \leq .001$ 
Table 5.10 contains the results for model 4 (median assessed value per square foot in 2010) alongside the SLM and SEM. The OLS model has a positive Moran's I, suggesting the presence of spatial dependence in the model. The Lagrange Multiplier tested positive for both spatial lag and error. The robust version of the lag test tested significant, while the robust for error was not. This suggests that the model suffers from spatial lag.

While the OLS coefficients estimates can be misleading, they remained somewhat consistent across the models. In this specification, the walkability measure did remain significant across all models. Therefore, even when spatial dependence is controlled for walkability relationship is still significant and positive. Three variables, number of bus stops per tract, high interest rate loans and total crime per 100,000 residents, lost significance. Furthermore, the OLS coefficients diminished in the spatial models, except for distance to the central business district which increased. The parameters for each spatial test, rho and lambda, were significant at the .001 level. SEM proved to be the better model fit, due to its greater gains in R-squared and log likelihood. However, both spatial models had a significant log likelihood ratio. Therefore, even though spatial dependence is controlled for it is still present within the models. 
Table 5.10 Median Assessed Value per Square Foot 2010 Spatial Regression

\begin{tabular}{|c|c|c|c|}
\hline & $\begin{array}{c}\text { Model 4: } \\
2010 \mathrm{MAV} \\
\text { per Sq. Ft }\end{array}$ & $\begin{array}{l}\text { Model 13: } \\
\text { SLM 2010 MAV } \\
\text { per Sq. Ft }\end{array}$ & $\begin{array}{c}\text { Model 14: } \\
\text { SEM 2010 MAV } \\
\text { per Sq. Ft }\end{array}$ \\
\hline & Unst. & Unst. & Unst. \\
\hline Constant & $97.62 * * *$ & $34.88 * * *$ & $65.77 * * *$ \\
\hline Streetsmart Score & $.16^{* *}$ & $.13^{* *}$ & $.14^{*}$ \\
\hline Distance to the CBD, 2010 & -0.109 & -.26 & -.55 \\
\hline $\begin{array}{l}\text { Percent of Nonwhite } \\
\text { Residents, } 2010\end{array}$ & $-.28 * * *$ & $-.16 * * *$ & $-.16 * * *$ \\
\hline Median housing Age, 2010 & $-.47 * * *$ & $-.23 * *$ & $-.29 * * *$ \\
\hline $\begin{array}{l}\text { Number of Housing Units, } \\
2010\end{array}$ & -.0 & -.0 & -.0 \\
\hline $\begin{array}{l}\text { Number of Bus Stops in } \\
\text { Tract, } 2010\end{array}$ & $.193 * *$ & .04 & .05 \\
\hline High Interest Loans & $-.454 * *$ & $-.24+$ & .03 \\
\hline $\begin{array}{l}\text { Percent of Vacant Units, } \\
2010 \\
\text { Median Household }\end{array}$ & $-1.56 * * *$ & $-.49 * *$ & -.06 \\
\hline $\begin{array}{l}\text { Income, } 2010 \\
2007 \text { Total Crime per }\end{array}$ & $.000 * * *$ & $.0 * * *$ & $.0 * * *$ \\
\hline 100,000 Residents & $-.001 * * *$ & -.0 & -.0 \\
\hline Total Jobs located in Tract & $.001 * *$ & $-.0 * * *$ & $.0 * * *$ \\
\hline Lag (rho) & - & $.63 * * *$ & - \\
\hline Error (lambda) & - & - & $.92 * * *$ \\
\hline Log Likelihood & -655.29 & -595.11 & -587.2 \\
\hline $\mathbf{R}^{2}$ & 0.82 & .92 & .93 \\
\hline Moran's I (error) & $.4 * * *$ & - & - \\
\hline Lagrange Multiplier (lag) & $105.01 * * *$ & - & - \\
\hline Robust LM (lag) & $39.16 * * *$ & - & - \\
\hline Lagrange Multiplier (error) & $70.4 * * *$ & - & - \\
\hline Robust LM (error) & 4.5 & - & - \\
\hline
\end{tabular}

Notes: Unst. $=$ unstandardized beta; $B$ eta $=$ standardized beta. Level of aggregation is census tract. $+\mathbf{p} \leq .1 ;{ }^{*} \mathbf{p} \leq .05 ; * * \mathbf{p} \leq .01 ; * * * \mathbf{p} \leq .001$ 
Table 5.11 contains model 4 (changes median assessed value per square foot from 2000-2010) alongside the results of the SLM and SEM. The OLS model has a positive Moran's I, suggesting the presence of spatial dependence in the model. The Lagrange Multiplier tested significant for both spatial lag and error. The robust test for lag was significant while the robust test for error was not. Suggesting the model suffers from lag.

While the OLS coefficients suffered from spatial dependence, the results were rather consistent. The walkability measure remained significant across all the models. Suggesting that even when spatial error and lag are controlled for walkability still has a positive significant correlation with the change median assessed value per square foot from 20002010. Two variables, 2007 total crime per 100,000 residents and high interest loans, lost significance when spatial dependence was placed in the model. Both of the models' parameters for spatial dependence test significant at the .001 level. R-squared and log likelihood were greater in SEM, suggesting it has better model fit. However, both models log likelihood ratio was significant at the .001 level suggesting that although spatial dependence is controlled for it is still present in the models. 
Table 5.11 Changes in Median Assessed Value per Square Foot From 2000-2010 Spatial Regression

\begin{tabular}{|c|c|c|c|}
\hline & $\begin{array}{c}\text { Model 6: } \\
\text { 2000-2010 MAV } \\
\text { per Sq. Ft chg. }\end{array}$ & $\begin{array}{l}\text { Model 15: } \\
\text { SLM 2000-2010 } \\
\text { MAV per Sq. Ft } \\
\text { chg. } \\
\end{array}$ & $\begin{array}{l}\text { Model 16: } \\
\text { SEM 2000-2010 } \\
\text { MAV per Sq. Ft } \\
\text { chg. }\end{array}$ \\
\hline & Unst & Unst & Unst \\
\hline Constant & $32.16 * * *$ & $22.3^{* * *}$ & $31.55 * * *$ \\
\hline Streetsmart Score & $.14 * * *$ & $.06 * * *$ & $.09 * *$ \\
\hline $\begin{array}{l}\text { Distance to the CBD, } \\
2000 \\
\text { Percent of Nonwhite }\end{array}$ & -.12 & -.4 & -.23 \\
\hline $\begin{array}{l}\text { Residents, } 2000 \\
\text { Median housing Age, }\end{array}$ & $-.11 * * *$ & $-.09 * * *$ & $-.12 * * *$ \\
\hline $\begin{array}{l}2000 \\
\text { Number of Housing }\end{array}$ & $-.291 * * *$ & $-.23 * * *$ & $-.033 * * *$ \\
\hline Units, 2000 & 0 & -.002 & -.0 \\
\hline $\begin{array}{l}\text { Number of Bus Stops } \\
\text { in Tract, } 2000\end{array}$ & 0.05 & -.036 & -.0 \\
\hline High Interest Loans & $-.3 * *$ & -.02 & .04 \\
\hline $\begin{array}{l}\text { Percent of Vacant } \\
\text { Units, } 2000 \\
\text { Median Household }\end{array}$ & -.172 & -.06 & -.06 \\
\hline $\begin{array}{l}\text { Income, } 2000 \\
2007 \text { Total Crime per }\end{array}$ & $.127 * *$ & $8.38 \mathrm{E}-005 *$ & $9.55 \mathrm{E}-005 *$ \\
\hline $\begin{array}{l}100,000 \text { Residents } \\
\text { Total Jobs located in }\end{array}$ & $.000 *$ & -.0 & -.0 \\
\hline Tract & $.0 *$ & $.0 * * *$ & $.0 * * *$ \\
\hline Lag (rho) & - & $.07 * * *$ & - \\
\hline Error (lambda) & - & - & $.78 * * *$ \\
\hline Log Likelihood & -559.67 & -539.48 & -534.59 \\
\hline $\mathbf{R}^{2}$ & .64 & .73 & .77 \\
\hline Moran's I (error) & $.27 * * *$ & - & - \\
\hline $\begin{array}{l}\text { Lagrange Multiplier } \\
\text { (lag) }\end{array}$ & $40.1 * * *$ & - & - \\
\hline Robust LM (lag) & $8.03 * *$ & - & - \\
\hline $\begin{array}{l}\text { Lagrange Multiplier } \\
\text { (error) }\end{array}$ & $33.5 * * *$ & - & - \\
\hline Robust LM (error) & 1.5 & - & - \\
\hline
\end{tabular}

Notes: Unst. = unstandardized beta; Beta $=$ standardized beta. Level of aggregation is census tract. $+\mathbf{p} \leq .1 ;{ }^{*} \mathbf{p} \leq .05 ; * * \mathrm{p} \leq .01 ; * * * \mathrm{p} \leq .001$ 


\section{Foreclosures}

The OLS regression results suggest walkability has a significant negative relationship with foreclosures from 2004-2008. Table 5.12 contains the OLS model for foreclosures from 2004-2008 along with the SEM and SLM. The Moran's I for the OLS model was significant indicating the presence of spatial dependence in the model. The Lagrange Multiplier for lag and error indicate the presence of both spatial lag and error. However, the robust version of these tests suggest only error is present in the model.

The results were rather consistent across the three models. The walkability variable held across all models, and the coefficient estimate increased when spatial dependence was included in the model. Furthermore, it remained significant at the .001 level. The one variable that was not significant in the OLS model, number of bus stops per census tract, became statistically significant and the coefficient also increased. Distance to the central business district was the only variable to lose significance across the models; however, it was approaching significance. With the exception of Walk Score and number of bus stops per census tract, the coefficients diminished across the models but the changes were not significant. The spatial parameters for each test were significant at the .001 level. The Rsquared and log likelihood indicate that SEM is best in terms of model fit. Although, both log likelihood ratio tests determine that spatial dependence is still present in both models. 
Table 5.12 Foreclosures from 2004-2008 Spatial Regression

\begin{tabular}{|c|c|c|c|}
\hline & $\begin{array}{c}\text { Model 7: } \\
\text { Foreclosures } \\
\mathbf{2 0 0 4 - 2 0 0 8} \\
\end{array}$ & $\begin{array}{c}\text { Model 17: } \\
\text { Foreclosures } \\
\mathbf{2 0 0 4 - 2 0 0 8} \\
\end{array}$ & $\begin{array}{c}\text { Model 18: } \\
\text { Foreclosures } \\
\text { 2004-2008 } \\
\end{array}$ \\
\hline Variable & Unst & Unst & Unst \\
\hline Constant & $-39.109 * *$ & $-29.89 *$ & -23.77 \\
\hline Walk Score & $-.315 * * *$ & $-.36 * * *$ & $-.407 * * *$ \\
\hline $\begin{array}{l}\text { Distance to the CBD, } 2000 \\
\text { Percent of Nonwhite }\end{array}$ & $2.371 * *$ & $1.2+$ & $1.47+$ \\
\hline Residents, 2000 & $.621 * * *$ & $.5 * * *$ & $.57 * * *$ \\
\hline Median housing Age, 2000 & $.772 * * *$ & $.6^{* * *}$ & $.68^{* * *}$ \\
\hline $\begin{array}{l}\text { Number of Housing Units, } \\
2000\end{array}$ & $.022 * * *$ & $.02 * * *$ & $.02 * * *$ \\
\hline High Interest Loans & $2.751 * * *$ & $1.2 * * *$ & $1.5 * * *$ \\
\hline $\begin{array}{l}\text { Number of Bus Stops in } \\
\text { Tract, } 2000\end{array}$ & .144 & $.2 * * *$ & $.3 * * *$ \\
\hline $\begin{array}{l}\text { Median Household Income, } \\
2000 \\
2007 \text { Total Crime per }\end{array}$ & $-.000 * * *$ & $-.0 * * *$ & $-.000 * * *$ \\
\hline 100,000 Residents & $.001 * * *$ & $.0 * * *$ & $.0 * * *$ \\
\hline Total Jobs located in Tract & $-.002 * * *$ & $-.0 * * *$ & $-.002 * * *$ \\
\hline Lag (rho) & - & $.22 * * *$ & - \\
\hline Error (lambda) & - & - & $.52 * * *$ \\
\hline Log Likelihood & -710.99 & -705.37 & -700.01 \\
\hline $\mathbf{R}^{2}$ & 0.86 & 0.87 & .89 \\
\hline Moran's I (error) & $.22 * * *$ & - & - \\
\hline Lagrange Multiplier (lag) & $10.8^{* * *}$ & - & - \\
\hline Robust LM (lag) & 0.8 & - & - \\
\hline Lagrange Multiplier (error) & $21.15 * * *$ & - & - \\
\hline Robust LM (error) & $11.10 * * *$ & - & - \\
\hline
\end{tabular}

Notes: Unst. $=$ unstandardized beta; $B$ eta $=$ standardized beta. Level of aggregation is census tract. $+\mathrm{p} \leq .1 ;{ }^{*} \mathrm{p} \leq .05 ; * * \mathrm{p} \leq .01 ; * * * \mathrm{p} \leq .001$ 


\section{Vacancy}

The OLS regression results did not signify a significant relationship between walkability and vacancy rates. Table 5.13 contains the OLS regression for neighborhood's vacancy rate in 2000, model 8, alongside the SLM and SEM. The significant Morin's I denotes spatial dependence is present in the model. The Lagrange Multiplier test for lag and error were both significant at the .001 level. However, only the robust test for lag was significant.

The OLS results were somewhat consistent with the spatial models. All of the coefficients did diminish in the spatial models. The measure for walkability remained nonsignificant. The total number of jobs located in the tract did increase in terms of significance in both SLM and SEM models. The sign for number of bus stops per census tract did change to a negative relationship in the spatial models. In terms of model fit, SEM had greater increases in R-squared and log likelihood. Both of the log likelihood ratio tests were significant at the .001 level which indicates that although spatial dependence was controlled for in both spatial models it is still present in the model. 
Table 5.13 Vacancy Rate 2000 Spatial Regression

\begin{tabular}{|c|c|c|c|}
\hline & $\begin{array}{c}\text { Model 8: } \\
\text { Vacancy Rate, } \\
\mathbf{2 0 0 0} \\
\end{array}$ & $\begin{array}{c}\text { Model 19: } \\
\text { SLM Vacancy } \\
\text { Rate, } 2000\end{array}$ & $\begin{array}{l}\text { Model 20: } \\
\text { SEM Vacancy } \\
\text { Rate, 2000 }\end{array}$ \\
\hline Variable & Unst. & Unst. & Unst. \\
\hline Constant & $5.98 * *$ & 2.3 & $7.5 * *$ \\
\hline Walk Score & -.009 & -.003 & -.02 \\
\hline $\begin{array}{l}\text { Distance to the CBD, } \\
2000\end{array}$ & $-.274^{*}$ & -.144 & $-.28+$ \\
\hline Residents, 2000 & $.064 * * *$ & $.03 * *$ & $.04 * *$ \\
\hline $\begin{array}{l}\text { Median housing Age, } \\
2000\end{array}$ & -.01 & -.009 & .009 \\
\hline $\begin{array}{l}\text { Number of Bus Stops } \\
\text { in Tract, } 2000\end{array}$ & .008 & -.003 & -.004 \\
\hline $\begin{array}{l}\text { Median Household } \\
\text { Income, } 2000\end{array}$ & 0 & $1.49 \mathrm{E}-05$ & $8.64 \mathrm{E}-006$ \\
\hline $\begin{array}{l}\text { Total Jobs located in } \\
\text { Tract }\end{array}$ & $.0+$ & $9.87 \mathrm{E}-005 *$ & $.0001 * *$ \\
\hline Lag (rho) & - & $.63 * * *$ & - \\
\hline Error (lambda) & - & - & $.705 * * *$ \\
\hline Log Likelihood & -447.76 & -422.18 & -420.9 \\
\hline $\mathbf{R}^{2}$ & .37 & .57 & .59 \\
\hline Moran's I (error) & $.35 * * *$ & - & - \\
\hline $\begin{array}{l}\text { Lagrange Multiplier } \\
\text { (lag) }\end{array}$ & $58.72 * * *$ & - & - \\
\hline Robust LM (lag) & $4.66^{*}$ & - & - \\
\hline $\begin{array}{l}\text { Lagrange Multiplier } \\
\text { (error) }\end{array}$ & $54.57 * * *$ & - & - \\
\hline Robust LM (error) & .5 & - & - \\
\hline
\end{tabular}

Notes: Unst. $=$ unstandardized beta; $B$ eta $=$ standardized beta. Level of aggregation is census tract. $+p \leq .1 ;{ }^{*} p \leq .05 ;{ }^{*} p \leq .01 ; * * * 0.001$ 
The final model for this section can be found in Table 5.14, which contains the OLS for the vacancy rates in 2010, model 9, alongside the SLM and SEM. The Moran's I for the OLS was statistically significant indicating the presence of spatial dependence. The Lagrange Multiplier tests reveal the presence of both lag and error in the model. However, the robust tests for both lag and error are not significant.

The OLS coefficients remained fairly similar across the models. Although, the coefficients diminished in the spatial models, except for distance to the central business district, which increased. The measure for Walk Score remained non-significant. The number of bus stops in each tract became significant and the sign remained constant; thus, it demonstrated a negative relationship with the dependent variable. Each of the spatial parameters was significant at the .001 level. In terms of model fit, both models were similar. Each of the log likelihood ratio test was significant indicating that although spatial dependence was controlled for it is still present in both models. 
Table 5.14 Vacancy Rate 2010 Spatial Regression

\begin{tabular}{|c|c|c|c|}
\hline & $\begin{array}{c}\text { Model 9: } \\
\text { Vacancy Rate, } \\
\mathbf{2 0 1 0}\end{array}$ & $\begin{array}{c}\text { Model 21: } \\
\text { SLM Vacancy } \\
\text { Rate, } \mathbf{2 0 1 0}\end{array}$ & $\begin{array}{c}\text { Model 22: } \\
\text { SEM Vacancy } \\
\text { Rate, } \mathbf{2 0 1 0}\end{array}$ \\
\hline Variable & Unst & Unst & Unst \\
\hline Constant & $8.796^{*}$ & 5.9 & $10.8 *$ \\
\hline Streetsmart Score & -.006 & -.019 & -.03 \\
\hline $\begin{array}{l}\text { Distance to the CBD, } \\
2010 \\
\text { Percent of Nonwhite }\end{array}$ & -.26 & -.26 & -.45 \\
\hline $\begin{array}{l}\text { Residents, } 2010 \\
\text { Median housing Age, }\end{array}$ & $.088 * * *$ & $.06^{* * *}$ & $.08 * *$ \\
\hline $\begin{array}{l}2010 \\
\text { Number of Bus Stops in }\end{array}$ & .061 & $.09+$ & $.13^{*}$ \\
\hline Tract, 2010 & -.035 & $-.06 *$ & $-.06^{*}$ \\
\hline $\begin{array}{l}\text { Median Household } \\
\text { Income, } 2010\end{array}$ & $-4.70 \mathrm{E}-005 * * *$ & $-3.52 \mathrm{E}-005$ & $-5.64 \mathrm{E}-005+$ \\
\hline $\begin{array}{l}\text { Total Jobs located in } \\
\text { Tract, } 2010\end{array}$ & .000 & $.0004 * * *$ & $.0004 * * *$ \\
\hline Lag (rho) & - & $.33 * * *$ & - \\
\hline Error (lambda) & - & - & $.39 * * *$ \\
\hline Log Likelihood & -528.41 & -525 & -525 \\
\hline $\mathbf{R}^{2}$ & .54 & .58 & .58 \\
\hline Moran's I (error) & $.15 * * *$ & - & - \\
\hline Lagrange Multiplier (lag) & $12.8 * * *$ & - & - \\
\hline Robust LM (lag) & 2.01 & - & - \\
\hline $\begin{array}{l}\text { Lagrange Multiplier } \\
\text { (error) }\end{array}$ & $11.01 * * *$ & - & - \\
\hline Robust LM (error) & .25 & - & - \\
\hline
\end{tabular}

Notes: Unst. $=$ unstandardized beta; $B$ eta $=$ standardized beta. Level of aggregation is census tract. $+p \leq .1 ;{ }^{*} \mathbf{p} \leq .05 ; * * p \leq .01 ; * * * p \leq .001$ 


\section{Summary and Conclusion}

This chapter has examined the impacts of walkability on median assessed housing valuation, foreclosures and vacancy rates for neighborhoods in Louisville, KY. The findings in this section suggest walkability has a significant correlation with housing valuation and foreclosures in Louisville, KY.

In terms of housing valuation, walkability was positive significant in all the OLS models with the exception of Model 1, the 2000 median assessed valuation specification. Although, this is expected as the housing bubble was flourishing during this period along with the fact that suburban areas exhibit substantially higher median assessed values, which is the reason why median assessed value per square foot was offered as a more superior specification. This suggests that in Louisville there is a walkable premium in terms of housing. However, the data was spatial and spatial regression was introduced in order to test for and control for autocorrelation. Since value per square foot was a superior measure, this was the only version of each median assessed value specification that was tested. The spatial regression revealed that for 2010, and the change in median assessed value between 2000 and 2010, walkable neighborhoods still had a higher valuation. Despite the insignificance of the year 2000, the significant findings of all the other specifications for median assessed valuation suggest Louisville's housing stock located in areas with greater walkability demand a higher price compared to similar housing in areas with lower levels of walkability.

These findings suggest the walkable premium as discussed by scholars Ehrenhalt (2012), Leinberger (2009) and Speck (2012) exists in Louisville, which is a more representative study area compared to the mega cities used in other studies. Additionally, it 
suggests Louisville's walkable neighborhoods' housing values were more resilient during the Great Recession.

In addition to housing values, the number of foreclosures from 2004-2008 had a statistically significant negative relationship with walkability. Therefore, walkable neighborhoods generally suffered from fewer foreclosures compared to non-walkable neighborhoods. These findings reveal the possibility of walkable neighborhoods being more resilient during times of economic turmoil (Immergluck, 2009). The significant findings surrounding foreclosures add value to research concerning foreclosure risk factors, such as Pivo (2013), but this study differs in that it examines a midsize city with longitudinal data.

These associations, foreclosures and median assessed value, propose that walkability is a value proposition - that more walkable areas have higher housing values and are less prone to foreclosure. These facts are especially timely when put into the context of the housing market collapse. The results imply that neighborhoods designed in the spirit of Jane Jacobs pedestrian communities, with safe and connected streets, high levels of density, and varied land uses, not only benefit residents though the intrinsic health and environmental benefits of more walking, but also offer owners the possibility of a more resilient and stable economic value.

The lack of significance between walkability and vacancy rates does not necessarily debunk the idea of walkable neighborhoods having greater levels of desirability. Walkable neighborhoods tend to have substantially more housing units compared to low density suburban areas (Schwartz, 2006; Gilderbloom, 2008; Williamson, 2010) therefore, creating greater opportunity for vacancies among them. 
Overall, these findings suggest that walkability has an impact on neighborhood resilience in urban vs. suburban areas, and that there may be more 'value' in the walkable mixed-use environments than in homogenized residential suburban developments. The next chapter will examine the socio-economic composition of walkable neighborhoods. 


\section{CHAPTER VI}

\section{SOCIO-ECONOMIC COMPOSITION}

This chapter examines the results of the hypotheses related to neighborhood composition, as outlined in Chapter 4. This chapter relies on binominal logistic regression to uncover the probability of a neighborhood being walkable based upon a number of socioeconomic measures. All models were checked for multicollinearity and no problems were detected. Prior to introducing the results of the analyses, the descriptive properties of the variables used in the binominal logistic regression section will be explored.

\section{Descriptive Statistics}

The descriptive statistics for the binominal logistic regression are located in Table 6.1 and 6.2. The variables in Table 6.2 are presented in three variations: 1) the statistics for all neighborhoods in Louisville; 2) statistics for walkable neighborhoods (Walk Score 50-100); and 3) statistics for all non-walkable neighborhoods (Walk Score 0-49).

\section{Dependent Variables}

Table 6.1 contains the two dependent variables that will be used in the logistic regression models. Both are representations of walkable neighborhoods: one measured in 2008 and the other measured in 2013. Walkable neighborhood indicators were derived from the 2008 Walk Score and the 2013 Streetsmart Score. Any neighborhood with a score of 50- 
100 was considered walkable and was coded with a 1 , while neighborhoods with a score of 49 or below were noted as non-walkable and were coded with a 0 . In 2008 there were 45 neighborhoods that were considered walkable, or $26 \%$ of all neighborhoods. Figure 6.1 shows that most of these neighborhoods are located in the inner ring but there are a few located in the middle ring. In 2013, only 41 neighborhoods were considered walkable, or $22 \%$ of all neighborhoods. Figure 6.2, which relies on Streetsmart Score, identifies most of the walkable neighborhoods to be contained within the inner ring and only a few are outside of the inner ring. Although the number of neighborhoods did decrease, it is important to note that all neighborhoods that are considered walkable in 2013 were also considered walkable in 2008.

Table 6.1 Descriptive Statistics for Dependent Variables

\begin{tabular}{|c|c|c|c|c|c|}
\hline & Source & Year & Mean & Std Dv & $\mathbf{N}$ \\
\hline Walkable Neighborhood, (1/0) 2008 & Walk Score.com & 2008 & .26 & .44 & 170 \\
\hline Walkable Neighborhood, (1/0) 2013 & Walk Score.com & 2013 & .22 & .27 & 190 \\
\hline
\end{tabular}




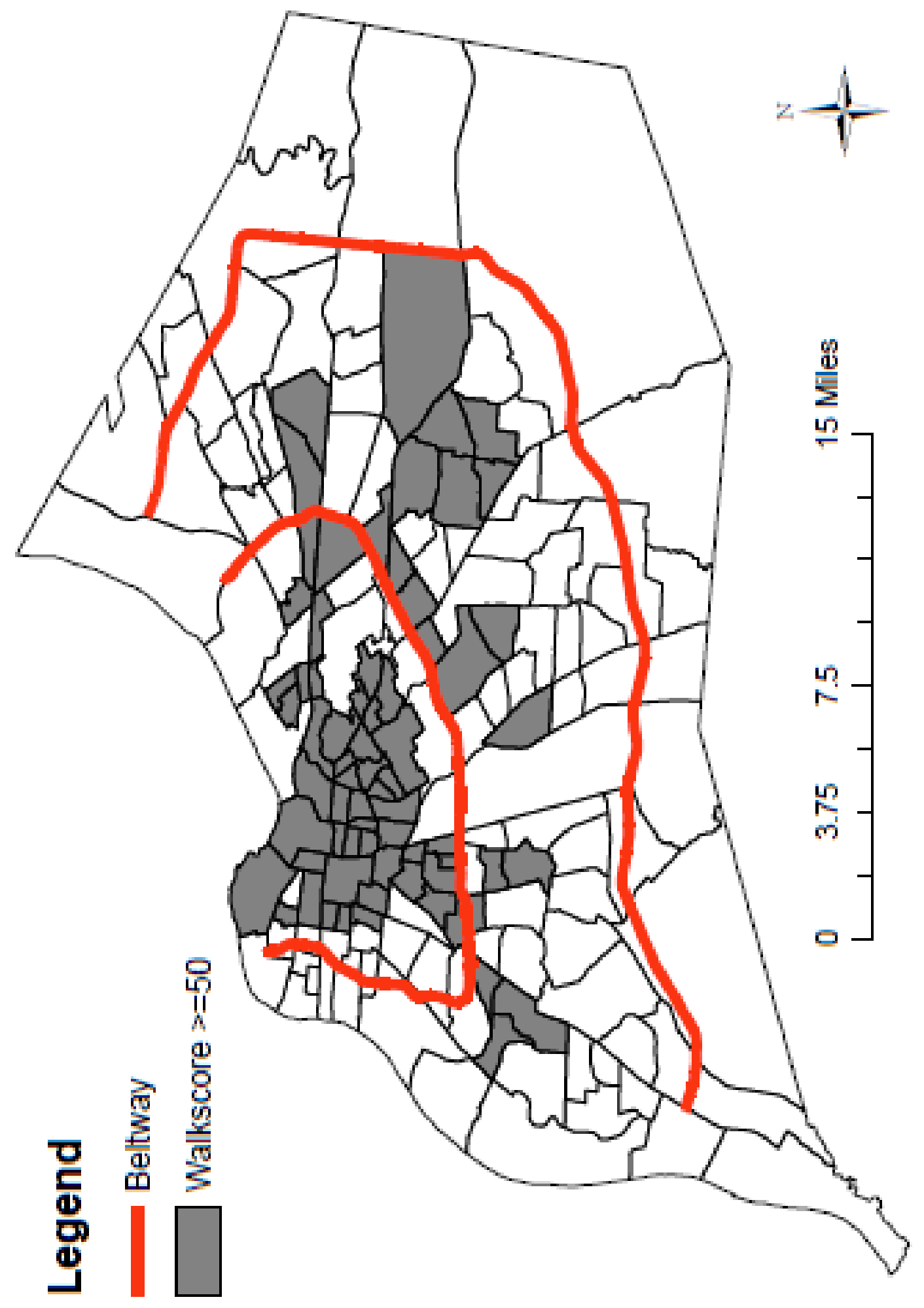

Figure 6.1. Louisville's Walkable Neighborhoods, 2008 Walk Score 


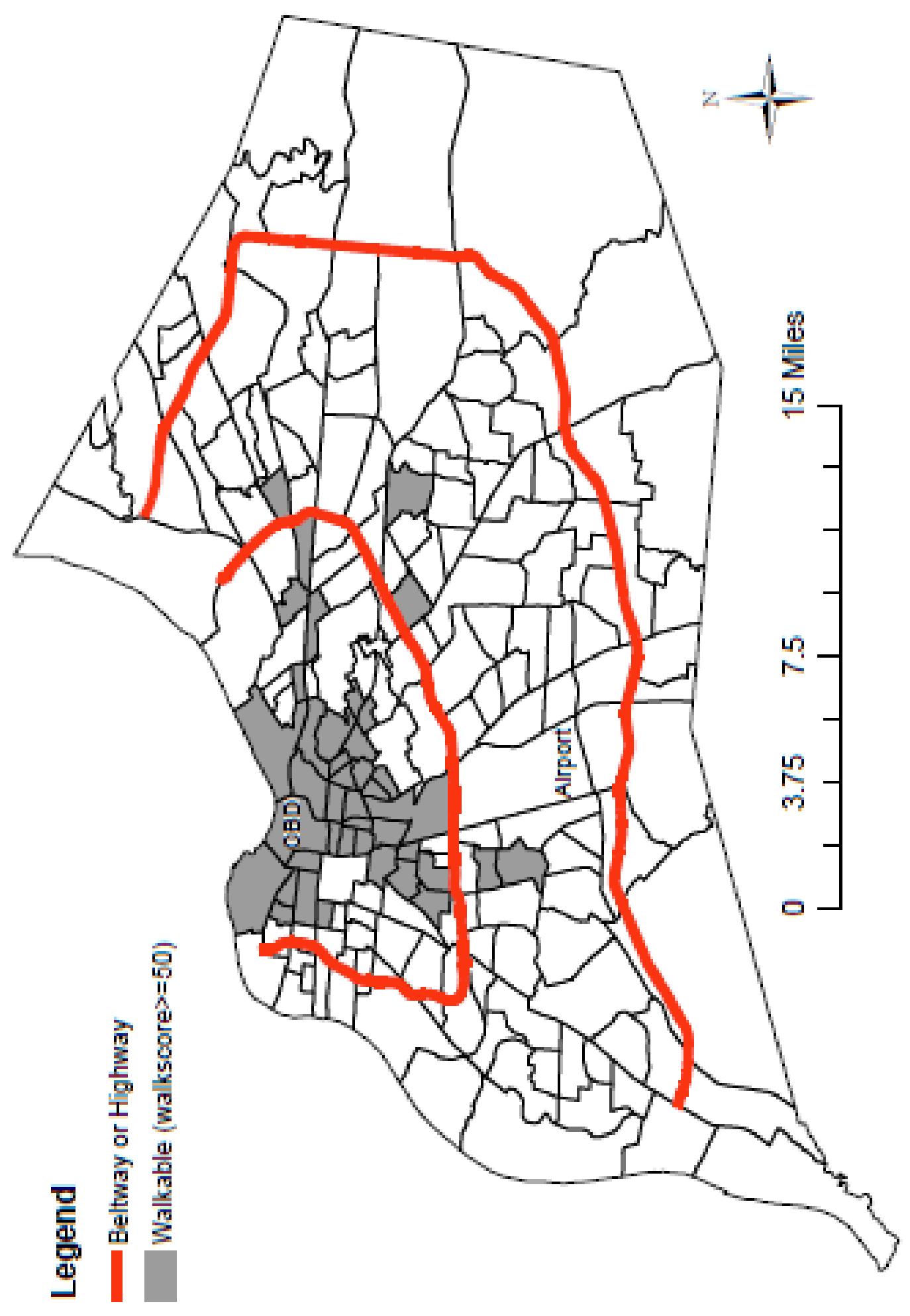

Figure 6.2. Louisville’s Walkable Neighborhoods, 2013 Streetsmart Score 


\section{Independent Variables}

Table 6.2 contains the independent variables used in the binomial logistic regression models in this section. The first variable presented in Table 6.2 is the average size of households per census tract in 2000. Louisville average size of households was 2.37 in 2000, while walkable neighborhoods had a mean of 2.09 and walkable neighborhoods had a mean of 2.48. In 2010, the mean for the average size of household slightly decreased to 2.35 for all neighborhoods in Louisville. The mean for the average size of household in walkable neighborhoods was 2.12 and non-walkable neighborhoods had a mean of 2.42 .

The mean for poverty levels in 2000 for all neighborhoods was $11.72 \%$, walkable neighborhoods had a mean of $16.87 \%$ and non-walkable neighborhoods had a mean of $9.93 \%$. The mean for poverty levels in 2010 increased by roughly $6 \%$ for all neighborhoods, walkable neighborhoods had a mean of $28.66 \%$ and non-walkable neighborhoods had a mean of $14.63 \%$. This large increase in poverty was a consequence of the Great Recession, which occurred in late 2007 and lasted until 2009. It had a large impact on unemployment and poverty throughout the U.S. (Dunne, 2012).

The mean for age of resident in 2000 was 36.72 for the city, while walkable neighborhoods mean for age of resident in 2000 was slightly smaller at 35.41 and nonwalkable neighborhoods had a higher mean of 37.2. In 2010 the mean for age of resident for

all neighborhoods in Louisville increased to 37.86 , non-walkable neighborhoods mean age of resident also increased to 38.5 while walkable neighborhoods slightly decreased in mean age of resident to 35.23 . 
The mean for median income for all households in Louisville was $\$ 40,524$ in 2000, walkable neighborhoods had a mean of $\$ 30,826$ and non-walkable neighborhoods had an average of $\$ 44,015$. In 2010 the mean for median income for households in Louisville increased by approximately $\$ 7,000$ to $\$ 47,876.99$, walkable neighborhoods mean only increased by roughly $\$ 2,000$ to $\$ 32,898.63$ and non-walkable neighborhoods mean increased over $\$ 7,000$ to $\$ 51,988.55$.

The last variable is the average percent of nonwhite residents per neighborhood. In 2000 the mean percent of nonwhite residents for all neighborhoods in Louisville was $25 \%$. Walkable neighborhoods average percent of nonwhite residents was nearly $29 \%$ and nonwalkable neighborhoods average percent of nonwhite individuals was roughly $24 \%$. In 2010 the average percent of nonwhite residents for all neighborhoods in Louisville slightly increased to roughly $31 \%$, walkable neighborhoods had an average percent of nonwhite residents of nearly $34 \%$ and non-walkable neighborhoods mean for percent of nonwhite residents increased to $30 \%$. 


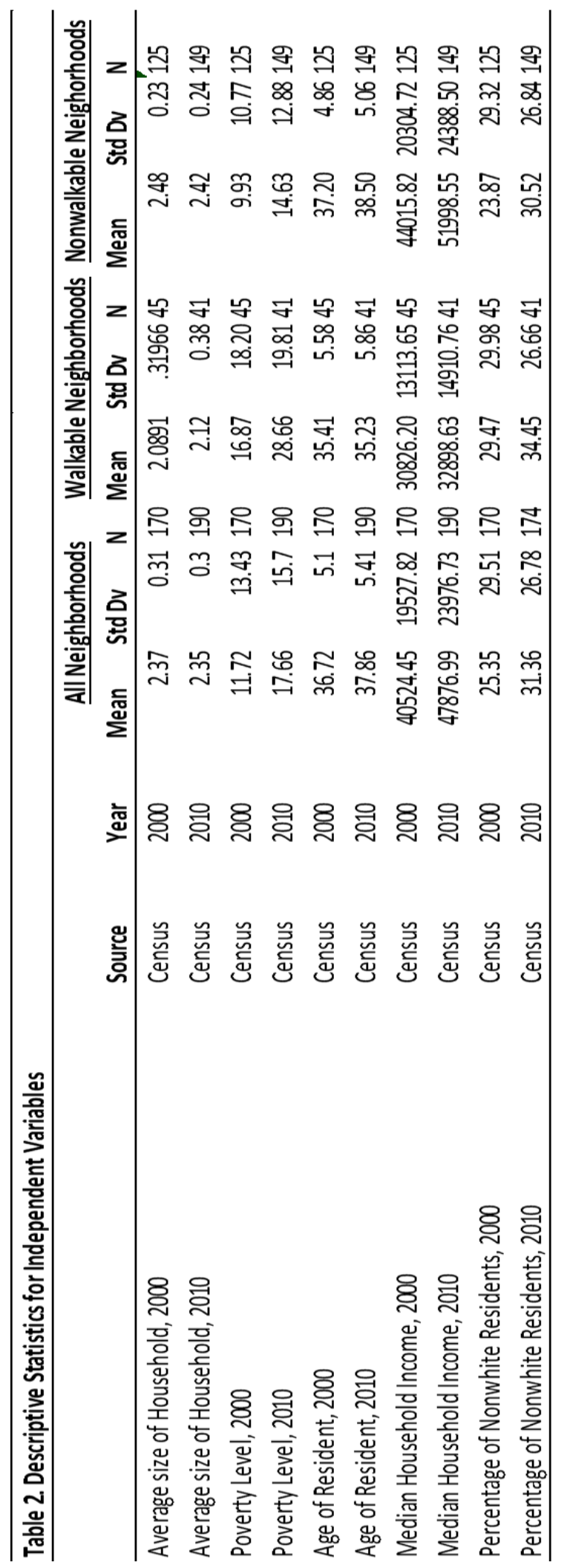




\section{Logistic Regression}

The first model that will be examined predicts the likelihood of a neighborhood being walkable based upon 2000 socio-economic characteristics, see Table 6.3. This will identify if there are any significant differences between socio-economic composition and the likelihood of a neighborhood being walkable. The model's R-squared indicates over half of the variation in the dependent variable is explained with this model. In the model only the variable average size of the household was significant. The variable indicates a negative relationship which suggests walkable neighborhoods are more likely to contain smaller households. All other variables in the model did not show significance suggesting that there was no statistical significant relationship between the likelihood of a Louisville neighborhood being walkable and race, income, age, unemployment or poverty. 
Table 6.3 Walkable Neighborhood (1/0) Binomial Regression Results

\begin{tabular}{lcc}
\hline & \multicolumn{2}{c}{ Walk Score2008 } \\
\cline { 2 - 3 } & Coefficient & $\begin{array}{c}\text { Standard } \\
\text { Error }\end{array}$ \\
\hline Constant & $15.2 * * *$ & $3.69 * * *$ \\
Percent of Nonwhite Residents, 2000 & -.002 & .013 \\
Percent of Unemployed Residents, 2000 & .004 & .1 \\
Percentage of Residents Below the Poverty Line, 2000 & .053 & .056 \\
Median Age of Residents, 2000 & -.057 & .07 \\
Median Household Income, 2000 & .0 & .0 \\
Average Household Size, 2000 & $-6.36^{* * *}$ & $1.17 * * *$ \\
\hline-2 log likelihood & \multicolumn{2}{c}{120.83} \\
Nagelkerke $\mathrm{R}^{2}$ & \multicolumn{2}{c}{.52} \\
$\mathrm{~N}$ & & 170 \\
\hline
\end{tabular}

Notes: $+p \leq .1 ;{ }^{*} \leq .05 ; * * p \leq .01 ; * * * p \leq .001$. Level of aggregation is census tract.

Table 6.4 examines the likelihood of a neighborhood being walkable, as identified by the 2013 Streetsmart Score, based upon 2010 socio-economic characteristics. In this model, the percent of nonwhite residents, percent unemployed and median household income are still not significant. Although, the variable percent of unemployed residents indicated a negative relationship in this model. The average size of the household still possessed a negative relationship with the dependent variable and the relationship remained significant at the $\mathrm{p} \leq .001$ level. The median age of residents had a significantly correlated negative relationship with the probability of a neighborhood being walkable. Additionally, the percentage of residents below the poverty line had a significant positive relationship with the dependent variable. 
Table 6.4 Walkable Neighborhood (1/0) Binomial Regression Results

\begin{tabular}{|c|c|c|}
\hline & \multicolumn{2}{|c|}{$\underline{\text { Streetsmart Score }}$} \\
\hline & Coefficient & Standard Error \\
\hline Constant & $19.75 * * *$ & $5.88 * * *$ \\
\hline Percent of Nonwhite Residents, 2010 & -.031 & .034 \\
\hline Percent of Unemployed Residents, 2010 & -.209 & .209 \\
\hline Percentage of Residents Below the Poverty Line, 2010 & $.121 *$ & $.052 *$ \\
\hline Median Age of Residents, 2010 & $-.255^{* * *}$ & $.091 * * *$ \\
\hline Average Household Size, 2010 & $-7.23 * * *$ & $1.85^{* * *}$ \\
\hline Median Household Income, 2010 & .0 & .0 \\
\hline-2 log likelihood & \multicolumn{2}{|r|}{47.27} \\
\hline Nagelkerke $\mathrm{R}^{2}$ & \multicolumn{2}{|r|}{.64} \\
\hline $\mathrm{N}$ & \multicolumn{2}{|r|}{190} \\
\hline
\end{tabular}

Notes: $+\mathbf{p} \leq .1 ;{ }^{*} \mathbf{p} \leq .05 ; * * \mathrm{p} \leq .01 ; * * * \mathrm{p} \leq .001$. Level of aggregation is census tract.

\section{Summary and Conclusion}

These two tests reveal important information concerning residential composition for walkable neighborhoods. First, smaller households were more likely to be found in walkable neighborhoods. This is a result of younger and older generations without children choosing to live in the inner city (Riggs, 2011). Second, the percentage of minorities within a neighborhood was not significant in predicting the probability of a neighborhood being walkable. In other words enclaves of minorities or whites were not prevalent in Louisville's walkable neighborhoods. Third, there was no indication in either model that higher income or lower income concentrations were present in walkable neighborhoods. Last, there were no 
indications that greater or lesser levels of unemployment were a predictor in the probability of a neighborhood being walkable.

Furthermore, the percentage of families in poverty and median resident age was not significant in 2000; however, greater levels of poverty and younger resident age were significant in predicting the probability of a neighborhood being walkable based on 2010 variables. The significance of median resident age and the negative relationship it had in the model follows national trends of younger populations moving into the inner city (Leinberger, 2008; Speck, 2012; Ehrenhalt, 2012; Leinberger and Alfonso, 2012). Finally, the significance and direction of the percentage of families in poverty follows national trends resulting from the Great Recession which had a significant impact on individuals' wealth (Dunne, 2012).

Overall, the data reveals that Louisville's walkable neighborhoods differ in socioeconomic composition. The next chapter will provide policy prescriptions based upon the findings of both this chapter and the previous chapter. 


\section{CHAPTER VII \\ DISCUSSION AND POLICY IMPLICATIONS}

The findings of this dissertation hold policy implications for cities and policymaking. These will be discussed in this chapter. Additionally, the limitations of this study and future research opportunities will be explored.

\section{Discussion and Policy Implications}

The analyses suggest there may be more value in the walkable, mixed-use neighborhoods than in homogenized sprawling developments. This dissertation shows that walkable neighborhoods have value, being built for active users and users of mass transit with a mix of purposes, which have incorporated employment, grocery stores, places of worship, restaurants, schools, medical services and recreational space. These areas contain economically diverse populations, in which the poor and working class live together in the same neighborhoods, along with higher income persons. These neighborhoods are in high demand. Seen in many of the most recognizably named neighborhoods around the United States: the West Village/Greenwich Village in New York; Beacon Hill in Boston; Shadyside in Pittsburgh; Old Louisville and the Highlands in Louisville; West Cleveland/ Tremont in Cleveland; Rogers Park in Chicago; the Mission District and Noe Valley in San Francisco; and downtown Ballard in Seattle. 
In this study, the idea of the value of the walkable environment was tested in Louisville, KY. The results indicate the aspects of walkable community have significant value. This may not come as a surprise to urbanists. Only recently has there been measures to quantify the social and economic impact of walkable neighborhoods been available. Until recently, urbanists have trusted the instincts of planners and advocates such as Jacobs. With the ability to benchmark communities, using a walkability measure, social scientists can now quantify these impacts. Walkability metrics now assist planners and policy makers in gauging the accessibility of daily living activities, and the likelihood of car dependence. Many inner city neighborhoods, built before the mass production of cars, are more walkable than sprawling residential-only suburban neighborhoods, which are isolated from the basic necessities of everyday life.

The results have shown, with an array of neighborhood indicators, that walkability has a significant net impact on neighborhood resilience. To test this ordinary least squares and spatial equations that control for recognized independent variables along with the test variable walkability were developed. The results revealed walkability is statistically significant with increases in neighborhood housing values, and has a significant negative correlation with the number of foreclosures in a neighborhood. Finally, the results showed no association between walkability and vacancy. Based on this, neighborhood hedonic equations testing for valuation and foreclosures should take walkability into consideration.

These kinds of outcomes have not been extensively documented in analysis of midsize cities, and the significant association of walkability in the models indicates specific policy implications for accessible neighborhood design. The associations suggest that 
walkability is a value proposition. These facts are especially timely when put into the context of the Great Recession. This implies that neighborhoods designed with safe and connected streets, high levels of density, and varied land uses, not only benefit residents though the intrinsic health and environmental benefits of more walking, but also offer owners the possibility of a more resilient and stable value. Furthermore, the findings suggest improving walkability will not only have increasing returns for residents but increasing walkability in turn will increase the tax rolls of local governments, thereby assisting many fiscally strapped localities.

The reasons people choose neighborhoods to live, work and enjoy is different today than in the past. As Jacobs (1961) said, there are people who will select the walkable neighborhood and others who will choose the suburbs. Nevertheless, there is a demand for walkable neighborhoods, as seen in the price premium for these neighborhoods. The binomial regression analysis shows that, in Louisville, residents of walkable neighborhoods tend to be younger populations with smaller households.

Soaring gas prices have many Americans seeking housing that is closer to employment, central city locations, cultural amenities (such as museums and sports complexes) and historic preservation areas (Ambrosius et al., 2010). Gentrification is just one expression of this change in preferences, starting in New York, London and Paris in the late 1950's and later in other cities such as San Francisco and Chicago in the 1970's (Savitch, 1981; Zukin, 1982; Gilderbloom \& Appelbaum, 1987; Ambrosius et al, 2010). Gasoline prices may continue to rise as supplies fall, and demand increases from other emerging industrialized countries. These factors may continue to influence how people get to school, 
work, stores and worship. However, as the models indicate, when individuals weigh neighborhood choices, accessibility will factor into that choice, alongside schools, crime rate, proximity jobs, downtown, etc. And since walkability matters, and is of increasing importance in housing choice, a clear question arises for policy makers- how can we best promote and create walkable places?

Cortright (2009) states:

Neighborhood walkability is the product of both public and private decisions. The public sector dictates the land use framework, regulation the location and composition of commercial land uses and the types and density of housing units... choosing the number, size and location of important destinations. If we're looking to shore up value in local housing markets, it appears promoting more walkable neighborhoods is one way to do so (p.26).

Considering this, there are two policy areas might be used to make neighborhoods more accessible: 1) land use and 2) affordability. Land use and neighborhood walkability is heavily tied to the number and variation of amenities or destinations available within a short walking distance. Unfortunately, many planning and zoning codes restrict land use variation. Policies that relax zoning, allowing for ground floor commercial or retail conversions, may encourage transactional uses that increase neighborhood interactions and walking destinations, even in suburban locations. Relaxing zoning codes, such as setbacks requirements, open space requirements and lot size requirements, could increase the opportunity to develop walkable communities in areas characterized by sprawl. 
Recent economic turmoil has caused a number of Americans to re-examine their communities and lifestyles. A National Association of Realtors (2013) survey found most Americans prefer to live in a traditional neighborhood and believe businesses and homes should be built closer together. In a 2011 survey, a vast majority said living in a walkable neighborhood matters more than housing size (National Association of Realtors, 2011). Homebuyers were willing to sacrifice both housing size and lot size in order to reduce their commute time to under 20 minutes or less. Campoli (2012) suggests walkable dense neighborhoods can make up for the loss of suburban amenities through smart and strategic neighborhood planning and design, i.e. the loss of private lots can be supplemented with public parks. Ultimately, this could signify a change in the American dream of suburban home ownership, Americans are returning to the idea of neighborhoods as a pedestrian shed where daily needs can be easily accessed. These developments are desirable and have been successful in Louisville. An example is Norton Commons, a new urbanist development in the eastern suburbs of Louisville - a highly desired neighborhood that succeeded in the Louisville suburbs, even during the housing market crash.

This shift of preference towards traditional neighborhoods can allow for the redevelopment and repurposing of obsolete land uses and underdeveloped land in sprawl areas into diverse mix use walkable communities (Davis, 2008). This type of policy is political feasibility; underdeveloped and vacant parcels could be identified and targeted for development into a diverse mix of uses. Many cities, such as Santa Cruz, CA and Salem, WA, have implemented land-to-improvement ratio strategies to identify vacant lots, abandoned buildings and underdeveloped property to target as development sites. The land- 
to-improvements ratio method compares property improvements to land improvement to identify vacant and underdeveloped properties. While this has been previously used to assess the impact of taxation on housing policy, this could be used to identify properties and create walkable urban spaces (Riggs, 2011). Louisville current has a program, VAPSTAT (Vacant and Abandoned Property Statistics), to identify vacant and abandoned properties. However, the program currently is not used to identify underutilized properties, but it could be fitted to this purpose.

Opportunities for redevelopment and repurposing are present in the deterioration of large shopping malls and large surface parking lots. The national decline in shopping malls creates opportunities to integrate amenities to create walkable communities within suburban areas (Hudson and O'Connell, 2009). Such projects have been undertaken in cities such as Belmar in Lakewood, CO a suburb of Denver and Dadeland in Miami, FL. The Dadeland project, in particular, has been able to introduce density and mix use while integrating the community with public transit. These types of conversions have been seen as key instruments in boosting the local economy and attracting new investments into the respective areas (Leinberger, 2008).

In Europe a number of cities have converted urban surface parking lots into new diverse places and have included underground uses, both for parking and other uses, into these communities. Other European cities such as Barcelona, Madrid and Torino have either relocated their light rail system underground and developed above it or have capped the existing rail in the city and built new boulevards on top with diverse mix uses. Louisville has 
an extensive amount of surface parking lots that can be repurposed into walkable communities.

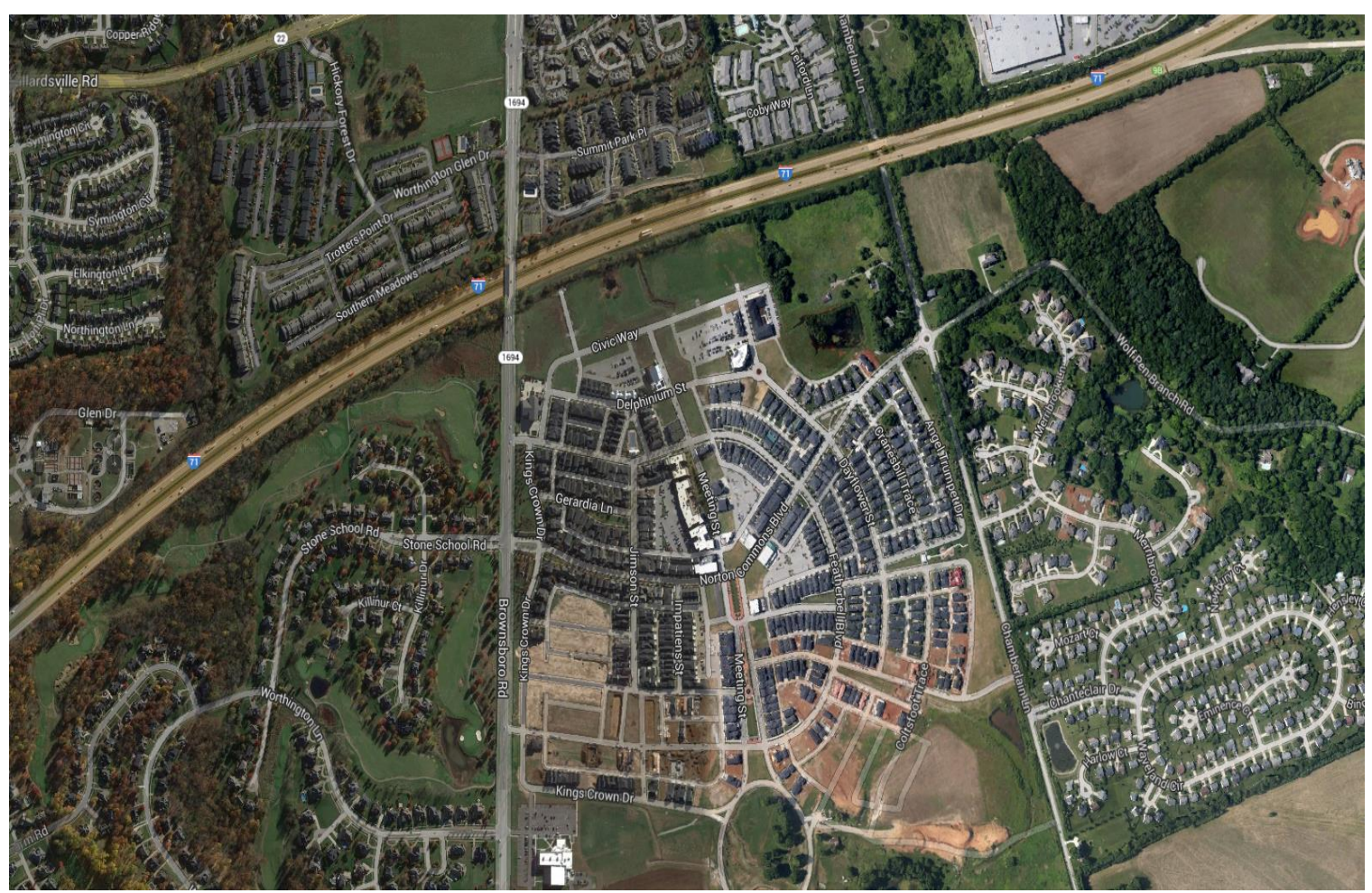

Figure 7.1 [Norton Commons]. (C) Google Maps. (2014). Ariel Photo of Norton Commons Louisville, KY. Accessed online:

https://www.google.com/mapmaker?11=38.324891,-$\underline{85.566244 \& \mathrm{spn}=0.005226,0.0069681}$ 


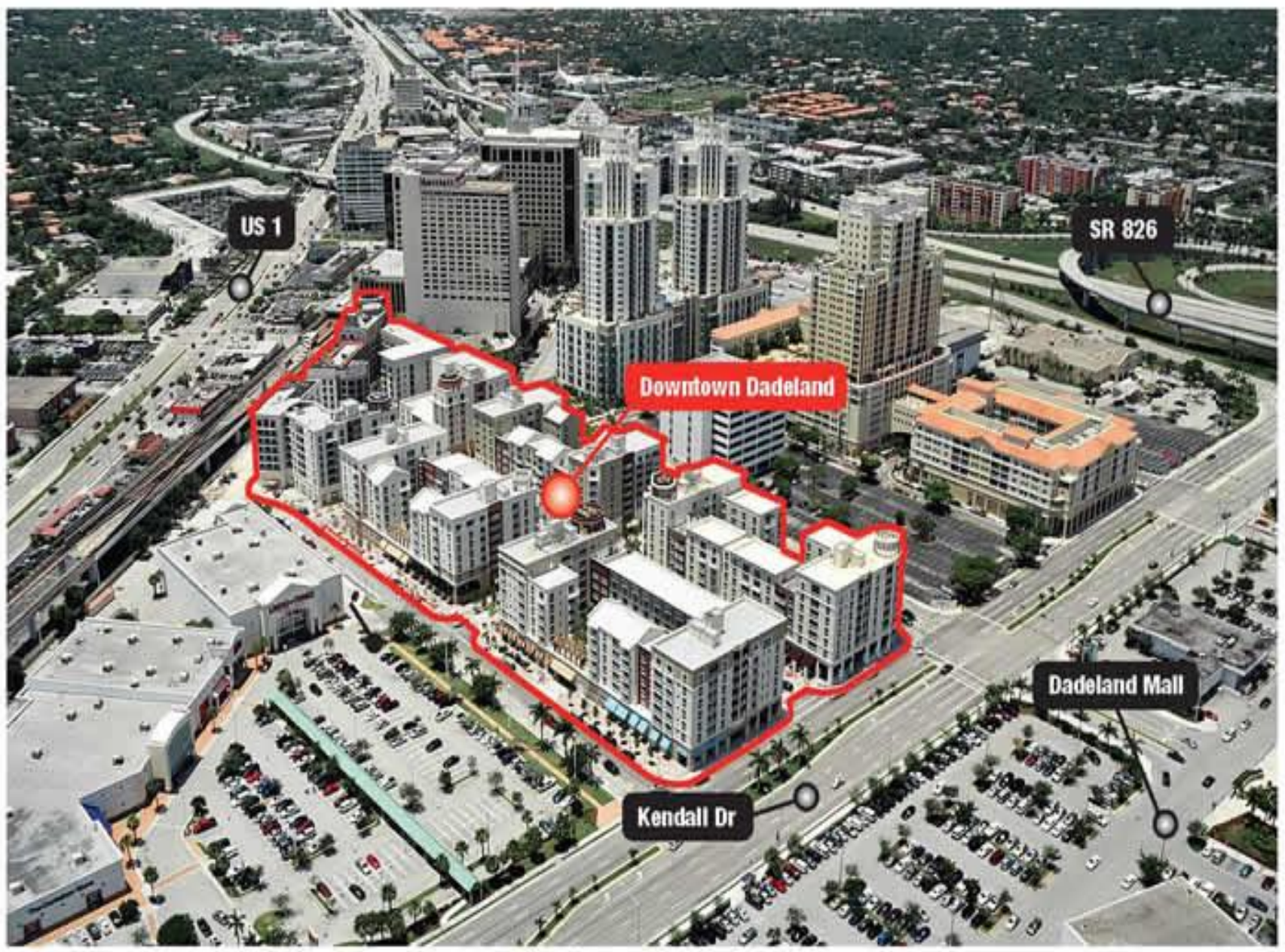

Figure 7.2 [Dadeland Kendall, FL.]. (2009) Photograph. (c) Downtown Dadeland. Accessed online at: http://www.downtowndadeland.com/ 


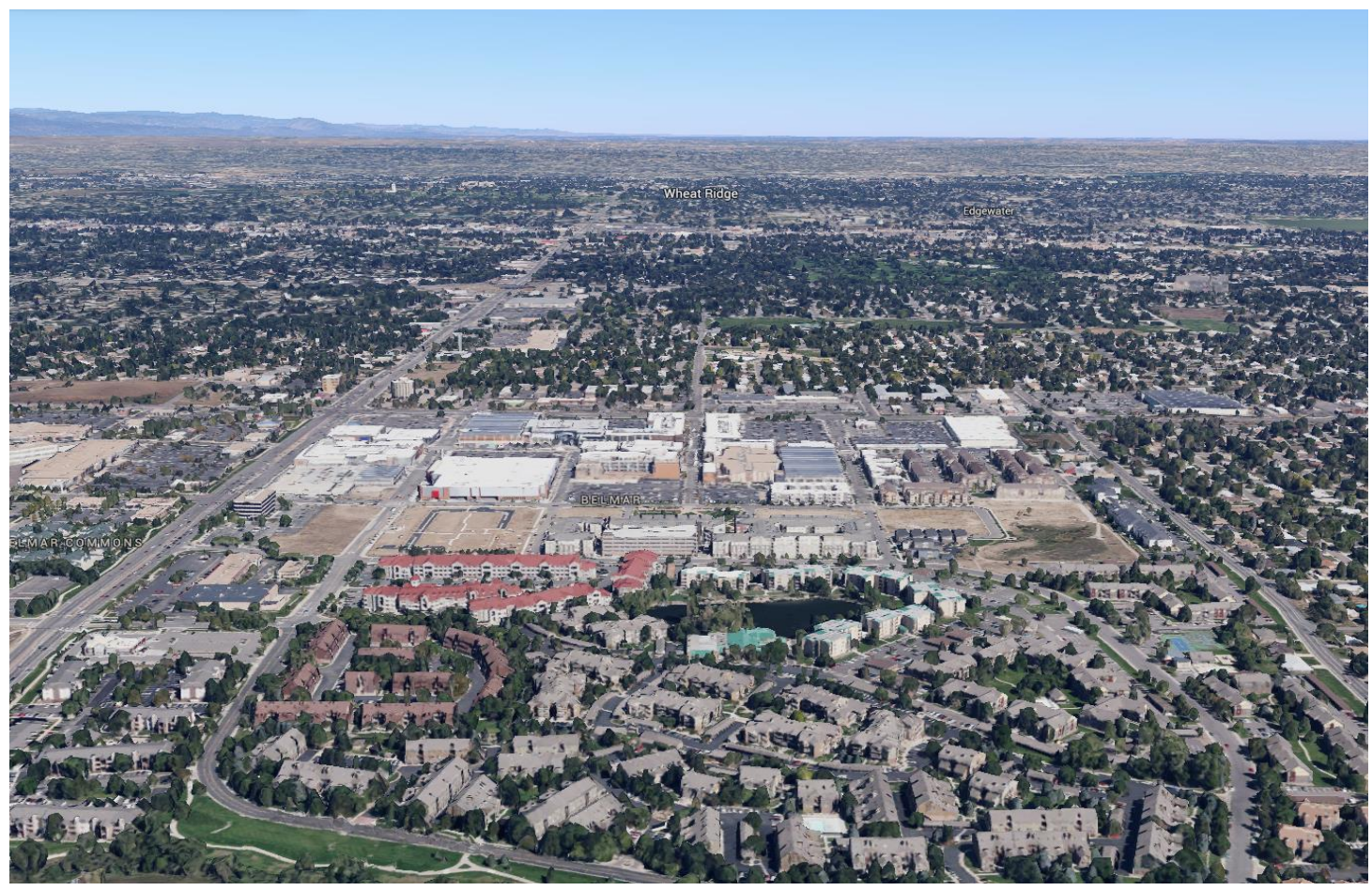

Figure 7.3 [Delmar. Lakewood, CO]. (2014). @ Google Maps.(2014). Ariel Photo of Delmar Lakewood, CO. Accessed online at: https://www.google.com/maps/@39.6947157,$\underline{105.0765871,342 \mathrm{a}, 35 \mathrm{y}, 77.86 \mathrm{t} / \mathrm{data}=! 3 \mathrm{~m} 1 ! 1 \mathrm{e} 3}$

Demand is shifting from unwalkable suburbs to neighborhoods with characteristics such as safety, walkability, mixed use and proximity to jobs and school. Relocating to a sustainable neighborhood means a better return on the initial investment, the option of being less dependent on automobiles, and the opportunity to live in denser neighborhoods with more diversity.

There is a need to reinforce affordability along with land use diversity, especially as walkable areas gain in attractiveness and importance during the course of housing decisions. The socio-economic findings suggest that walkable areas in 2010 did house more families in poverty. But simply investing in an area can exacerbate inequities that may already exist; 
thus, policies should be implemented to increase affordable housing for those who may face increasing prices as a consequence of on-street public investment.

Opportunities to counteract the possibility of gentrification due to investment might germinate policies that would increase or establish required below market rate (BMR) unit thresholds for new construction, or introduce policies expanding density thresholds, in order to increase the number of units available by right—driving down price by increasing supply. However, in comparison to other units within the development BMR units tend to be poorly planned and are generally considered lower quality housing. This creates a situation where affordable units can be considered inferior in comparison with other units in the development.

Variation in the size of housing units could be used to target a variety of incomes in development areas. Simple techniques might involve the conversion of warehouses into housing, or the conversion of basements, garages and attic, infilling historic neighborhoods, mixed-use homes and a denser population of individuals living closer to downtown business centers. Recent developments in San Francisco, CA have relied on efficiency units and single-room occupancy (SRO) zoning in order to attempt to provide affordable homeownership units for a variety of incomes (Riggs, 2011). While these SRO developments are popular in Europe, they have yet to become a significant feature in the U.S. urban landscape mainly due to the rigidity of the U.S. planning codes. These developments have proved profitable and can increase the availability of walkable units. Furthermore, since average household sizes tend to be smaller in these neighborhoods, as indicated in both 2000 
and 2010 in the analysis, these units fit the demographics of Louisville. Developers could be incentivized to create these types of units on smaller vacant or underutilized parcels.

Each of these areas- increasing the number of land uses, and increasing affordability options and standards - are goals that neighborhood organizations and policymakers might implement to increase neighborhood walkability. Done in tandem, they could provide neighborhood investment and increase opportunity for a diverse cross-section of individuals to live and play in areas that are walkable. However, as Jacobs (1961) noted, not all people are going to select walkable neighborhoods, a fact that cities must recognize. Speck (2012) points out that only a portion of the city can be walkable, because the demand for walkable neighborhoods will reach a saturation point. When undertaking these policies, cities must be careful not to overdevelop this type of neighborhood.

\section{Limitations and Future Research}

There are limitations in this research that provide opportunities for future research. There are three key areas that can provide greater validity to the results of this study: 1) a longitudinal study of multiple cities; 2) an attentive examination of metrics and benchmarking techniques; and 3) inclusion of street quality variables.

First, the limited number of data points and the use of a single study area does create

limitations. A longitudinal study of multiple cities concerning neighborhood design and the socio-economic makeup of neighborhoods is needed as a follow up to this study. This study has laid the ground work in identifying if value exist in walkability for mid-size cities. It is 
also important to understand the trajectory of this trend as well as the point of saturation, when demand for walkability in cities ceases with neighborhood gentrification.

A longitudinal analysis of neighborhood accessibility and socio-economic composition of neighborhoods in multiple cities is a natural progression of this research. Future research should include significant factors found here, but also include additional variables surrounding neighborhood housing conditions such as the presence of brownfield sites, percentage of rental units and quality of schools. A full examination of socio-economic variables will create the best understanding of the impact of walkability.

An additional recommendation would be to press this study further to examine the success of various redevelopment efforts and housing policy interventions in high poverty neighborhoods. Obtaining a pre-intervention benchmark data and collecting the postintervention data will allow for a comparison of the residents' neighborhood design to understand if there is a variation among outcomes and neighborhood accessibility.

Second, even though the Walk Score metric used in this study has been validated in the literature, it needs to be further tested. For the purpose of this study, a quantifiable measure of walkability provided by Walk Score, serves as a proxy of access to compare Louisville's neighborhoods to one another. This metric is a composite of thirteen categories. The traditional Walk Score does not differentiate categories; all have the same weight. But, Streetsmart Scores weighted categories based upon their effects on walking behavior. The question is which of these categories has the largest impact on foreclosure resilience and housing value? This study has made no attempt to understand these impacts. Perhaps only a 
few categories matter to housing valuation and foreclosure resilience; this reality would call for a reconsideration of the weights assigned to categories, when estimating Walk Score impact on foreclosure resilience and housing valuation.

Finally, an inclusion of streetscape and other suitability variables need to considered in future studies. This study did not include these factors in its analyses, though it recognizes it is the individual choice in neighborhood. Some of these measures include the presence and condition of sidewalks, vegetation, streetlights, tragic, slopes (Southworth, 2005; Ewing and Cervero, 2010; Speck, 2012). These variables affect mobility and access to various amenities needed for daily life. These suitability variables could affect evaluation, foreclosure and the composition of neighborhoods. They also create the possibility to differentiate neighborhood designs. These variables need to be tested alongside walkability metrics, or included in them, to better understand the impact of walkability on neighborhoods. 


\section{CHAPTER VIII}

\section{CONCLUSION}

Jane Jacobs (1961) in The Death and Life of Great American Cities explained that there are two types of individuals, foot people and car people. She does not argue that neighborhoods or cities designed for car people are inferior. Rather, she claims there are benefits specific to walkable neighborhoods, especially in the form of crime reduction and the creation of social capital.

Social scientists have been able to use neighborhood design to gain insight into neighborhood effects and some of the benefits of neighborhood type, but little research has been conducted to understand the impact that walkability can have on neighborhoods and residents. Mainly because until 2008 there were no widely available metric to assess an area's walkability. Since the creation of such a metric, scholars have tested the effects of walkability on the health, resilience, economic vitality and housing valuation. However, most of these studies focus on mega cities, sections of cities or on random parcel data sales data.

The literature review uncovered a gap in the scholarship concerning walkability, principally the lack of research concerning mid-sized American cities. This study is a start to fill this void. Furthermore, this study focused on another gap in the literature by examining how the socio-economic composition of walkable neighborhoods differs from non-walkable neighborhoods. 
In the spirit of Jacobs, the notion of walkability is tested to understand if neighborhoods that have greater levels of accessibility benefit in terms of housing valuation, foreclosures and vacancy. The City of Louisville, KY, a mid-sized Midwestern city, was selected as the study area for this dissertation. Using Louisville as a study area was a more suitable choice than megacities such as New York, Los Angeles and Chicago; its size and Midwestern location makes Louisville more representative of U.S. cities (Barrow, 2004; Savitch \& Vogel, 2004; Ambrosius, 2010; Gilderbloom et al., 2012).

Relying on a number of statistical methods (OLS regression and spatial regression), the Front Seat Inc. index measuring neighborhood walkability and a number of commonly used control variables this hypothesis was tested. The key findings were:

1) Neighborhoods in Louisville with greater levels of walkability had higher valuations in 2010 and greater increases in valuation between 2000 and 2010.

2) Louisville neighborhoods with greater levels of walkability tended to have a lower number of foreclosures from 2004-2008.

3) Vacancy rates were not significantly correlated with walkability in Louisville.

This study explored neighborhood demographics to understand if there is a difference in the residential composition between walkable neighborhoods and non-walkable neighborhoods. Relying on a logistic regression the probability of a neighborhood being walkable was determined based upon a number of characteristics. The key findings were: 
1) In both 2000 and 2010 the greater the presence of smaller average household sizes increased the likelihood of a neighborhood being walkable in Louisville.

2) In 2010 a younger population and greater poverty also were significant in predicting the likelihood of a neighborhood being walkable.

3) Race was not a significant factor in estimating the probability of a Louisville neighborhood's walkability.

This dissertation shows that walkable neighborhoods have value, being built for active users and users of mass transit with a mix of purposes. These areas contain economically diverse populations, in which the poor and working class live together in the same neighborhoods, along with higher income persons. These neighborhoods are still in high demand.

The findings from both analyses inform two policy areas: 1) increase the diversity of land uses; and 2) increase affordability options and standards. Findings point to policy prescriptions for Louisville, via relaxed zoning and expanding VAPSTAT_- identifying vacant and underutilized properties to be repurposed with a mix of uses. Findings also suggest policies that encourage the development of housing set at various price points and below market rate obligation on developers, which will result in the mixing of socioeconomic classes.

Although, this study has moved forward the argument that walkability provides additional benefits to neighborhoods there is more work to be done. The limitations of this study provide opportunities for future research, three future research areas are: 1) a 
longitudinal assessment with more data points to provide greater understanding of walkable neighborhood and demographic shifts; 2) a study to further insight into the Walk Score metric; and 3) a study that includes variables measuring suitability of walking.

Accessibility, as measured by walkability, has the potential to benefit residents and to help increase the property tax revenue of cities. This is especially important in a time of economic uncertainty, when many cities are cash strapped. Future research can build upon this study's finding that walkable neighborhoods are often engines of economic resilience and value. 


\section{REFERENCES}

Acevedo-Garcia, D., Osypuk, T. and Mcardle. (2009). "Racial/Ethnic Integration and Child Health Disparities" In Hartman, C., and Squires, G. (Eds.). The integration debate: Competing futures for American cities. Rutledge

Agresti, A., and Finlay, B. (2009). An introduction to advanced methodology. Statistical methods for the social sciences, 519-544.

Ambrosius, J.D. 2010. Religion and regionalism: congregants, culture, and city-county consolidation in Louisville, Kentucky. Doctoral Dissertation. Louisville, KY: University of Louisville.

Ambrosius, J. D., Gilderbloom, J. I., and Hanka, M. J. (2010). Back to Black... and Green? Location and policy interventions in contemporary neighborhood housing markets. Housing Policy Debate, 20(3), 457-484.

American Obesity Association. (2007). American Obesity Fast Facts. American Obesity Association Obesity Statistics. Retrieved electronically from http://obesity1.tempdomainname.com/subs/fastfacts/obesity US.shtml

Anderson, E. (1990). Streetwise: Race, class, and change in an urban community. University of Chicago Press

Anselin, L. 1988. Spatial econometrics: Methods and models. Dordrecht: Kluwer Academic 
Appelbaum, R., Bigelow, J., Kramer, H., Molotch, H., and Relis, P. (1976) The Effects of Urban Growth: A Population Impact Analysis. New York: Praeger, 1

Appelbaum, R. (1978). Size, growth, and U.S. cities. New York: Praeger Publishing.

Babbie, E. (2012) The Basics of Social Research. Belmont, CA: Wadsworth Publishing CO.

Bajari, P. and Kahn, M. E. (2005). Estimating housing demand with an application to explaining racial segregation in cities. Journal of Business and Economic Statistics, 23(1), 20-33.

Bogart, W. T. (2006). Don't Call it Sprawl: Metropolitan Structure in the 21st century. Cambridge University Press.

Bothwell, S. E., Gindroz, R., and Lang, R. E. (1998). Restoring community through traditional neighborhood design: a case study of Diggs Town public housing. Housing Policy Debate, 9(1), 89-114.

Brazley, M., and Gilderbloom, J. I. (2007). HOPE VI housing program: was it effective?. American Journal of Economics and Sociology, 66(2), 433-442.

Briggs, X. De Souza. 2005. The Geography of Opportunity: Race and Housing Choice in Metropolitan America. Washington, DC: Brookings Institution Press.

Brooks, D. (2004). On paradise drive: How we live now (and always have) in the future tense. Simon and Schuster. 
Brownson, R. C., Hoehner, C. M., Day, K., Forsyth, A., and Sallis, J. F. (2009). Measuring the Built Environment for Physical Activity: State of the Science. American Journal of Preventive Medicine, 36(4), S99-S123.

Brueckner, J. K. (2011). Lectures on Urban Economics. The MIT Press, Cambridge, MA

Brueckner, J. (2000). Urban sprawl: diagnosis and remedies. International regional science review, 23(2), 160- 171

Bruegmann, R. (2006). Sprawl: A compact history. University of Chicago press.

Bureau of Labor Statistics (2011). Annual Household Transportation Expenses. Accessed online at: http://www.bls.gov/news.release/cesan.nr0.htm

Burns, N. (1994). The formation of American local governments: Private values in public institutions. New York, NY: Oxford University Press.

Bursik, R. J. (1988). Social disorganization and theories of crime and delinquency: Problems and Prospects. Criminology, 26(4), 519-552.

Carr, L. J., Dunsiger, S. I., and Marcus, B. H. (2010). Walk Score ${ }^{\mathrm{TM}}$ As a Global Estimate of Neighborhood Walkability. American journal of preventive medicine, 39(5), 460463.

Carr, L. J., Dunsiger, S. I., and Marcus, B. H. (2011). Validation of Walk Score for estimating access to walkable amenities. British Journal of Sports Medicine, 45(14), $1144-1148$.

Castells, M. (1977). The Urban Question. Cambridge: The MIT Press. 
Chaskin, R. J., and Joseph, M. L. (2012). 'Positive' Gentrification, Social Control and the 'Right to the City' in Mixed-Income Communities: Uses and Expectations of Space and Place. International Journal of Urban and Regional Research

Charles, C. Z. Can we live together? Racial preferences and neighborhood outcomes. In Briggs, X and Wilson, W. (2005). The geography of opportunity: Race and housing choice in metropolitan America. Washington, DC: Brookings Institution Press.

Chatman, D., and Voorhoeve, N. (2010). The transportation-credit mortgage: a post-mortem. Housing Policy Debate, 20(3), 355-382.

Clapp, J. M., and C. Giaccotto. (1992). Estimating price indices for residential property: A comparison of repeat sales and assessed value methods. Journal of the American Statistical Association, 87(418): 300-306.

Cortright, J. (2009). Walking the Walk: How Walkability Raises Home Values in U.S. Cities. CEOs for Cities. Retrieved electronically from http://www.ceosforcities.org/pagefiles/WalkingTheWalk_CEOsforCities.pdf

Davis, L. S. (2008). Malls, the Future of Housing? Housing Wire. Retrieved from: http://www.housingwire.com/news/malls-future-housing

DeFilippis, J., and Fraser, J. (2010). Why do we want mixed-income housing and neighborhoods?. Critical urban studies: New directions, 135-147.

Deluca, S. (2012). What is the Role of Housing Policy? Considering Choice and Social Science Evidence. Journal of Urban Affairs, 34: 21-28. 
DeLuca, S., Duncan, G. J., Keels, M., and Mendenhall, R. M. (2010). Gautreaux mothers and their children: An update. Housing Policy Debate, 20(1), 7-25.

DeLuca, S. and Rosenbaum, J. (2009) Residential Mobility, Neighborhoods and Poverty: Results from the Chicago Gautreaux Program and the Moving to Opportunity Experiment, in Hartman, C., and Squires, G. (Eds.) The integration debate: Competing futures for American cities. Routledge.

Diao, M., and Ferreira, J. (2010). Residential Property Values and the Built Environment. Transportation Research Record: Journal of the Transportation Research Board, 2174(- 1), 138-147.

Dowling, R. G., Reinke, D. B., Flannery, A., Ryus, P., Vandehey, M., Petritsch, T. A., Landis, B. W., et al. (2008). NCHRP Report 616: Multimodal Level of Service Analysis for Urban Streets. Transportation Research Board of the National Academies, Washington, DC.

Doyle, S., Kelly-Schwartz, A., Schlossberg, M., and Stockard, J. (2006). Active community environments and health: the relationship of walkable and safe communities to individual health. Journal of the American Planning Association, 72(1), 19-31.

Dreier, P., Mollenkopf, J. and Swanstrom, T. (2004). Place matters: Metropolitics for the twenty-first century. Studies in government and public policy. Lawrence: University Press of Kansas. 
Duany, A., Plater-Zyberk, E., and Speck, J. (2001). Suburban nation: The rise of sprawl and the decline of the American dream. Macmillan.

Dubin, R.A. 1998. Spatial autocorrelation: A primer. Journal of Housing Economics 7: 30427.

Duke, J. (2009). Mixed income housing policy and public housing residents' 'right to the city'. Critical Social Policy, 29(1), 100-120.

Duncan, D. T., Aldstadt, J., Whalen, J., Melly, S. J., and Gortmaker, S. L. (2011). Validation of Walk Score ${ }^{\circledR}$ for estimating neighborhood walkability: An analysis of four U.S. metropolitan areas. International journal of environmental research and public health, 8(11), 4160-4179.

Dunne, T. (2012). Household Formation and the Great Recession. Federal Reserve Bank of Cleveland, August, 23, 2012-12.

Durkheim, E. (1897). Suicide: a study in sociology. Translated by JA Spaulding and G. Simpson. (1951). The Free Press: Glencoe, Illinois.

Ellen, I. G. (2008). Continuing isolation: Segregation in America today. Segregation: The rising costs for America, 261-77

Ewing, R. (2005). Can the physical environment determine physical activity levels? Exercise and sport sciences reviews; 33(2), 69-75.

Ewing, R., and Cervero, R. (2010). Travel and the Built Environment -- A Meta-Analysis. Journal of the American Planning Association, 76 (3), 256-294. 
Ehrenhalt, A. (2012). The Great Inversion and the Future of the American City. Random House Digital, Inc.

Farley, R., Schuman H., Bianchi S., Colasanto D., and Hatchett S. (1978). Chocolate city, vanilla suburbs: Will the trend toward racially separate communities continue? Social Science Research 7(4): 319-44.

Farley, R., Fielding, E. L., and Krysan, M. (1997). The residential preferences of blacks and whites: A four-metropolis analysis. Housing Policy Debate, 8(4), 763.

Florida, R. L. (2012). The Rise of the Creative Class: Revisited. Basic books.

Foster, S., and Giles-Corti, B. (2008). The built environment, neighborhood crime and constrained physical activity: An exploration of inconsistent findings. Preventive Medicine, 47(3), 241-251.

Frank, L., Engelke, P., and Schmid, T. (2003). Health and community design: The impact of the built environment on physical activity. Island Press.

Frank, L. D., Schmid, T. L., Sallis, J. F., Chapman, J., and Saelens, B. E. (2005). Linking objectively measured physical activity with objectively measured urban form: Findings from SMARTRAQ. American Journal of Preventive Medicine, 28(2), 117 125.

Frank, L., Kerr, J., Chapman, J., and Sallis, J. (2007). Urban form relationships with walk trip frequency and distance among youth. American Journal of Health Promotion, 21(4 Suppl), 1-8. 
Frumkin, H., Frank, L., and Jackson, R. J. (2004). Urban sprawl and public health: Designing, planning, and building for healthy communities. Island Press.

Galea, S., Freudenberg, N., and Vlahov, D. (2005). Cities and population health. Social Science and Medicine, 60(5), 1017-1033.

Galster G.C., and Killen S.P. (1995) The geography of metropolitan opportunity: a reconnaissance and conceptual framework. Housing Policy Debate. 6: 7-43.

Galster, G., Santiago, A. M., Smith, R. E., and Tatian, P. A. (1999). Assessing property value impacts of dispersed housing subsidy programs. Report to the U.S. Department of Housing and Urban Development. Washington, DC.

Galster, G., Hanson, R., Ratcliffe, M. R., Wolman, H., Coleman, S., and Freihage, J. (2001). Wrestling sprawl to the ground: defining and measuring an elusive concept. Housing policy debate, 12(4), 681- 717.

Gans, H. J. (1990). Deconstructing the Underclass The Term's Dangers as a Planning Concept. Journal of the American Planning Association, 56(3), 271-277.

Geronimus, A. T., and Thompson, J. P. (2004). To denigrate, ignore, or disrupt: racial inequality in health and the impact of a policy-induced breakdown of African American communities. Du Bois Review: Social Science Research on Race, 1(2), $247-279$.

Gilderbloom, J. I. (2007). Invisible city. Austin, TX: University of Texas Press.

Gilderbloom, J. I., and Appelbaum, R. P. (1987). Rethinking Rental Housing. Temple University Press. 
Gilderbloom, J. I., Ambrosius, J. D., Squires, G. D., Hanka, M. J., and Kenitzer, Z.E. (2012). Investors: The missing piece in the foreclosure racial gap debate. Journal of Urban Affairs, 34(5), 559-582.

Gilderbloom, J. I., Hanka, M. J., and Ambrosius, J. D. (2011). Without Bias? Government policy that creates fair and equitable property tax assessments. The American Review of Public Administration, 42(5), 591-605.

Gilderbloom, J.I., Hanka, M.J. and Ambrosius, J.D. (2010). Historic Preservation's Impact on Job Creation, Property Values, and Environmental Sustainability, Journal of Urbanism, vol.2, no.2, 2009: 83-101.

Glaeser, E. (2011). Triumph of the city: How our greatest invention makes us richer, smarter, greener, healthier and happier. Pan Macmillan.

Goering, J. (2013). Neighborhood Effects and Public Policy. City and Community, 12(1), 1320.

Goetz, E. G. (2003). Clearing the way: Deconcentrating the poor in urban America. Washington D.C.: Urban Institute Press.

Goetz, E. and A. Chapple, (2010) "Dispersal as Anti-Poverty Policy" in Davies, J. S., and Imbroscio, D. L. (Eds.) Critical urban studies: New directions. SUNY Press.

Gordon, P., and Richardson, H. W. (1997). Are compact cities a desirable planning goal?. Journal of the American planning association, 63(1), 95-106

Gordon, P., and Richardson, H. W. (1998). Prove it. Brookings Review, 16(4), 23-26.

Guerry, A.-M. (1833). Essai sur la statistique morale de la France. Crochard, Paris 
Handy, S. (1993). Regional Versus Local Accessibility: Implications for Non-work Travel. Transportation Research Record 1400: 58-66.

Handy, S., Cao, X., and Mokhtarian, P. (2005). Correlation or causality between the built environment and travel behavior? Evidence from Northern California. Transportation Research Part D: Transport and Environment, 10(6), 427-444.

Handy, S., Cao, X., and Mokhtarian, P. L. (2006). Self-selection in the relationship between the built environment and walking: Empirical evidence from Northern California. Journal of the American Planning Association, 72(1), 55-74.

Handy, S., Sallis, J. F., Weber, D., Maibach, E., and Hollander, M. (2008). Is support for traditionally designed communities growing? Evidence from two national surveys. Journal of the American Planning Association, 74(2), 209-221.

Hartgen, D and Fields, G. (2009). Gridlock and Growth: The Effect of Traffic Congestion on Regional Economic Performance. Reason Foundation Study No. 371 Summary.

Holin, M., Buron, L., Locke, G., and Cortes, A. (2003). Interim assessment of the HOPE VI program cross-site report. Available at SSRN 1760002.

Howell-Moroney, M. (2008). The Tiebout hypothesis 50 years later: lessons and lingering challenges for metropolitan governance in the 21st century. Public Administration Review, 68(1), 97-109.

Hu, F. B., Li, T. Y., Colditz, G. A., Willett, W. C., and Manson, J. A. . (2003). Television watching and other sedentary behaviors in relation to risk of obesity and type 2 
diabetes mellitus in women. The Journal American Medical Association, 289(14), 1785.

Hudson, K., and O'Connell, V. (2009). Recession turns malls into ghost towns. The Wall Street Journal (May 22, 2009).

Imbroscio, D.L (2008). "United and Actuated by Some Common Impulse of Passion: Challenging the Dispersal Consensus in American Housing Policy Research," Journal of Urban Affairs, Vol. 30, No. 2: 111-130; 2008.

Imbroscio, D. L. (2010). Urban America reconsidered: Alternatives for governance and policy. Ithaca, NY: Cornell University Press.

Imbroscio, D. (2012). Beyond mobility: The limits of liberal urban policy. Journal of Urban Affairs, 34(1), 1-20

Immergluck, D. (2009). The foreclosure crisis, foreclosed properties, and federal policy: some implications for housing and community development planning. Journal of the American Planning Association, 75(4), 406-423.

Ioannides, Y. M., and Zabel, J. E. (2008). Interactions, neighborhood selection and housing demand. Journal of Urban Economics, 63(1), 229-252.

Jackson, K. T. (1985). Crabgrass frontier: The suburbanization of the United States. Oxford University Press.

Jacobs, J. (1961). The death and life of great American cities. Random House Digital, Inc. 
Jencks ,C. and Mayer, S. 1990. The social consequences of growing up in a poor neighborhood. In Inner-City Poverty in the United States, ed. L Lynn, Jr., MGH McGeary, pp. 111-85. Washington, DC: National Academy Press.

Judd, D. R., and Simpson, D. W. (Eds.). (2011). The city, revisited: urban theory from Chicago, Los Angeles, and New York. U of Minnesota Press.

Kain, John F. 1968. “Housing Segregation, Negro Employment, and Metropolitan Decentralization.” The Quarterly Journal of Economics, 82:175-197.

Kain, J. F. (1992). The spatial mismatch hypothesis: three decades later. Housing policy debate, 3(2), 371-460.

Katz, B., and Bradley, J. (2013). The metropolitan revolution: How cities and metros are fixing our broken politics and fragile economy. Brookings Institution Press.

Kenworthy, J. and Laube, F. (1999). Patterns of Automobile Dependence in Cities: An International Overview of Key Physical and Economic Dimensions with some Implications for Urban Policy. Transportation Research Part A: Policy and Practice, 33, No. 7-8, 691-723.

Krysan, M., and Farley, R. (2001). Residential Preferences of Blacks: Do They Explain Persistent Segregation. Social Forces, 80, 937-980.

Leinberger, C. (2009). The Option of Urbanism: Investing in a New American Dream. Washington, DC: Island Press 
Leinberger, C.B. and Alfonso, M. (2012), Walk This Way: The Economic Promise Of Walkable Places In Metropolitan Washington, D.C., The Brookings Institution, Washington, DC.

Leslie, E., Saelens, B., Frank, L., Owen, N., Bauman, A., Coffee, N., and Hugo, G. (2005). Residents' perceptions of walkability attributes in objectively different neighborhoods: a pilot study. Health and Place, 11(3), 227-236.

Leyden, K. M. (2003). Social capital and the built environment: the importance of walkable neighborhoods. American journal of public health, 93(9), 1546-1551.

Litman, T. A. (2003). Economic value of walkability. Transportation Research Record: Journal of the Transportation Research Board, 1828/2003, 3-11.

Litman, T. A. (2006). Socially Optimal Transport Prices and Markets. Victoria Transport Policy Institute. Retrieved Electronically from: www.vtpi.org

Litman, T. A. (2011). Economic value of walkability. World Transport Policy and Practice, 10(1), 5-14.

Local Government Commission's Center for Livable Communities. (2000). The Economic Benefits of Walkable Communities. Retrieved From: http://www.lgc.org/freepub/docs/community_design/focus/walk to money.pdf.

Logan, J., and Molotch, H. (1987). Urban fortunes: The political economy of place. Berkeley: CA. University of California Press. 
Ludwig, J., Duncan, G. J., Gennetian, L. A., Katz, L. F., Kessler, R. C., Kling, J. R., and Sanbonmatsu, L. (2012). Neighborhood effects on the long-term well-being of lowincome adults. Science, 337(6101), 1505-1510.

Massey, D. S. (1993). American apartheid: Segregation and the making of the underclass. Harvard University Press.

Matthews, J. W., and Turnbull, G. K. (2007). Neighborhood Street Layout and Property Value: The Interaction of Accessibility and Land Use Mix. The Journal of Real Estate Finance and Economics, 35(2), 111-141.

Mayer, S. E. and Jenks, C. (1999). Growing up in poor neighborhoods: How much does it matter?. Science, 243, 1441-1445. McKibben, B. (2008). The Bill McKibben reader: Pieces from an active life. St. Martin's Griffin.

McMeekin, I.M. (1946). Louisville: The Gateway City. New York: Julian Messner.

Meen, D. and Meen, G. (2003). Social Behaviour as a Basis for Modeling the Urban Housing Market: A Review. Urban Studies, 40(5-6), 917 -935.

Moudon, A. V., Lee, C., Cheadle, A.D., Garvin, C., Johnson, D., Schmid, T. L., Weathers, R.D., and Lin, L. (2006) "Operational definitions of walkable neighborhood: theoretical and empirical insights." Journal of Physical Activity and Health, 3, S99. National Association of Realtors (2011). National Community Preference Survey. Retrieved from: http://www.realtor.org/sites/default/files/reports/2011/2011-communitypreference-analysis-slides.pdf 
National Association of Realtors (2013). National Community Preference Survey. Retrieved from: http://www.realtor.org/sites/default/files/reports/2013/2013-communitypreference-analysis-slides.pdf

Natural Resources Defense Council. (2010). Reducing Foreclosures and Environmental Impacts through Location-Efficient Neighborhood Design. Retrieved from: www.nrdc.org/globalwarming/energy/contents.asp.

Newman, O. (1973). Defensible space: Crime prevention through urban design. New York: Collier Books.

Oakes, J. Michael. 2004. "The (mis)estimation of neighborhood effects on causal inference for a practicable social epidemiology," Social Science and Medicine 58: 1929-52.

Ostrom, V., and Ostrom, E. (1971). Public choice: A different approach to the study of public administration. Public Administration Review, 203-216.

Owen, D. (2009). Green Metropolis: Why Living Smaller, Living Closer, and Driving Less Are the Keys to Sustainability. Riverhead.

Pi-Sunyer, F. X. (1993). Medical hazards of obesity. Annals of Internal Medicine, 119 (7 Part 2), 655 .

Pivo, G. (2013). The effect of Transportation, Location, and Affordability Related Sustainability Features on Mortgage Default Prediction and Risk in Multifamily Rental Housing. Fannie Mae. Retrieved electronically from http://www.fanniemae.com/resources/file/aboutus/pdf/hoytpivo_mfhousing_sustainab ility.pdf 
Pivo, G., and Fisher, J. D. (2011). The Walkability Premium in Commercial Real Estate Investments. Real Estate Economics, 39(2), 185-219.

Pahl, R. E. (1979). Socio-political factors in resource allocation. Social Problems and the City, 33-46.

Park, R. E. and Burgess, E. W. (1925), The city. Chicago/Londres, The University of Chicago Press.

Popkin, Susan J., Larry F. Buron, Diane K. Levy, and Mary K. Cunningham. (2000). “The Gautreaux Legacy: What Might Mixed Income and Dispersal Strategies Mean for the Poorest Public Housing Tenants." Housing Policy Debate 11 (4): 911-942.

Popkin, S. J., Katz, B., Cunningham, M. K., Brown, K. D., Gustafson J., and Turner. M., (2004). A Decade of HOPE VI; Research Findings and Policy Challenges.

Washington, DC: The Urban Institute and The Brookings Institution. http://urban.org/uploadedPDF/411002_HOPEVI.pdf

Putnam, R. D. (2001). Bowling alone: The collapse and revival of American community. Simon and Schuster

Rauterkus, S., Thrall, G., and Hangen, E. (2010). Location Efficiency and Mortgage Default. The Journal of Sustainable Real Estate, 2(1), 117-141.

Riggs, B. (2011) Walkability and Housing: A Comparative Study of Income, Neighborhood Change and Socio-Cultural Dynamics in the San Francisco Bay Area. Berkeley: University of California: Ph.D. Dissertation 
Rosenbaum, J. E. (1995). Changing the geography of opportunity by expanding residential choice: Lessons from the Gautreaux program.” Housing Policy Debate, 6(1), 231269.

Saelens, B., Sallis, J., and Frank, L. (2003). Environmental correlates of walking and cycling: Findings from the transportation, urban design, and planning literatures. Annals of Behavioral Medicine, 25(2), 80-91.

Sampson, R. J. (2008). Moving to Inequality: Neighborhood Effects and Experiments Meet Social Structure1. American Journal of Sociology, 114(1), 189-231.

Sampson, R. J. (2012). Great American City: Chicago and the Enduring Neighborhood Effect. Chicago: University of Chicago Press.

Sampson, R. J., Morenoff, J. D., and Gannon-Rowley, T. (2002). Assessing" neighborhood effects": Social processes and new directions in research. Annual review of sociology, 443-478.

Savitch, H.V. (1981) Post-Industrial Cities: Politics and Planning in New York, Paris, and London. Princeton: Princeton University Press.

Savitch, H. (2012). Analysis and Comment: Task Force on Merger 2.0. Retrieved electronically from: http://www.google.com/url?sa=tandrct=jandq $=$ andesrc $=$ sandsource=webandcd=2and ved=0CDMQFjABandurl=http $\% 3 \mathrm{~A} \% 2 \mathrm{~F} \% 2 \mathrm{Farchives}$. wfpl.org $\% 2 \mathrm{Fwp}-$ content $\% 2$ Fuploads $\% 2$ F2011\%2F11\%2FUofLReportOnMerger.docandei $=\mathrm{Vw}$ vvUp2 yDa-WyAGE6IDwCAandusg=AFQjCNErG- 
ZAkYoWSwnk6LjjtGDPtFsBAwandsig2=DA79Y8kAbF3w5bzd_VLWwQandbvm= bv. 55123115, d.aWc

Savitch, H. V., and Vogel, R. K. (2004). Suburbs without a City Power and City-County Consolidation. Urban Affairs Review, 39(6), 758-790.

Schutt, R. K. (2011). Investigating the social world: The process and practice of research. Pine Forge Press.

Schrank, D, Lomax, T and Eisele, B (2011). “Texas Transportation Insitute's 2011 Urban Mobility Report.” The Texas Transportation Institute, the Texas A and M University System. Retrieved From: http://mobility.tamu.edu/ums/report/.

Schragger, R. C.(2009) Mobile Capital, Local Economic Regulation, and the Democratic City. Harvard Law Review, 2, 482

Schwartz, A. F. (2006). Housing Policy in the United States: An Introduction. New York: Routledge Press.

Southworth, M. (2005). Designing the Walkable City. Journal of Urban Planning and Development, 131(4), 246-257.

Speck, J. (2012). Walkable City: How Downtown Can Save America, One Step at a Time. Macmillan.

Squires, G. D. (1992). From Redlining to Reinvestment: Community Responses to Urban Disinvestment. Philadelphia, PA: Temple University Press.

Squires, G. D. (Ed.). (2002). Urban sprawl: causes, consequences, and policy responses. Urban Inst Press. 
Squires, G. D. (2012), Beyond the Mobility Versus Place Debate. Journal of Urban Affairs, 34: 29-33.

Squires, G. (2012). Partnership and the pursuit of the private city. In Lin, J., and Mele, C. The Urban Sociology Reader, Routledge. 118- 128.

Steinberg, S. (2010) “The Myth of Concentrated Poverty" in Hartman, C., and Squires, G. (Eds.). The integration debate: Competing futures for American cities. Routledge

Stevens, J. P. (2009). Applied multivariate statistics for the social sciences. Taylor and Francis.

Swanson, K. (2012) Bicycling and Walking in the United States 2012 Benchmarking Report. Washington, D.C.: Alliance for Biking and Walking

Talen, E. (2003). Neighborhoods as Service Providers: A Methodology for Evaluating Pedestrian Access. Environment and Planning B: Planning and Design 30, 2:181200.

Talen, E. (2010). The context of diversity: a study of six Chicago neighbourhoods. Urban Studies, 47(3), 486-513.

Talen, E. (2013). Prospects for walkable, mixed-income neighborhoods: insights from US developers. Journal of Housing and the Built Environment, 28(1), 79-94.

Talen, E. and J. Koschinsky (forthcoming). The Neighborhood Quality of Subsidized Housing.

Talen, E., and Koschinsky, J. (2011). Is subsidized housing in sustainable neighborhoods? Evidence from Chicago. Housing Policy Debate, 21(1), 1-28. 
Thompson, D., Edelsberg, J., Colditz, G. A., Bird, A. P., and Oster, G. (1999). Lifetime health and economic consequences of obesity. Archives of Internal Medicine, 159(18), 2177.

Tiebout, C. M. (1956). A pure theory of local expenditures. The journal of political economy, 64(5), 416-424.

Troy, A., and Grove, J. M. (2008). Property values, parks, and crime: A hedonic analysis in Baltimore, MD. Landscape and Urban Planning, 87(3), 233-245.

Turner, M.A. (2010). Hope VI, Neighborhood Recovery, and the Health of Cities in Cisneros, H. G., and Engdahl, L. From despair to hope: Hope VI and the new promise of public housing in America's cities. Brookings Institution Press

Turner, M. A., Nichols, A., and Comey, J. (2012). Benefits of Living in High-Opportunity Neighborhoods: Insights from the Moving to Opportunity Demonstration. Retrieved electronically from: http://www.urban.org/UploadedPDF/412648 Benefits-of-Livingin-High-Opportunity-Neighborhoods.pdf

United States Census Bureau. (2000). American Community Survey. Retrieved from American Community Survey Online: http://www.census.gov/acs/www/.

United States Census Bureau. (2010). American Community Survey. Retrieved electronically from American Factfinder: http://factfinder2.census.gov/faces/tableservices/jsf/pages/productview.xhtml?pid=A CS_12_1YR_B01003andprodType=table 
Wang, Y., Beydoun, M. A., Liang, L., Caballero, B., \& Kumanyika, S. K. (2008). Will all Americans become overweight or obese? Estimating the progression and cost of the US obesity epidemic. Obesity, 16(10), 2323-2330.

Warren, M. R., Thompson, J. P., and Saegert, S. (2001). The role of social capital in combating poverty. Social capital and poor communities, 1-28.

Williams, D., and Jackson, P. (2005). Social sources of racial disparities in health. Health Affairs, 24(2), 325 .

Williamson, T. (2010). Sprawl, justice, and citizenship: The civic costs of the American way of life. Oxford University Press.

Williamson, T., Imbroscio, D. L. and Alperovitz, G. (2002). Making a place for community: Local democracy in a global era. Psychology Press

Wilson, W. J. (1978). The truly disadvantaged: The inner city, the underclass, and public policy. Chicago: University of Chicago Press.

Wilson, W. J. (2009). More than just race: Being black and poor in the inner city (issues of our time). WW Norton

Wilson, W. J. (2011). When work disappears: The world of the new urban poor. Vintage.

Wirth, L. (1938). Urbanism as a Way of Life. American journal of sociology, 1-24.

Zukin, S. 1982, Loft Living: Culture and Capital in Urban Change. Baltimore: MA: John Hopkins University 


\section{CURRICULUM VITAE}

Wesley L. Meares

School of Urban and Public Affairs

University of Louisville

Room 226

426 W. Bloom Street

meareswesley@yahoo.com

wlmear01@cardmail.louisville.edu
5834 Prince William Street

Louisville, KY 40207

Mobile: (706) 604-2759

\section{Current Affiliation}

Ph.D. Candidate, University of Louisville

Graduate Research Assistant, School of Urban and Public Affairs

Senior Researcher Associate, Center for Sustainable Urban Neighborhoods

\section{Education}

Ph.D. 2011-present Urban and Public Affairs

Urban Policy and Administration Specialization

University of Louisville, Louisville, KY

Expected Date of Graduation July 2014

Dissertation: The Walkable Dividend: The Impacts of Walkability On

Housing And Socio-Economic Composition In

Louisville, $K Y$

Committee: Dr. John Gilderbloom (Chair), Dr. David Simpson, Dr. Gregory

Squires, and Dr. Steve Koven

M.P.A 2010-2011 Master Public Administration

Western Kentucky University, Bowling Green, KY 

B. A. $2006-2010$
Political Science
LaGrange College, LaGrange, GA

\section{Other Educational Experiences}

Future Faculty Program, College of Education and Human Development, University of Louisville, 2013-2014

\section{Research Interest}

Housing, Sustainable Urban Development, Program Evaluation and Policy Analysis, Community/Political Participation, Urban Service Delivery, Urban Politics and Policy, Nonprofits Role in Neighborhood Redevelopment and Urban Governance

\section{Research Experience}

Senior Graduate Research Associate for the Center for Sustainable Urban Neighborhoods, University of Louisville, 2012-present

Graduate Research Associate for Dr. John I. Gilderbloom, University of Louisville, 2011-2012

Graduate Research Assistant, Center for Leadership Excellence, Western Kentucky University, 2010-2011

Research Assistant for Department of Political Science, LaGrange College, 20072010

\section{Peer Reviewed Publications:}

Gilderbloom, John I., Wesley Meares and Billy Riggs. (Forthcoming). How Brownfield Sites Kill Places and People: An Examination of Neighborhood Housing Values, Foreclosures and Lifespan. Journal of Urbanism.

Tures, John and Wesley Meares. 2010. "The Myth of Southern Studies: Race, Politics and the Future of Such Course." Review of Higher Education and Self-Learning. Vol. 3, Iss. 6. 


\section{Reports, Book Reviews and Other Publications:}

John I. Gilderbloom, Charles Porter Stevens, and Wesley L. Meares (Forthcoming). Book Review: The Great Inversion and the Future of the American City by Alan Ehrenhalt 2012 New York: Vintage pages: 277 includes an index Journal of Urbanism.

Gilderbloom, John I, Wesley L Meares and James Canfield. 2013. "Covington Hope VI Year 3 Report.” Covington, Kentucky: Housing Authority of Covington.

Gilderbloom, John I and Wesley L Meares. 2013. "Village Development: Economic Impacts on Muncie, IN: Executive Summary for the Mayor's Office.” Munice, IN. Report prepared for Investment Property Advisors.

Gilderbloom, John I., Wesley L Meares and Kirsten Silveira. 2012. “ Covington Hope VI Progress Report Year Two.” Covington, Kentucky: Housing Authority of Covington.

Gilderbloom, John I and Wesley L Meares. 2012. " 9 on Canal: Economic Impacts on Indianapolis: Executive Summary for the Mayor's Office.” Indianapolis, IN. Report prepared for Investment Property Advisors.

Gilderbloom, John I and Wesley L Meares. 2011. " Golf Courses and Property Evaluation.” Louisville, Kentucky: Center for Sustainable Urban Neighborhoods.

Gilderbloom, John I and Wesley L Meares. 2011. " Covington Hope VI Baseline Report." Covington, KY: Housing Authority of Covington.

Tures, John, Britt Gaylor, Wesley Meares, Lindley Morton, Luke Riley, Jamaica Thomas, Joseph Wowk and Daniel Yim. 2009. "Angels and Demons ... and Democracy." Georgia Political Science Association Conference Proceedings. Pine Mountain, GA.

Meares, Wesley. May 2009.“To Serve and to Protect.” Citations Undergraduate Research Journal.

\section{Books and Journals Edited}

Guest co-editor for "Sustain: A Journal of Environmental and Sustainability Issues. Special Issue: Alternative Transportation" published at the Kentucky Institute for the Environment and Sustainable Development, Summer 2012 


\section{Articles, Reports and Books in Progress:}

Meares, Wesley. The Impact of Section 8 on the nearby neighborhood. Article (In Progress).

Ambrosius, Joshua, William Steele, John Gilderbloom, Wesley Meares and Dennis Keating. Forty Years of Rent Control Reexamining the Impact of Moderate Rent Controls on New Jersey Cities after the Crash (In Progress)

Gilderbloom, John I. and Wesley Meares. Urban Revolution: Sustainable

Neighborhood and Smart Economics. Book. (University of Texas Press reviewed the prospectus and wishes to publish it pending a full review of the manuscript, which is expected by the spring of 2014.)

Meares, Wesley, Tobin Williams, Greg Squires and John Gilderbloom. Can Renewal Happen without Removal? Observations of a Black Community? Article. (Under Review: Journal of Community Development)

Hanka, Matt, Gilderbloom, John I., and Wesley Meares. How Economic Multipliers in HOPE VI Revitalize Communities. Article. (Under Review: Journal of Community Development)

Gilderbloom, John I., Billy Riggs and Wesley Meares. The Impacts of Walkability on Valuation, Foreclosure and Crime. Article. (Revise and Resubmit: Cities)

Gilderbloom, John I., Wesley Meares and Justin Mog. Green Dividend of Urban Biking: Evidence of Improving Community and Sustainable Development. Article. (Under Review: Journal of Community Development)

\section{Conference Presentations:}

Joshua Ambrosius, John I Gilderbloom, William Steele, Wesley L. Meares and Dennis Keating. March 21, 2014. "Forty Years of Rent Control in New Jersey". Urban Affairs Association Meetings San Antonio

Meares, Wesley L. and John I. Gilderbloom. April 2013. Eastside Revitalization: Revisiting the Neighborhood Twenty Years After." Urban Affairs Association Meetings, San Francisco, CA

Gilderbloom, John I. Wesley L Meares and Billy Riggs. April 2013. "Does Walkability Matter? Exploring the Relationship Between Walkability and Housing, 
Foreclosures, Crime and Health.” Urban Affairs Association Meetings, San Francisco, CA

Meares, Wesley L., John I Gilderbloom, Justin Mog and Kat Becker. November 2012. "The Economic Benefits of Bicycling in Urban Neighborhoods." American Collegiate Schools of Planning 53 ${ }^{\text {rd }}$ Annual Conference. Cincinnati, OH.

Gilderbloom, John I., Wesley L Meares and Billy Riggs. November 2012. "Does Walkability Matter? Exploring the Relationship Between Walkability and Housing, Foreclosures, Crime and Health.” American Collegiate Schools of Planning 53 $3^{\text {rd }}$ Annual Conference. Cincinnati, OH.

Gilderbloom, John I. and Wesley L Meares. June 2012. Urban Revolution: Neighborhood Sustainability and Smart Economics. 2012 Hawaii International Conference on Social Sciences. Honolulu, Hawaii.

Gilderbloom, John I. Wesley L Meares and Billy Riggs. April 2012. "How Toxic Waste Sites in Neighborhoods Kill Places and People." Urban Affairs Association Meetings, Pittsburgh, PA

Meares, Wesley L, Matthew Hanka and Gilderbloom, John I. April 2012. "HOPE VI: Why the Critics got it wrong" Urban Affairs Association Meetings, Pittsburgh, PA

Gilderbloom, John I and Wesley L Meares. October 2012. How to Revitalize an Impoverished Neighborhood: Thirty Years of Successful Green Urbanism. Lorman Webinar International Broadcast around the World

Meares, Wesley and John Tures. 2011. "Gone with the Wind.” Kentucky Political Science Association Conference, Bowling Green, KY

Tures, John and Wesley L Meares. 2010 "The Myth of Southern Studies: Race, Politics and the Future of Such Course.” The Citadel Symposium on Southern Politics, Charleston, SC

Tures, John, Wesley L Meares, Kristoffer E. Appel, Derek G. Baldridge, Kimberly S. Beaver, Jeremy C. Davis, Britt C. Gaylor, Lindley R. Morton, Jessica R. Shaver, Morgan D. Shields, William T. Smith, Stephen L. Spivey. 2009.“Tomorrow Never Comes." Association for Private Enterprise Education Conference, Guatemala City, Guatemala.

Tures, John, Wesley Meares, Kristoffer E. Appel, Derek G. Baldridge, Kimberly S. Beaver, Jeremy C. Davis, Britt C. Gaylor, Lindley R. Morton, Jessica R. Shaver, 
Morgan D. Shields, William T. Smith, Stephen L. Spivey, Carl F. Straumsheim, Jamaica L. Thomas, Trevor F. Tullock, Andrew T. Williamson, and Joseph P. Wowk. 2009. "Angels and Demons ... and Democracy." Georgia Political Science Association Conference, Pine Mountain, GA

\section{Professional Presentations}

Meares, Wesley L. and John I. Gilderbloom. September 2013. Ten Ways to Improve Your Neighborhood. University of Louisville, School of Urban and Public Administration. Louisville, KY

Gilderbloom, John I and Wesley L Meares. November 2012. "Newport and Covington HOPE VI Program." Covington, KY. Ad Hoc program for ACSP participants (not listed on the ACSP program)

Meares, Wesley L., John I Gilderbloom and Kat Becker. November 2012. "Student Participation in Developing a Sustainable Study." Jefferson Community College. Louisville, KY 2012.

Gilderbloom, John I., Gregory Squires and Wesley Meares. "Investors: The Missing Piece in the Foreclosure Racial Gap Debate." Sociology and Africana Studies George Washington University. Washington D.C. May 2012.

Gilderbloom, John I and Wesley Meares. "10 Things That you Need to Know About the Louisville Real Estate Market" Louisville Realtors Association. Louisville, KY January 2012

Gilderbloom, John I. and Wesley L Meares "The Impact of Golf Course and Commercial Development on Neighborhood Housing Values". City of Louisville Board of Zoning Hearing January 2012.

Gilderbloom, John I and Wesley Meares. "Thirty years of Green Sustainability." Lamar Education Services. Louisville, KY. November 2011

Tures, John Wesley Meares and Bo Tiller. "Presidential Experience and Effectiveness." LaGrange Kiwanis Club, LaGrange, GA. March 2008 


\section{Teaching Experience}

University of Louisville

UPA 680:

Special Topics in Sustainability.

(Co-Instructor with John I Gilderbloom)

Spring 2012

BUS 603: $\quad$ Entrepreneurship

Spring 2013

(Guest Lecturer)

UPA 648: Housing and Community Development.

(Guest Lecturer for 3 classes)

UPA 679: $\quad$ Environmental Policy.

(Guest Lecturer for 4 classes)

Fall 2013

Fall 2013

\section{Professional Memberships}

Urban Affairs Association

American Political Science Association

Omicron Delta Kappa

Pi Sigma Alpha

\section{Honors and Awards}

Graduate Student Council Travel Grant. Spring 2012. Amount (\$300)

Graduate Research Assistantship, School of Urban and Public Affairs, University of Louisville, 2011-present

Graduate Research Assistantship, Center for Leadership Excellence, Western Kentucky University, 2010-2011

Robert Pajari Award (co-winner). Georgia Political Science Association 2010.

Political Science Department Award for Outstanding Senior, 2010

Cum Laude Graduate, LaGrange College, 2010.

LaGrange College Methodist Scholarship recipient, 2006-2010 


\title{
Software Knowledge
}

\author{
Excel \\ Word \\ PowerPoint \\ SPSS \\ IMPLAN \\ ArcGIS and GeoDa \\ Prezi
}

\section{References}

John I. Gilderbloom, Ph.D.

Professor Urban and Public Affairs

Director, Center for Sustainable Urban Neighborhoods

Urban Studies Institute, Room 235

Department of Urban and Public Affairs

University of Louisville

$426 \mathrm{~W}$ Bloom Street

Louisville, KY 40209

jigild01@,louisville.edu

(502) 852-8557

John A. Tures, Ph.D.

Professor Political Science

Department of Political Science, Fuller E. Callaway Academic Building LaGrange College

601 Broad Street

LaGrange, GA 30240

jtures@lagrange.edu

(706) 880- 8066

David Simpson, Ph.D.

Associate Dean for Faculty Affairs, School of Arts and Sciences

Department Chair, Department of Urban and Public Affairs

Fifth Third Bank Endowed Professor of Community Development

Director, Center for Hazards Research and Policy Development

School of Urban and Public Affairs

University of Louisville

426 W. Bloom Street

Louisville, Kentucky 40208

david.simpson@louisville.edu

(502) 852-7906 
David L. Imbroscio, Ph.D.

Director, Ph.D. Program in Urban and Public Affairs

Professor, Political Science

Department of Political Science

Ford Hall, Room 107

University of Louisville

Louisville, Kentucky 40292

david.imbroscio@1ouisville.edu

(502) 852-3311 